\title{
REPORT ON THE \\ REGIONAL AND SYSTEM TYPE DISAGGREGATION OF THE SINGLE FAMILY DWELLING SPACE HEAT ENERGY DEMAND SECTOR
}

Thomas J. Muench, Myrna H. Wooders, and Richard Mclean

August 1976

ECONOMIC ANALYSIS DIVISION

NATIONAL CENTER FOR ANALYSIS OF ENERGY SYSTEMS

BROOKHAVEN NATIONAL LABORATORY ASSOCIATED UNIVERSITIES, INC.

UNDER CONTRACT NO. 14-01-001-1922 WITH THE

UNITED STATES FEDERAL ENERGY ADMINISTRATION 


\section{DISCLAIMER}

This report was prepared as an account of work sponsored by an agency of the United States Government. Neither the United States Government nor any agency Thereof, nor any of their employees, makes any warranty, express or implied, or assumes any legal liability or responsibility for the accuracy, completeness, or usefulness of any information, apparatus, product, or process disclosed, or represents that its use would not infringe privately owned rights. Reference herein to any specific commercial product, process, or service by trade name, trademark, manufacturer, or otherwise does not necessarily constitute or imply its endorsement, recommendation, or favoring by the United States Government or any agency thereof. The views and opinions of authors expressed herein do not necessarily state or reflect those of the United States Government or any agency thereof. 


\section{DISCLAIMER}

Portions of this document may be illegible in electronic image products. Images are produced from the best available original document. 
BNL 50581

[General, Miscellaneous, and Progress

Reports (Nonnuclear) - TID-4500]

REPORT ON THE

REGIONAL AND SYSTEM TYPE DISAGGREGATION

OF THE SINGLE FAMILY DWELLING

SPACE HEAT ENERGY DEMAND SECTOR

Thomas J. Muench,* Myrna H. Wooders, ** and Richard Mclean $\dagger$

*Professor, Department of Economics, State University of New York at Stony Brook.

**Assistant Professor, Department of Economics, State University of New York at Stony Brook.

†Lecturer, Department of Economics, State University of New York at Stony Brook.

August 1976

Prepared for the

OFFICE OF ENERGY SYSTEMS MODELLING AND FORECASTING

FEDERAL ENERGY ADMINISTRATION

\author{
ECONOMIC ANALYSIS DIVISION \\ NATIONAL CENTER FOR ANALYSIS OF ENERGY SYSTEMS \\ BROOKHAVEN NATIONAL LABORATORY \\ UPTON, NEW YORK 11973
}

This report was prepared as an eccount of work the United the United States Government. Neither Research and Development Administration, nor any or theis employees, not any of their contractors, waras any liability or repess ar impled, or assumes any legal or usefulnes of any infor the accuracy, completeness process ditclosed or represion, apparatus, product or

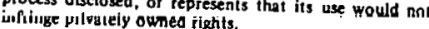




\section{NOTICE}

This report was sponsored by the United States Federal Energy Administration. Views and conelusions expressed herein shuuld inot bi intcipieled as lle ullicial opinion of the sponsoring agency.

Printed in the United States of America

Available from

National Ter.hniral Information Servire.

U.S. Department of Commerce

5285 Port Royal Road

Springfield, VA 22161

Price: Printed Copy $\$ 4.50$; Microfiche $\$ 3.00$

November $1976^{\circ}$

375 copies 


\section{Acknowledgement.:}

This study is an outgrowth of a program sponsored by the U.S. Energy Research and Development Administration to develop and apply an interfuel substitution model to national energy policy". analysis: In BNL Report SEAG-1," 1969 and 1985 Validation of the BNI Energy System Optimization Model" it was shown that this model; BESOM, could be used to estimate price elasticities of demand for energy. This capability is eririched in this study by disaggregating demand by region and by type of end-use capital equipment and also: by reformulating the model into a dynamic, multiple time period framework.

This work would not have been possible without William Marcuse's original price elasticity studies with BESOM, the computer programming assistance of Yasuku Sanborn, the project supervision by Raymond Tessmer, and the data and computer facilities of Brookhaven National Laboratory. 


\section{Abstract}

Two models are developed which can estimate derived fuel demands in single family dwellings, given fixed final demand for space heat by states. One is an extension of a single period linear programming model of the nation's energy system, the Brookhaven Energy System Optimization Model. In it the demand for single family space heat is disaggregated by state and type of home heating system. The other is a multiple period dynamic programming model of single family space heat demand, also disaggregated by state and type of system. Preliminary results for each model are presented and compared. 


\section{Table of Contents}

I. Purpose of the Project....................... 1

II. General Modelling Strategy......................

III. Static Model, Addition to BESOM

A. Description of the Disaggregation of the

Space Heat Category in BESOM................ 2

B. Preliminary Results..................... 4

IV. Dynamic Model, CURVE

A. General Description of CURVE............... 6

B. Preliminary Results...................... 10

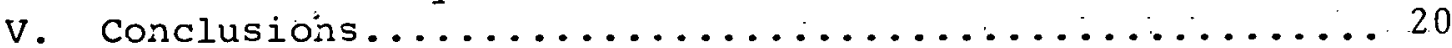

VI. Suggestions for Further Research............... 21

Appendix A. Technical Description of Program CuRVE

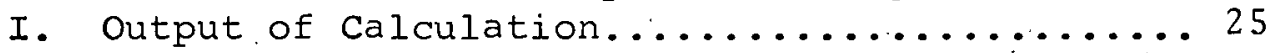

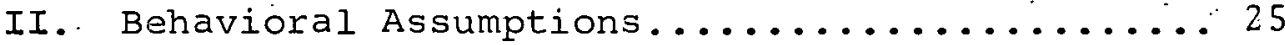

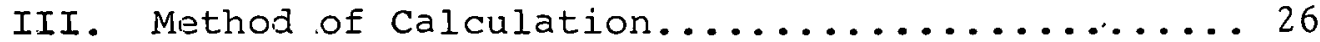

IV. Flow of $\operatorname{Program} \ldots \ldots \ldots \ldots \ldots \ldots \ldots \ldots \ldots \ldots \ldots$

V. Input Data..................... 32

VI. Output......................... 32

VII. Curve variables - Definitions and Units

by Comnon Block...................4 41

Appendix B. Data Construction

I. System Size, Efficiency, and cost Estimates...445

II. Fuel Price Data...................... 50

III. Climatic Data....................... 51

Ív. Housing stoak and Prójections............. 51

V. Existing Fuel systens................ 52

VI. CURVE and Besom Data by state............. 53

References........................... 56 
Figure 1. Demand for Oil as a Function of the Price of Gas (BESOM) ........................... 7

Figure 2. Demands for Oil, Gas, and Electricity as a. Function of the Price of óil (BESOM) .......... 8

Figure 3. Demand for Gas as a Function of the Price of Gas (Curve) .......................... 11

Figure 4. Demand for Oil as a Function of the Price of

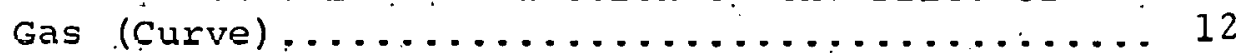

Figure 5. Demand for Electricity as a Function of the

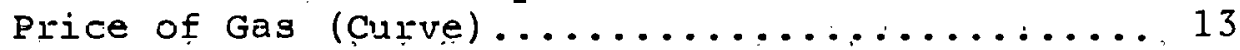

Figure 6. Demand for Gas as a Function of the Price of Oil

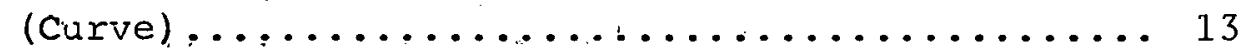

Figure 7. Demand for Oil as a Function of the Price of Oil (Curve) ............................. 14

Figure 8, Demand for Electricity as a Function of the

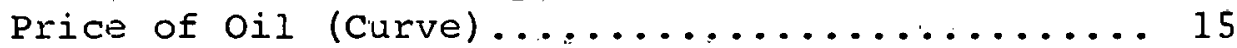

Figure 9. Demand for Gas as a Function of the Price of Electricity (Curve) ................... 16

Figure 10. Demand for Oil as a Function of the Price of

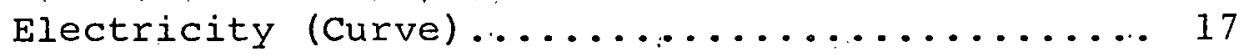

Figure 1l. Demand for Electricity as a Function of the Price of Electricity (curve)............... 18 


\section{List of Tables}

Table I

Table II

Table III

Table IV

Table V

Table VI

Table VII

Table VIII

Table IX

Table $\mathrm{x}$

Table XI

Table XII

Table XIII
Annual Fuel Use as a Function of the

Page

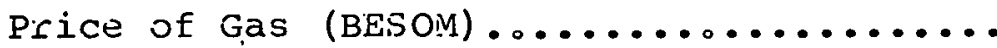

Fuel Use by State as a Function of

the Price of Gas (BESOM)............... 9

Fuel Use by States in 1935 as a Function

of the Price of Gas (CURVE) ............. 19

Global Floin of Program CuRVE, Spot

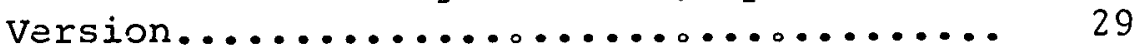

Listing of Program CiJRVE (Spot version)... 33

Standard Oidtpidt (SPOT.Version).......... 40

Standard Oxtput (FLDOD Version).......... 42

Investment Cost in $\$ /$ Design $10^{3}$. Btu/hr

of oxtput....................... 48

Operating and Maintenance as a Parcentage

of Capital Costs.................... 48

Annual Amortized System Cost for BESOM.... 48

Matrices (BO and BOM) of Unit Capital

Costs for CiJRVE..................... 49

State Specific Data for BESOM............ 54

State Specific Data for CURVE........... 55 


\section{PURPOSE OF THE PROJECT}

The purpose of the project is to determine if "reasonably smooth" demand surves can be calculated for heating fuels (gas, oil, an'a electricity) used in single family dwellings. Note. that demand here means derived demand, given a fixed final demand for space heat in energy terins. Equivalently, the demand curves taken together trace out a technological iso-quant. in the 3-dimensional fuel space.

"Reasonably smooth" must be understood in the context of a linear programming model. such as BESOjy. [3]. In such a model, demand curves are step functions, with local slopes of either zero or infinity (and corresponding elasticities). The question is, does regional disaggregation give rise to national demand Curves with many small steps instead of a small nunber of large steps. If such "smoothing" can be done, the denand curves can be approximated by a small number of segnents of functions of a simple form such as linear or. log linear.

The main emphasis in the project is on a methodology of doing the disaggregation. Therefore, the numerical data used is necessarily a crude approximation.

In addition, the models developed and the preliminary results are expected to shed light on the following aspects of national heating fuel demand: with price,

a) how the geographical distribution of fuel use changes

b) the relative importance of climatic differences and fuel price differences between regions;

c) predictions of geographical penetration of new technologies such as the heat pump;

d) the dependence of demand on rates of price change, for both fuel and fixed investment, due to technological change and increased scarcity; and

e) short run versus long run effects due to the conversion costs for systems in existing dwelling unit.s.

\section{GENERAL MODELLING STRATEGY}

The general strategy was to develop two models, one static but with general equilibrium properties, and the other dynamic but with partial equilibrium properties.

The static model consists of disaggregating the space heat activity of BESOM, Brookhaven Energy System Optimization Model. This model takes all end-use demands for energy ás given and imposes various constraints. In addition, BESOM allows instantaneous flexibility of the capital stock. In this sense it is a long run model; however, the demands and constraints are those appropriate to the year 1985. It is a "general equilibrium" 
model in the sense that there are effects on and feedbacks from the other energy using sectors of the economy. For example, when the price of oil is varied, the prices of gas and electricity can in principle change concurrently.

The dynamic model, named CURVE。 allows the three fuel prices to vary independently by modelling only the single family dwelling space heat demand. In return, CURVE allows us to analyze: time; and

a) the effects of expected price and technology changes over

b) long run versus short run demand effects by taking account of conversion costs for existing units and letting households switch fuels only when economically rational.

Both models are linear programming models, although the second, CURVE, is not solved by a standard linear programuing routine but by dynamic programming.

\section{STATIC MODEL, ADDITION TO BESOM}

III. A. Description of The Disaggregation of The Space Heat category In BESOM

Modifications were made to BESOM to disaggregate national space heat supply costs and demand into 52 sectors; one for each state (in the U.S.), one for the District of Columbia, and one for "other" space heat. The "other" sector dealt with that portion of national space heat not attributable to single family residences.

We will algebraically describe the modifications made to BESOM. For simplicity in description, we will refer to 52 states. The 5lst "state" is the District of Columbia, and the 52nd is "other" space heat.

Notation, We introduce the following notations

$I=I \Omega\{1, \ldots . .52\}$, an inder get of stater;

SHS (I); demand for space heat in state $I$ in units of $10^{6}$ BTUs in final energy form;

EF: electricity used in electric furnaces;

ER: electricity used in electric resistance heaters;

HP: electricity used in heat pumps;

Fir: elertririty used for spare heat;

TYPE: TYPE $\in\{O I L$, GAS, EF, ER, HP

$X$ [TYPE] (I): the amount of the fuel TYPE used in state I to provide spare heat to single family residential units. in units of $10^{6}$ BTUs in intermediate energy form*(IEF): SH[TYPE]: the total (national) amount of the fuel TYPE used in the 52 states (these are the space heat activity variables for space heat that appear in the unmodified BESOM);

*Delivered fuel oil, natural gas。 or electricity. 
$\mathrm{EFF}(I)$ : the efficiency of the heat pump in state.I;

$C_{\text {OIL }}$ : national cost of OIL, in $\$ / 10^{6}$ BTU IEF;

$\mathrm{C}_{\text {GAS }}$ : national cost of GAS, in $\$ / 10^{6} \mathrm{BTU}$ IEF;

$C_{E L}: \quad$ National cost of electricity, in $\$ / 10^{6}$ BTU IEF.

Demand equations. For each of the first 51 states, the model

is required to satisfy the following demand equation as an equality:

$$
\begin{gathered}
.60 \times[\mathrm{GAS}](\mathrm{I})+.55 \times[\mathrm{OIL}](\mathrm{I})+\mathrm{X}[\mathrm{EF}](\mathrm{I})+\mathrm{X}[\mathrm{ER}](\mathrm{I}) \\
+\mathrm{EFF}(\mathrm{I}) \cdot \mathrm{X}[\mathrm{HP}](\mathrm{I})=\mathrm{SHS}(\mathrm{I})
\end{gathered}
$$

where .60 is the efficiency of gas in providing space heat, .55

is the efficiency of oil, and the efficiencies of the electric

furnace and electric resistance heater are both equal to 1.

It is assumed that the heat pump is not used to satisfy space heat demand in the 52nd state (other)。 or equivalently, that $\mathrm{EFF}(52)=0$. Therefore, for the 52nd state, the demand equation is $.60 \times$ [GAS] (52) $+.55 \times$ [OIL] (52) $+\mathrm{X}$ [EF] (52) $+\mathrm{X}$

$$
\text { [ER] }(52)=\operatorname{SHS}(52) \text { 。 }
$$

Balance equations. It is required that the sum of the amounts of a fuel used in the 52 states equals" the total (national) amount of that fuel used.

$$
\begin{aligned}
& \sum_{I=1}^{52} x[O I L](I)=S H[O I L] \\
& \sum_{I=1}^{52} x[G A S](I)=S H[G A S] \\
& \sum_{I=1}^{52}[X[E F](I)+X[E R](I)+x[H P](I)]=S H[E L] .
\end{aligned}
$$

objective function. We represent the objective function of the original (unmodified) BESOM model in the following form:

Minimize $\mathrm{Z}=\mathrm{C}+\mathrm{C}_{\mathrm{OIL}} \cdot \mathrm{SH}$ [OIL $]+\mathrm{C}_{\mathrm{GAS}} \cdot \mathrm{SH}[\mathrm{GAS}]+\mathrm{C}_{\mathrm{EL}}$ 。 $\mathrm{SH}$ [EL]

where $C$ represents the non-space heat part of the objective function.

The objective function of the modified BESOM model with space heat disaggregated is:

$$
\begin{aligned}
& \text { Minimize } \\
& Z=C+C_{O I L} \cdot S H[O I L]+C_{G A S} \cdot S H[G A S]+C_{E L} \cdot S H[E L]+ \\
& \sum_{I=1}^{5 I}\left\{C_{O I L}(I) \cdot x[O I L](I)+C_{G A S}(I) \cdot x[G A S]\right. \\
& \left.\begin{array}{l}
+C_{E R}(I) \circ X,[E R] \text { (I) }+C_{E F}(I) \circ X[E F] \text { (I) } \\
+C_{H P}(I) \therefore X[H P] \text { (I) }
\end{array}\right\}
\end{aligned}
$$


$\mathrm{C}_{\text {OIL }}$ (I) represents the deviation of the cost of OIL in state I from the national price of oil in intermediate energy form plus the annualized investinent cost of oil space heating equipinent per $10^{5}$ BTUs of intermediate energy form. Therefore, ceteris paribus an inccease of one unit of oil usage in state $I$ will raise the value of the objective function by $c$

(I) $+\mathrm{C}$

In general, $C_{\text {TYPE }}$ (I) represents Ehe deviation of the cost of the intermediate energy form TYPE in state I from the national average cost of TYPE plus the annualized investment cost of the space heating equipment required per $10^{\circ}$ BTUs of the intermediate energy form.

We remark that the formulation of the objective function for the modified BESOM model implies that intermediate energy forms used to satisfy "other" space heat demand have national average costs, or, equivalently, $C_{\text {TYPE }}(5 \%)=0$.

\section{B. Preliminary Results}

The first experiment using the model was to generate national demands for fuels (in intermediate energy form) as functions of the price, or cost, of gas.

The supply constraints on gas and imported oil were both increased to $35 \times 10^{15}$ BTUs so that the shadow (scarcity) prices of gas and oil were both initially zero.

The initial cost of oil in BESOM for space heat was $\$ 2.56$ per $10^{6}$ BTU and the initial cost of gas. was $\$ 1.62$ per $10^{6}$ BTU: . The cost of gas was then increased until no space heat demand was satisfied by gas.

Table I gives the optimal annual total (national) amounts of gas, oil, and electricity in immediate energy forms used to provide space heat to single family residences as functions of the cost of gas. We remark that fuel use in the 52nd state is not included. The data in Table I were used to estimate the cross elasticity of demand for oil as a function of the cost of gas. The parameters estimated were $a$ and $b$ in the equation,

$$
\ln Q=a \cdot \ln P+B \text {, }
$$

where $Q$ is the quantity of oil and $P$ is the cost of gas. The estimated values were $a=6.62602$ and $b=-6.759135$. The correlation coefficient was $r=.99$.

Figure $\perp$ graphically illustrates some of the information of Table $I_{\text {; }}$ in particular, the cross demand curve tor oil as a function of the cost of gas. We observe that, for a large range, the cross demand curve appears quite smooth.

The figures in parentheses on the demand curve in Figure 1 indicate the costs (including scarcity costs) of electricity generated by the model for the associated costs of gas.

Figure 2 gives the demand for oil, gas, and electricity as a function of the price of oil. These curves are comparable to 
Table 1

Annual Fuel Use as a Function of the Price of Gas (BESOM)

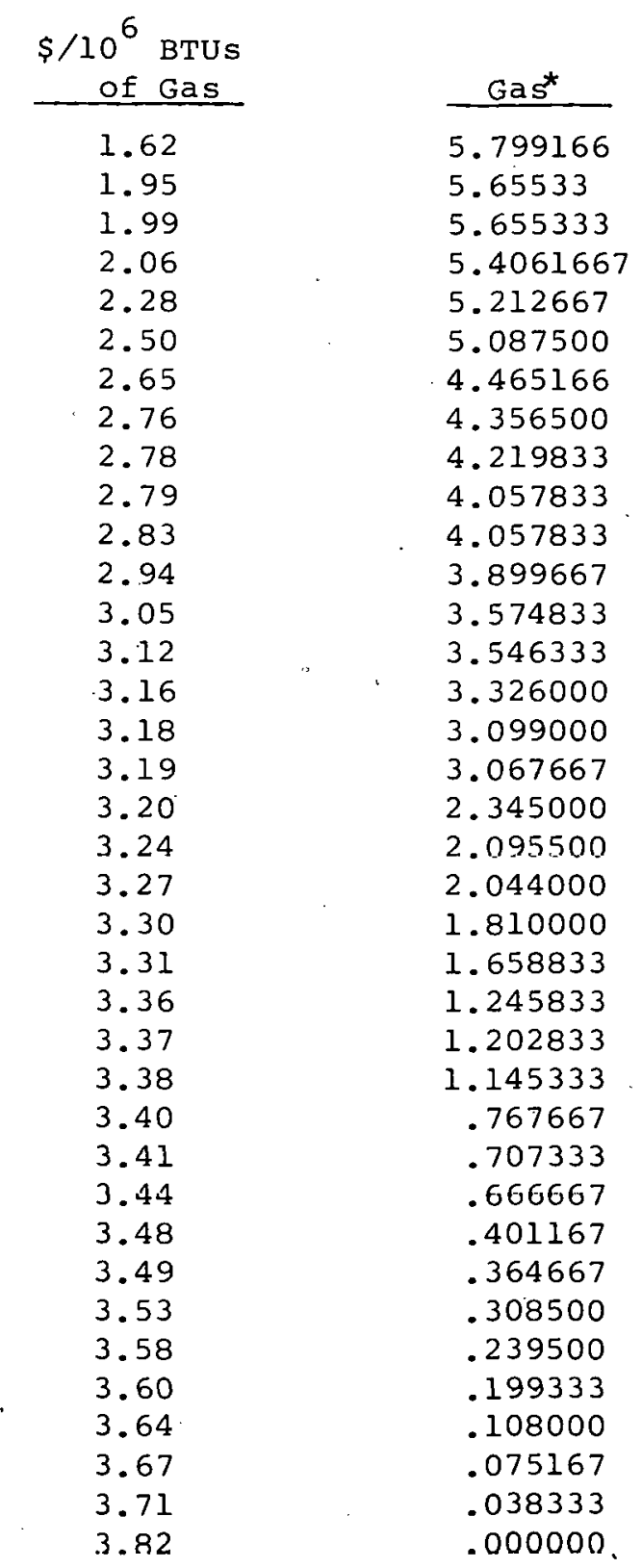

\begin{tabular}{l} 
Oi1 \\
\hline .025273 \\
.066727 \\
.119091 \\
.119091 \\
.330182 \\
.466727 \\
1.065273 \\
1.065273 \\
1.214364 \\
1.391091 \\
1.391090 \\
1.563636 \\
1.563637 \\
1.594728 \\
1.834992 \\
2.082728 \\
2.116909 \\
2.905273 \\
3.177455 \\
3.177454 \\
3.432727 \\
3.597636 \\
4.048182 \\
4.095091 \\
4.157818 \\
4.569818 \\
4.635638 \\
4.680000 \\
4.979636 \\
5.009454 \\
5.070727 \\
5.146000 \\
5.189818 \\
5.289454 \\
5.325272 \\
5.365454 \\
5.407272
\end{tabular}

Electricity

.063600.

.097635

.103378

.167643

.167643

.167643

.190723

.229464

.229464

.229464

.229464

.229464

.345269

.345269

.345269

.345269

$3.45,269$

3.45269

3.45269 .

3.63484

3. 63484

3.63484

3.63484

3. 63484

3. 63484

3.63484

3. 63484

3.63484

3. 63484

3. 63484

3.63484

3.63484

3. 63484

3.63484

3. 63484

3.63484

3. 63484

* Demand is in $10^{15}$ BTU (Intermediate Energy Form) Price of oil is $2.56 \$ / 10^{6}$ BTU. See Fig. 2 for electricity prices. 
figures 6-8 derived from CURVE, at least for gas and oil. Since the electricity price cannot presently be manipulated independently in BESOM, but it can be in CURVE, the electric demand, though low in both, exhibits a greater relative difference between the two models than do the oil/gas demands.

Table II shows the fuel used by each state as a function of the cost of gas. This table is derived from the same experiment as Table I and Figure 1.*

We observe that at the initial BESOM cost of gas without effective supply limits $\left(\$ 1.62 / 10^{6}\right.$ BTUs) all states are using gas except Alaska and Tennessee. In addition, we observe that the heat pump is not employed in the warmer regions of the country. but in the "middle" climatic areas such as New Jersey。 Washington。 and oregon. A possible rationale for this is that the portion of the heat pump capital cost which is allocated to space heating is invariant with respect to the $\mathrm{mix}$ of space. heating and air conditioning demands in any state. Thus, in the southern areas capital costs of the heat pump are relatively high per BTU of space heat demand because of the small unit demand for space heat. This is not offset by the high efficiency of the heat pump in southern climates. In the "middle" climatic areas since relatively more space heat is required and the heat pump still has high efficiency**, the gains in efficiency offset the capital costs.

\section{DYNAMIC MODEL。 CURVE}

IV. A: General Description of CURVE

The dynamic model。 named CURVE, calculates the demand for fuel and fuel systems required to heat sinqle family dwelling units to approximately $70^{\circ}$ during the heating season. The objective of the model is to minimize total discounted future costs including delivered fuel costs and capital and operating costs of home heating systems. Seven heating systems are considered: gas warm air。 gas hot water, oil warm air, oil hot water, electric warm air (electric furnace)。 electric resistance, and heat pump. Demand for space heat is disaggregated by state and by year.

*When the constraints on the supply of gas and oil were set at $24.04 \times 10^{15} \mathrm{BTU}^{\circ} \mathrm{s}$ and $26.44 \times 10^{15} \mathrm{BTU}^{\circ} \mathrm{s}$ respectively (BNL BESOM estimates for 1985) the costs (including scarcity costs) of gas, oil, and electricity (IEF) were $\$ 2.79, \$ 2.56$ and $\$ 4.65$ per $10^{6} \mathrm{BTU}^{\circ} \mathrm{s}$ respectively:

**For example。 in New Jersey the estimated efficiency of the heat pump is 1.72 and in Louisiand it is 1.96 . 


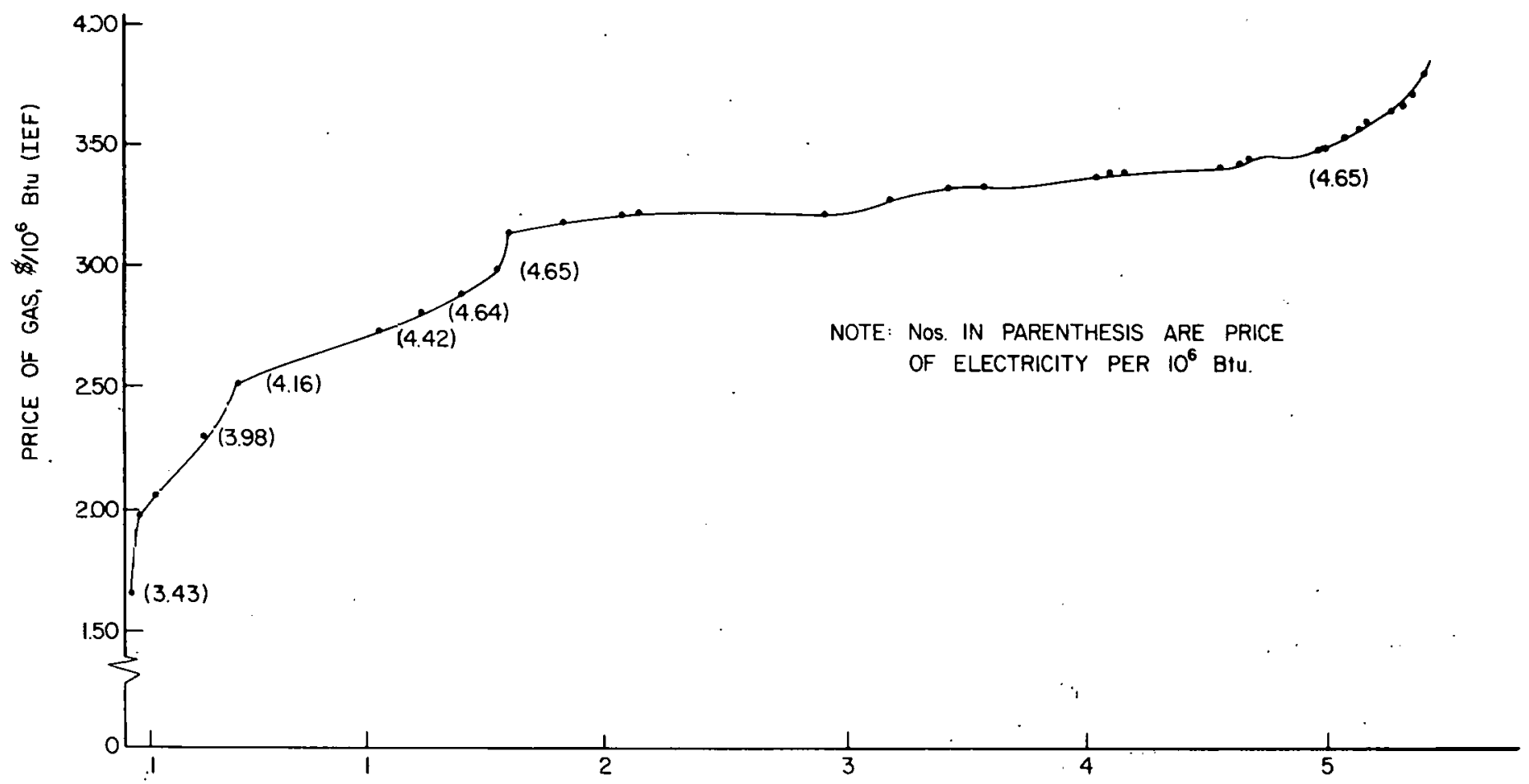

OUANTITY OF OIL USED FOR SPACE

HEAT IN SINGLE FAMILY HOUSING, $10^{15}$ Biu

Figure 1. Demand ‡or oil as a function of. the price of gas (BESOM). 


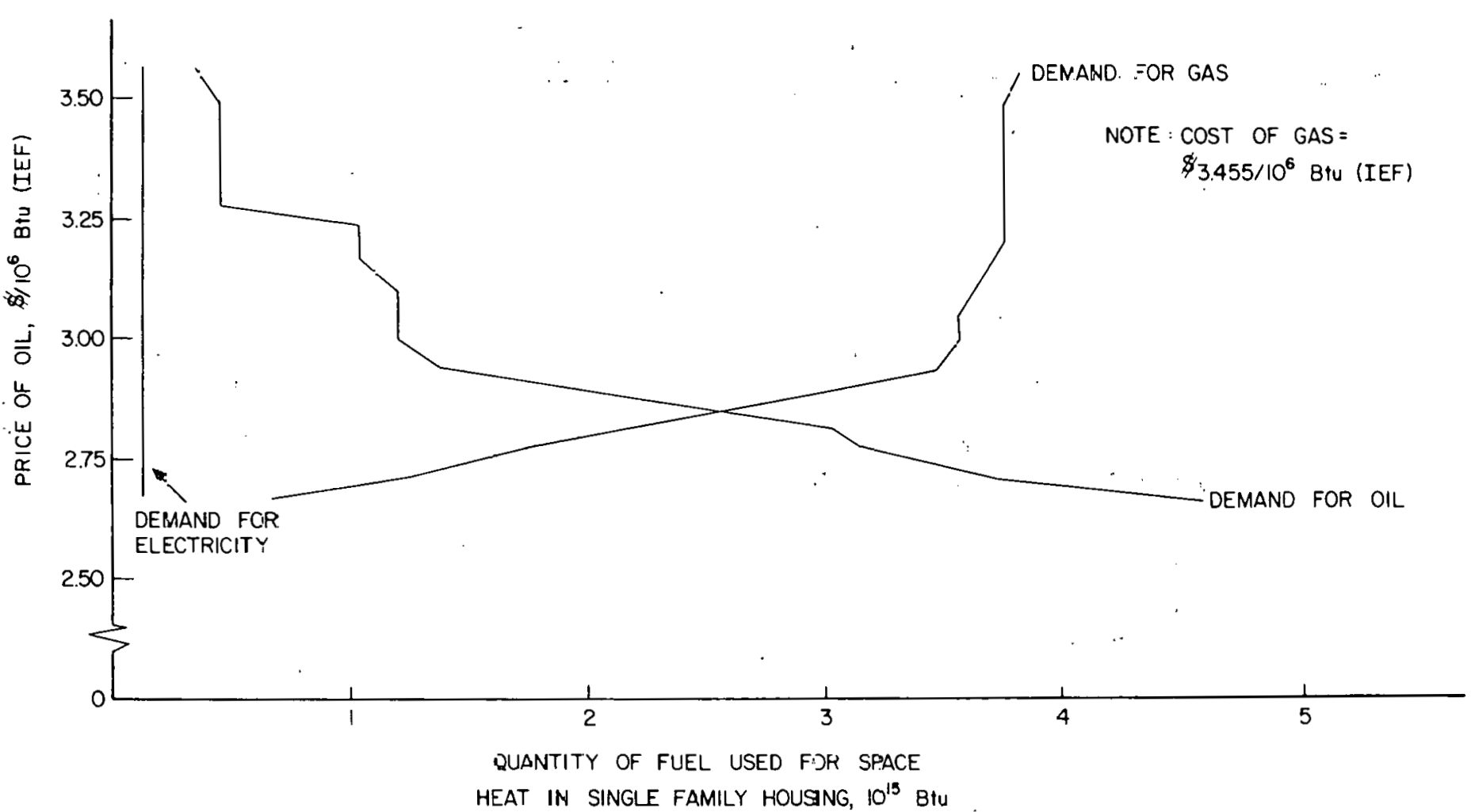

Figure 2. Demands for oil, gas, ard electricity as a function of the price of oil (BESOM). 
TABLE II ,

Fuel Use by State as a Function of the Price of Gas (BESOM)

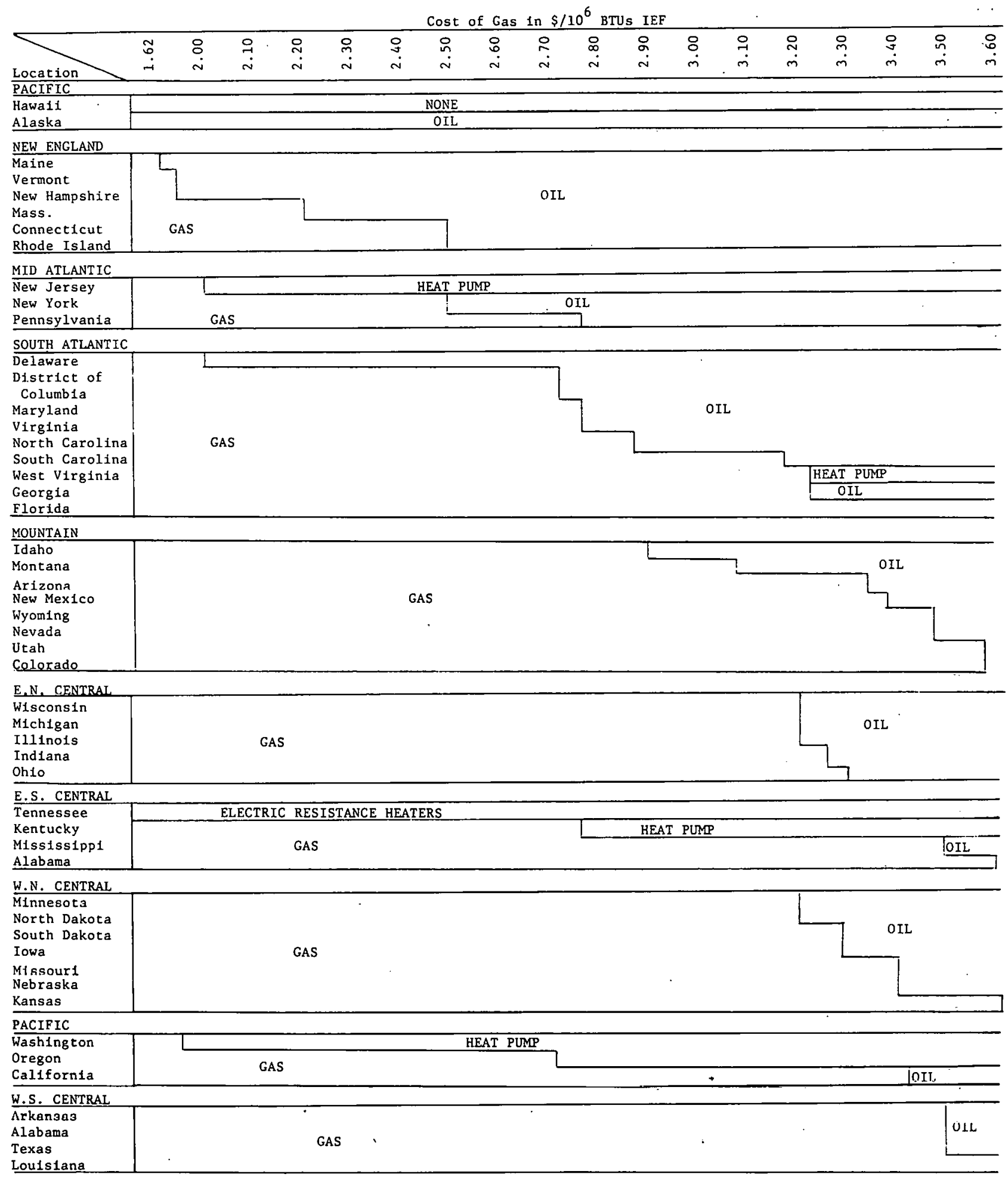


The optimal system to be used in a home in each year is computed by the method of dynamic programming. This is a solution procedure whose major stage consists of computing backwards in time. However, in order to describe the setup of the problem in more detajl, it is convenient to do so from the point of view of the householder looking forward.

At the end of relative year $T$ each dwelling unit has one of seven heating system types installed which has a given age from 1 to $L$ years. An $L$ year old system must be replaced. Tine task of the householder is to choose either to continue with the old system or to replace it with a new system so as to minimize discounted future total heating costs. Because of technological improvements the replacement is not necessarily to a different type of system.

The dynamic programing calculation starts at the end of the relative terminal year (1985 in this case). Since the cost parameters do not change after this year, the optimal. path after this point is easily computed. Optimal decisions by year are then made backwards in time to the initial year (1970 in this case). When the optimal decisions are known for all years, fuel demands and the actual number of divelling units with each fuel system type and age can be determined for each year.

IV: B: Preliminary Results

The results of basic runs with CURVE are presented in Figures 3-11. These demand curves are made on the assumption of constant prices and technologies over time. Thus the two curves in each graph are for 1975 and 1985. They may be interpreted as short and long run curves relative to each other.

Although Figures 3-ll are based on only a moderate number of price points, the curves seem to be fairly "smooth" in the sense discussed in Section $I$.

The short and long run curves do relate to each other in an expected way -- short run flatter with respect to the price axis than the long run.

The curves in Figures $6-8$ have shapes very similar to the comparable curves generated by BESOM in Figure 2 .

In Table III, the fuel system used by each state for new construction in 1985 as a function of the price of gas is shown graphically. This can be compared to Table II fur. BESOM and is practically the same, with fuel prices equal to $365.49 \% / \mathrm{mcf}$ $\left(3.54 \$ / 10^{6}\right.$ BTU) for gas, $42.4 \% / \mathrm{gal}\left(3.06 \$ \% 10^{6} \mathrm{BTU}\right)$ for oil and $1.9 \% / \mathrm{kwh}\left(5.8 \$ / 10^{6} \mathrm{BTU}\right)$ for electricity. The distribution of fuels for new construction by state seens to roughly correspond to current trends (Table III). 

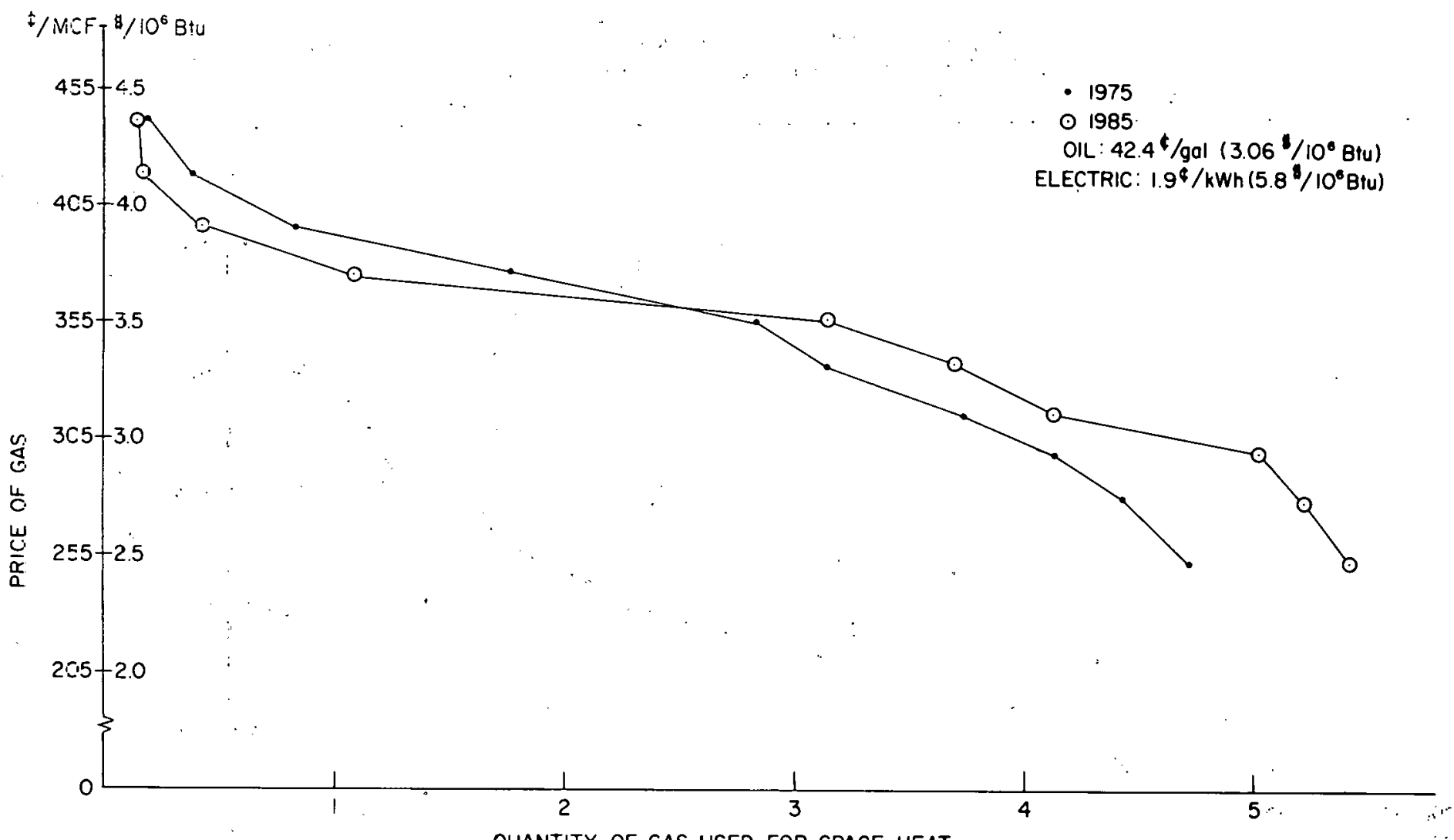

QUANTITY OF GAS USED FOR SPACE HEAT

IN SINGLE FAMILY HOUSING, $10^{13}$ BIU

Figure 3. Demand for gas as a function of the price of gas (curve). 


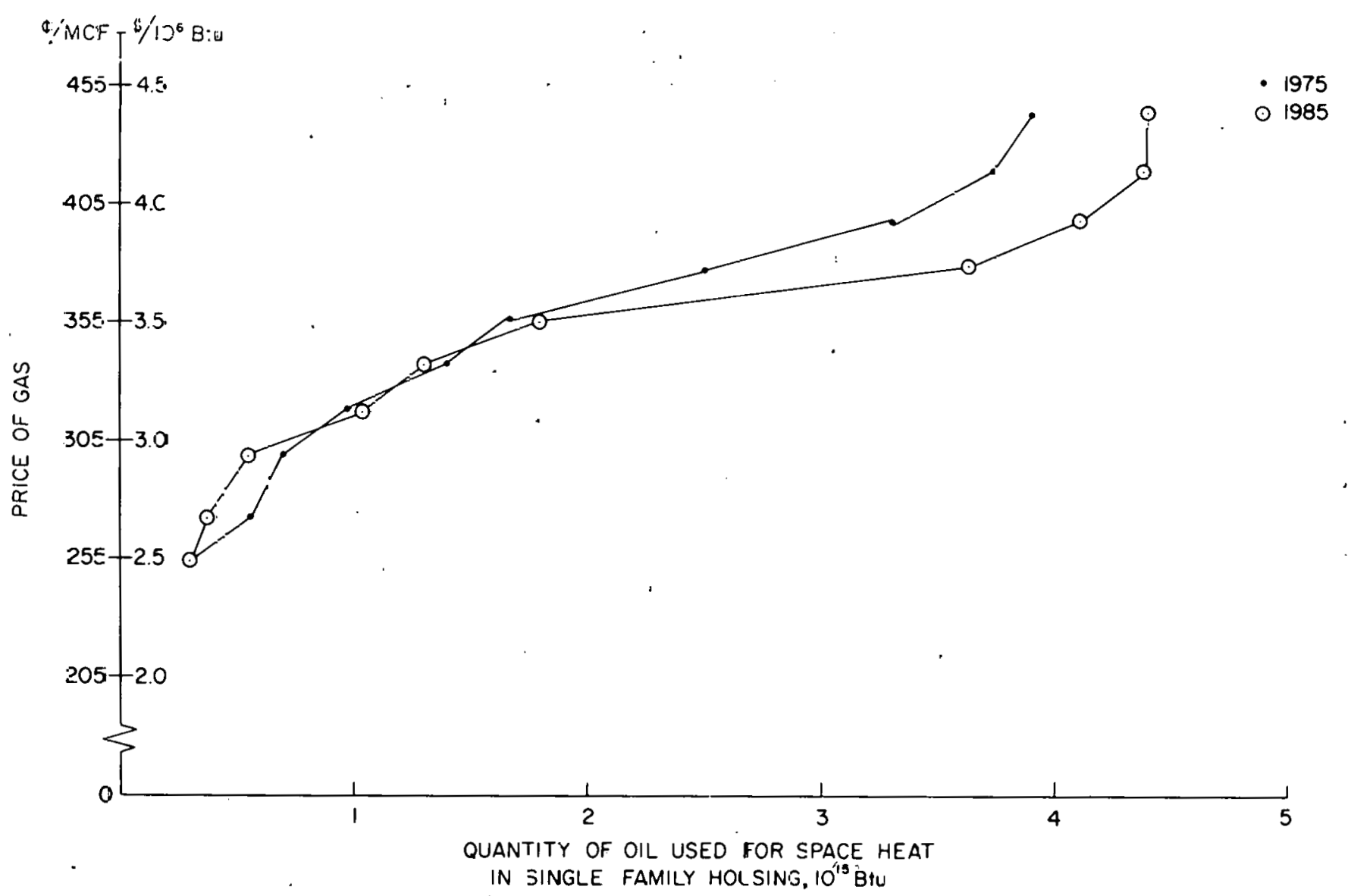

Figure 4. Demand for oil as a function of the price of gas (curve). 

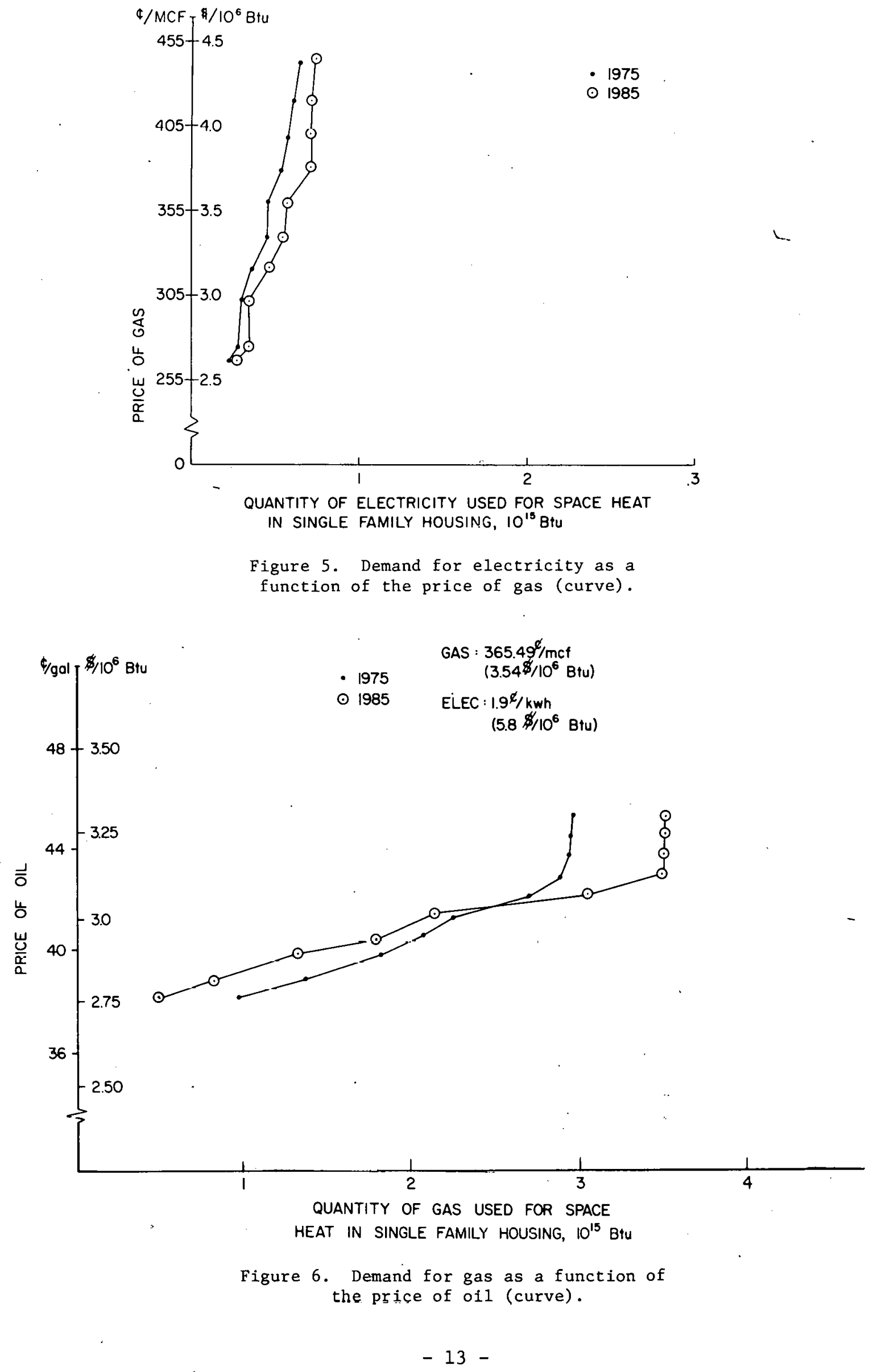


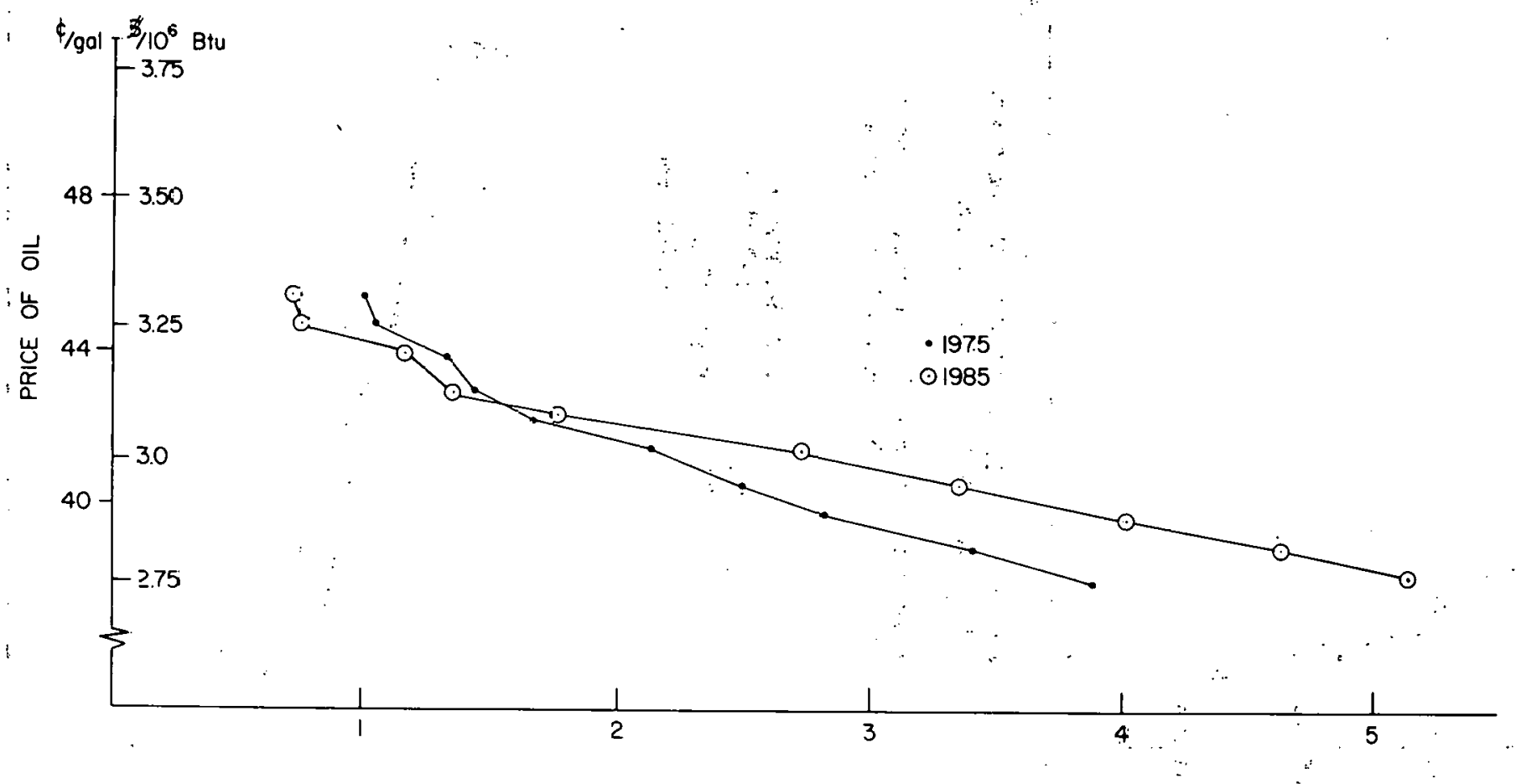

DUANTITY OF OIL USED FOR SFACE

HEAT IN SINGLE. FAMILY HOUSING, $10^{15}$ BtU

Figure 7. Denand for oil as a function of the price of oil (curve). 


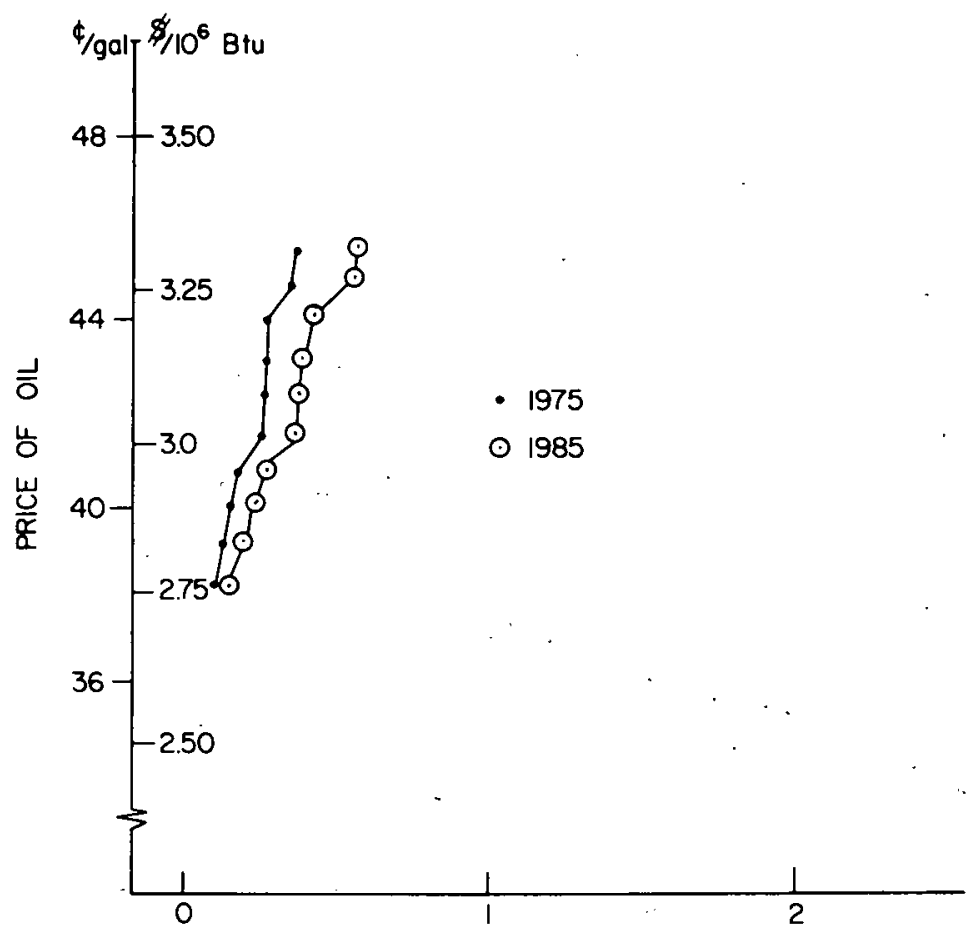

QUANTITY OF ELECTRICITY USED FOR SPACE

HEAT IN SINGLE FAMILY HOUSING, $10^{15}$ Btu

Figure 8. Demand for electricity as a

function of the price of oil (curve). 


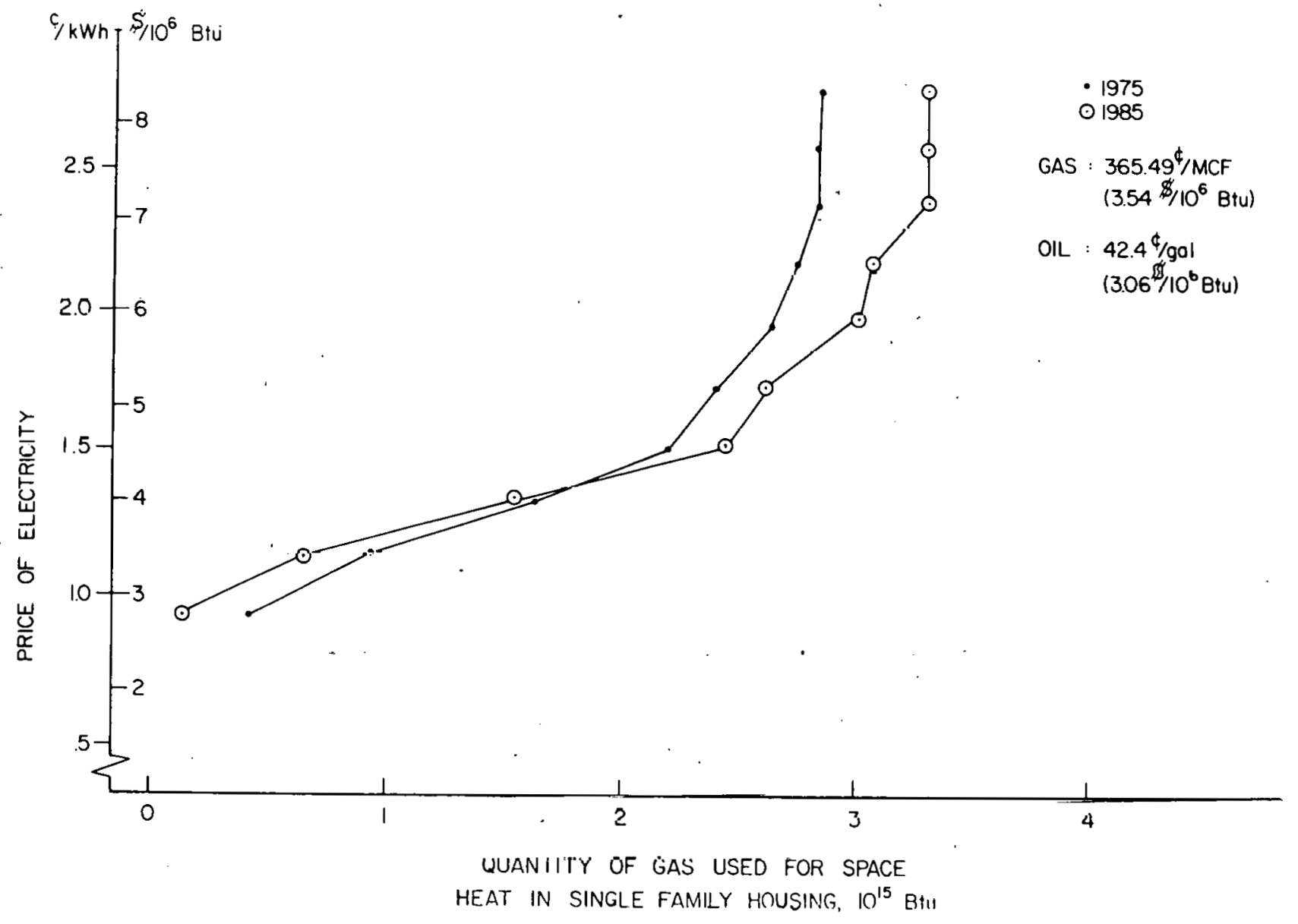

Figure 9. Demand for gas as a function of the price of electricity (curve). 


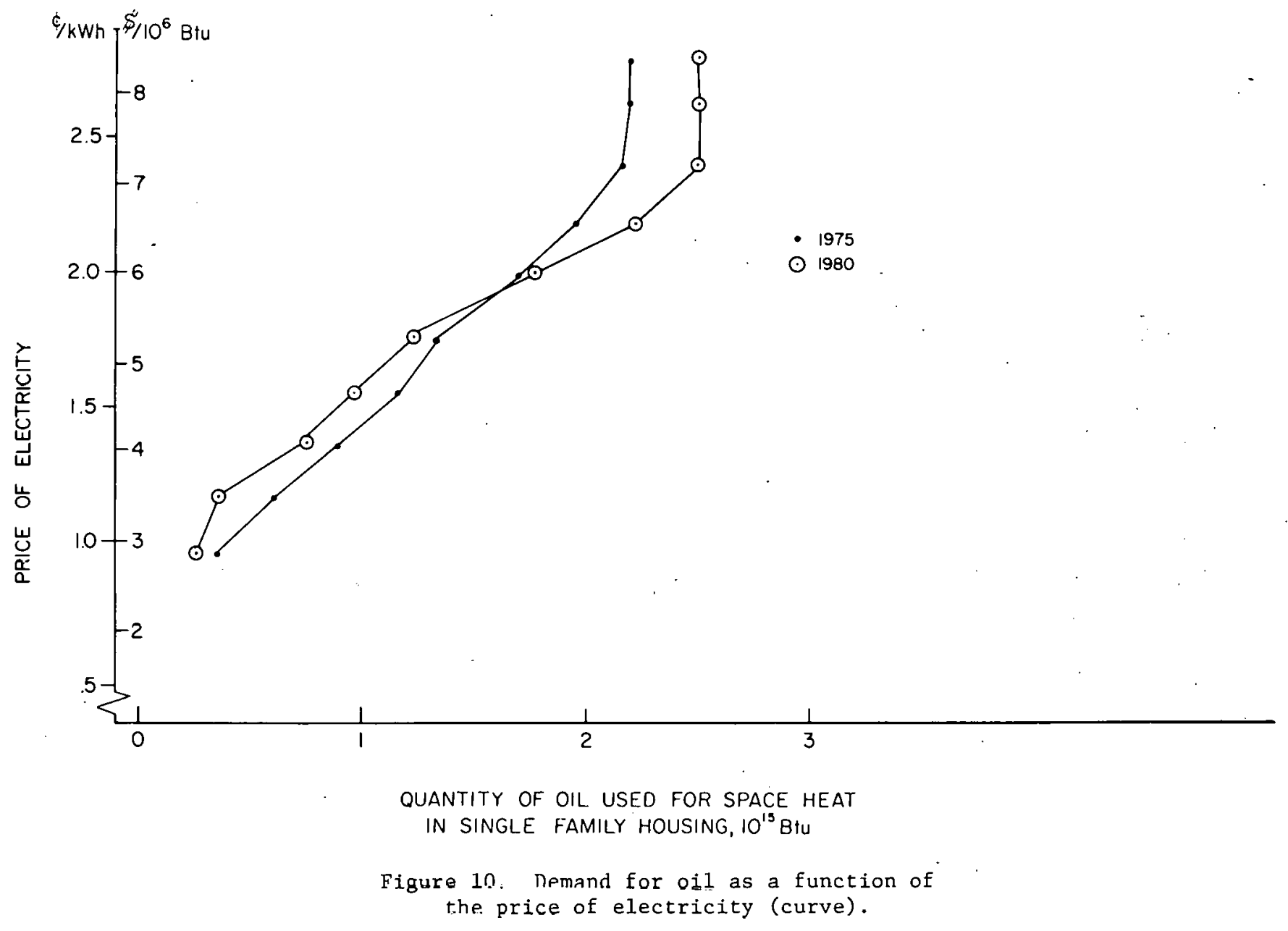




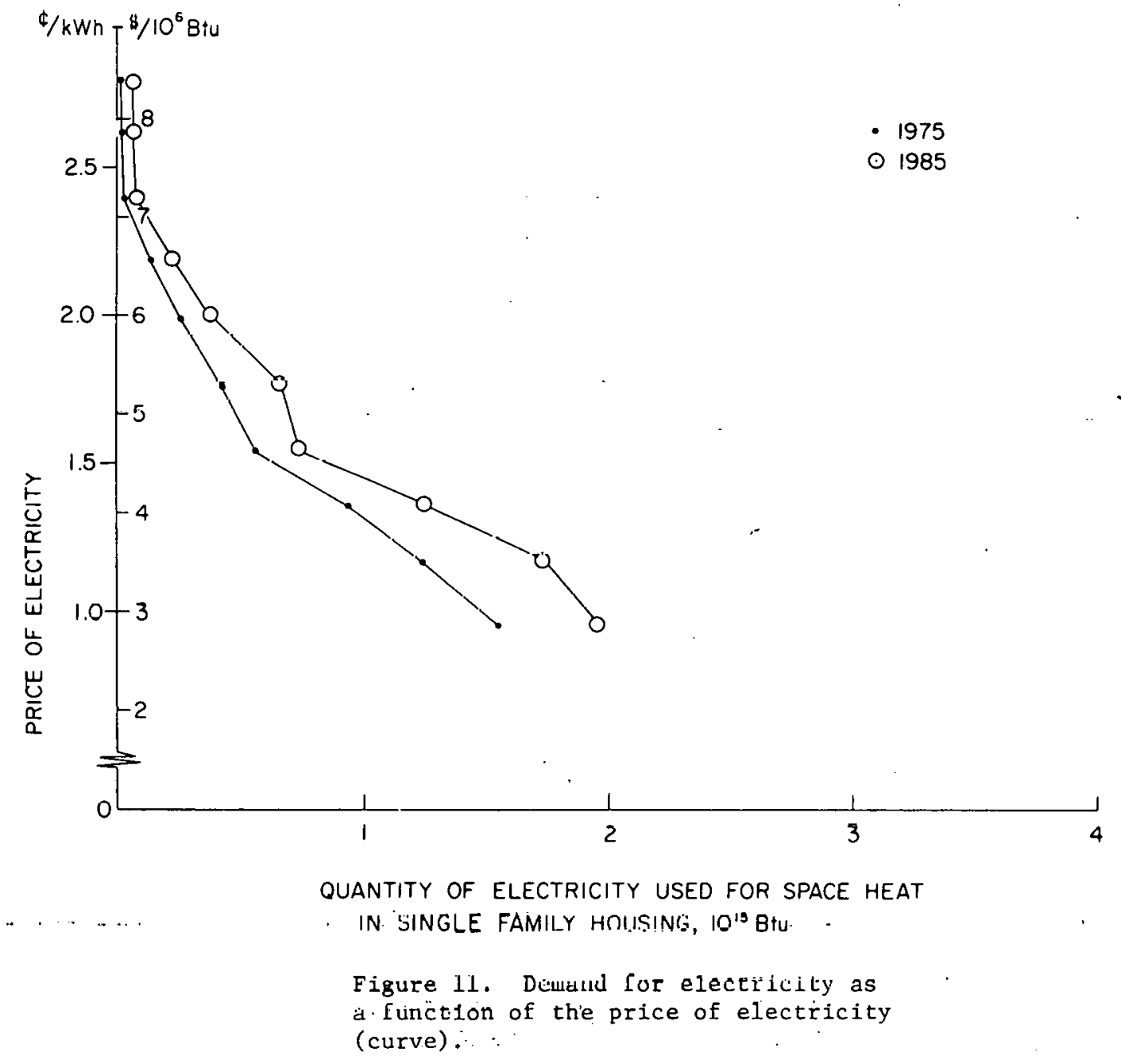


TABLE III

Fuel Use by States in 1985 as a Function of the Price of Gas (CURVE)

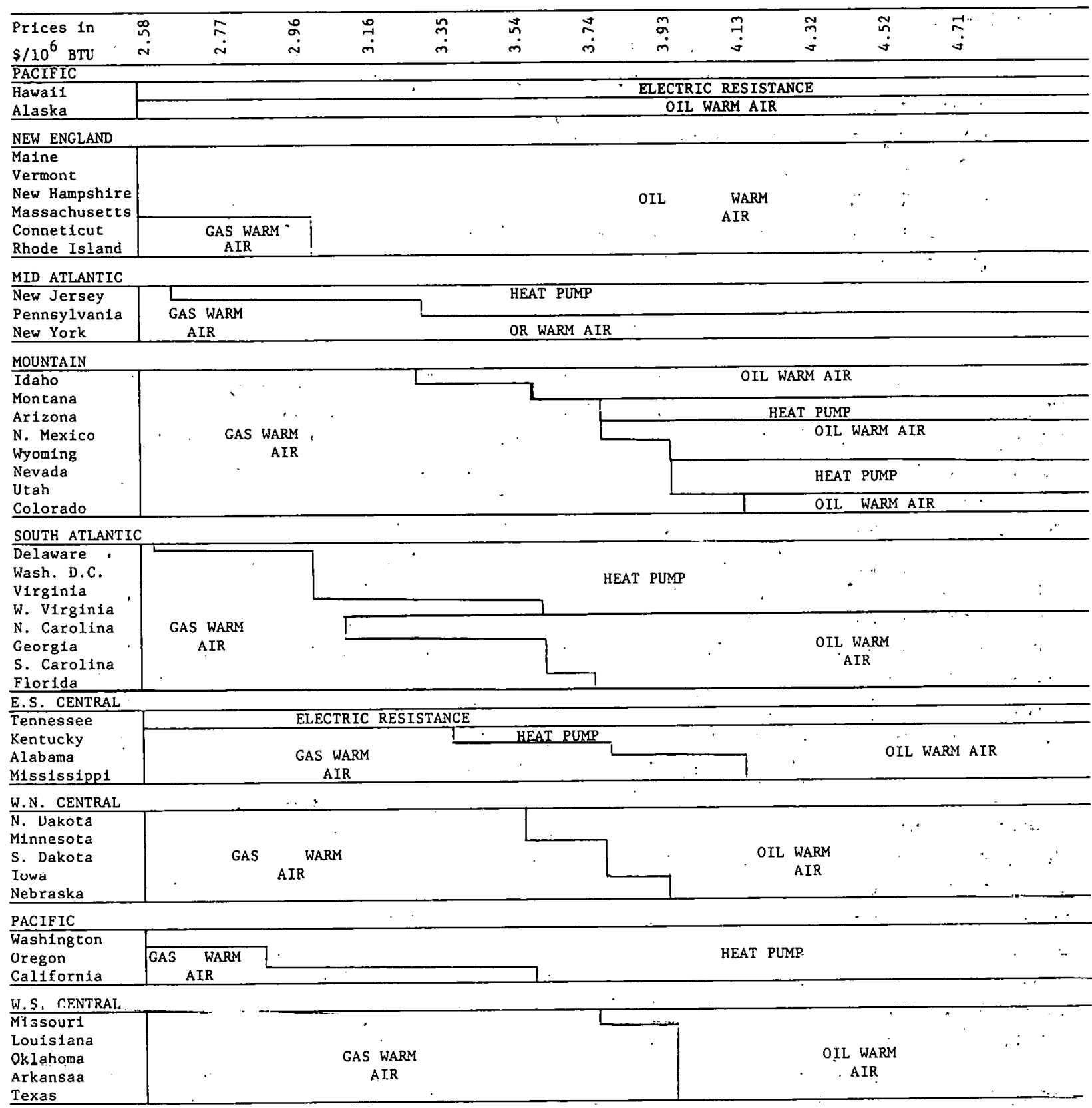


These curves represent only a small set of possible experiments that can be done with this model. A whole set of these experiments should be done, of course, both for historical periods (to check the model parameters) and for future periods (to see which expected future technology and price developments are significant). hypotheses :

However, a gross check of the present results leads to several

a) Between gas and oil the primary influence is the structure of regional prices: Oil almost flat, gas strongly transport dominated.

b) Climatic effects have the greatest influence on the use of the heat pump.

c) Gas and oil prices must be much higher relative to oler-m tricily than is presently the case for electricity to penetrate significantly into the SFDU space heat market.

\section{CONCLUSIONS}

The conclusions we draw here are really preliminary hypotheses. The funding of the study allowed only for development of methodology and crude data estimation. No large.scale systematic validation and experimentation could be done with the models in this level of program effort. Nevertheless some strong preliminary conclusions which are worth following up emerge:

On smoothness. 1) It appears that for many applications the demand curves could be approximater in segments by linear and/ or constant elasticity (log-log) curves. However, at a few price levels, there are large jumps in quantities demanded; and for some range of prices almost no price effect. 2) The phenomenon noted in $\left(1_{0}\right)$ is due to very reqular geographical patterns in switches in fuels as national price changes.

$$
\text { on relationship to actual behavior. 3) with a }
$$

suitable choice of prices, the model results appear upon casual observation to approximate the existing national mix of space heat devices. 4) current regulated natural gae prices do nul appear from the model to be market clearing prices since the model would then imply that gas would be the predominant choice in every state. 5) The actual and BESOM price data for electricity would lead to electricity being used very little. For a sufficiently low relative national price, however, the heat pump would be used in medium usage states such as the Middle Atlantic.

On BESOM VS。CURVE. 6) The demand curves generated by BESOM and by CURVE are very similar in shape. At this point it has not been determined if there are any significant systematic differences between the two sets.

On short run-long run. 7) Long run and short run demand curves which are significantly different in the expected direction are generated by CURVE. 
On sensitivity analysis. 8) The relative demands for gas versus oil appear to be dominated by regional price differences. 9) The demand for heat pumps appears to be dominated by capital. costs, electricity prices, efficiency data and climatic data. 10) The demand for electric resistance heating, when and where it exists, seems to be dominated by the geographically erratic electricity prices. Indeed, actual electric usage appears to be a local phenomenon dominated by widely varying residential rates even within a state. (Variations intra-state are the same order of magnitude as those inter-state.)

On data. 11) The most uncertain and yet important data are, first, the investment cost and efficiencies of heat pump versus gas-oil systems and, second, the regional price differences.

\section{SUGGESTIONS FOR FURTHER RESEARCH}

Suggestions-for further research can be divided into five lines of inquiry: Data improvement (including improved interregional price sub-model); Validation and comparison with econometric models; Experimentation; Inclusion of more fuel system options; and Reduction of CURVE to simple analytic form. Data improvement (and inter-regional price sub-model). As indicated in the conclusions, a dominant factor in gas-oilelectric resistance demand is the assumed set of fixed regional price differences from the national "average" price which is the figure varied to produce demand curves. However, as is indicated in the fuel price section of the Data Appendix these price differences are based on scanty data and either crude models (in the case of gas and oil) or no model (in the case of electricity). More data, backed up by a theoretically believable model, should be developed to bolster this important part of the demand projections 。

An important point relevant to this suggestion is that if simple but reasonably good regional price difference models are developed, they would be extremely useful for many other sectors besides space heat.

of second importance in general, but of primary importance. for new technologies such as the heat pumps, are better and more consistent estimates of capital costs, conversion costs, and, for the heat pump, the dependence of efficiency on climatic factors.

One way to estimate a part of the data is by comparing model output with actual data for historical periods. However, it should be clear that to gain enough degrees of freedom to do this estimation, it is necessary to first decompose the data set into a part to be set by prior belief or asumption and a part to be estimated 
by. trying to get the model output to approximate historical data. In the next suggestion, we discuss other aspects of such a procedure.

Validation and comparison with econometric models. It is important that a thorough statistical comparison of model outputs with historical data be undertaken. This is necessary to determine if any systematic and controllable elements have been left out of the model.

One factor that has obviously been left out of the model: that could affect the data is consumer substitution of other commodities for heat, i.e., consumer conservation (economizing) behavior. One way to make a first validation of the model and take account of the above problem is to investigate if the residuals are consistent with the assumption that on average they are caused by consumer economizing, or, if consistent with other data sources and prior beliefs, the results can be seen to be consistent with economizing behavior. (This problem and procedure obviously ties in with the. estimation procedure described at the end of the data improvement. suggestion.)

In addition to, or in place of comparison with the raw data, comparisons could be made with the results of other (non-process. non-engineering) econometric models. In this context, the technological models we have developed. might be viewed as part of a structural system for which the. (non-process) econometric models are reduced forms which do not allow technology and price expectations to be varied independently of present or recent fuel prices. : (The last suggestion in this section is relevant to this effort at comparison.)

The validation and comparisons suggested here are of ten forgotten in the rush to add to the model to make it more "realistic", when, in fact, it is not yet known if the model. is "unrealistic" in any way which could significantly affect prediction and policies.

Experimentation. The model is capable of a great many more experiments than we have conducted. In particular, we do not know if any of the more complicated behavior (such as a. sequence of system switching for a given SFDU) will occur for any likely prices or technology paths. If simple behavior is more likely, then perhaps a simpler model than CURVE could be constructed.

We have not made a systematic comparison hetween the BESOM and CURVE models:. We do not know, for instance, if the inertia. of the capital stock is really significant in national projections, or if the computed minimum discounted future costs calculated by CURVE are consistent with the annual amortized costs used by BESOM.

We have not testcd whether disaggregation has any overall effect. If, for instance, other sectors, when disaggregated. behave "like" space heat, will such behavior change the sources 
and uses of national energy sufficient to warrant the disaggregation effort? Perhaps the biggest effect of disaggregation is the ability to link regional behavior with economic and technological parameters. This could, however, have large economic repercussions if inter-regional adjustments are difficult.

Inclusion of more fuel system options. The mostlikely-to-be-important options would be (1) air conditioning in conjunction with heating, (2) insulation, and (3) economizing behavior.

Air conditioning: There are conceptual problems, but some strong and possibly reasonable assumptions would allow this to be included within the framework of BESOM or CURVE. The proof of the assumptions would be the empirical validation of the model predictions.

Insulation: The biggest problem here is the data on cost and effectiveness. Institutional factors which dictate heavy insulation of electric homes should be incorporated as well as market factors which permit the choice of alternative levels of home insulation.

Economizing behavoir: To include this possibility could entail a major complication of the model. Unless, in the validation stage, economizing behavoir turns out to be explained by a particularly simple scheme consistent with the present model. Reduction of CURVE to simple analytic form. By this we mean developing a simple formula (or small set of formulae) which predicts the choice path of heating-systems for a given household as a function of climatic variables and variables parametrizing expected future paths of fuel prices, investment costs (as a function of system size), and technology (efficiencies)。 This could be particularly important for (1) rapid (by hand) prediction of fuel demands in given regions, (2) insertion in more complicated models to reduce computation time and increase understanding of model behavior, and (3) more straightforward comparison with (non-process) econometric models.

The analytic form could be arrived at by two possible directions: (1) "Fitting" model output to algebraic forms or (2) Theoretical deduction. 
THIS PAGE

\section{WAS INTENTIONALLY LEFT BLANK}




\section{APPENDIX A. TECHNICAL DESCRIPTION OF PROGRAM CURVE}

I. Output of calculations. Program curve calculates the demand for fuel and fuel systems required to heat single family dwelling units (SFDU ${ }^{\circ} \mathrm{s}$ ) to approximately $70^{\circ}$ during the heating season. The system is chosen to minimize discounted future costs. The results are given by state and by year.

II. Behavioral assumptions.* 1) Seven heating systems are considered: gas warm air (GAS-WA), gas hot water (GAS-HW), OIL-WA, OIL-HW, electric WA (ELEC-WA), electric resistance (ELECRES), and heat pump (HEAT-P). 2) The number of SFDUs with each heating system during the initial year (year 1) is given. This is stored in BDU (J), in $10^{3}$ SFDUs. 3) The total number of SFDUs in each state grows by a fixed rate, $Y$ (GAM), and units are removed from the stock at a fixed rate $\rho$ (RHO). 4) The costs of installing each type of system at the time of construction and converting existing systems is linear with respect to the design BTUs of the system. The basic cost coefficient for transforming system I-I to system $J$ at the start of year 1 (in $\$ / 10^{3}$ BTU/hour of output) is in array $B C(I, J)$. (System $O$ is new construction.) The basic costs decrease in subsequent years at fixed rates, BETA(J). 5) Basic operation and maintenance costs depend on the year in which the system is installed. For systems installed at the start of year 1 , these costs are stored in BOM(J) in $\$ / 10^{3}$ BTU/hr output. A rate of decrease per year of O\&M costs for systems installed at the beginning of a subsequent year is given in ETA(J). 6) The efficiency of system $J$ purchased at the start of year $T$ is given in $\operatorname{EFF}(J, T)$. 7) The conversion factors for input BTUs are stored in $Q(J)$ as 1.0 (MCF of gas $/ 10^{6}$ BTU), 7.0423 (gal of oil/10 $\mathrm{BTU}$ ), and 293.0 (KWH of electricity $/ 10^{6} \mathrm{BTU}$ ). 8) iuel systems are given a lifetime of 20 years. Taxes and insurance are computed as a fixed percentage (TXIN) of installation costs in new construction at the beginning of the year. All payments are discounted at the rate $R$. 9) National price for fuel in year 1 is given in PIND(J). Actual prices in a given year, $P(J)$, are computed by increasing prices at a rate ALPHA $(J)$ per year and subtracting a pseudo-transportation cost for each state from this figure. For each state the transportation cost for fuel $J$ is stored in $\operatorname{TDP}(J)$, "Transportation Difference in Price." Prices are measured in $\xi / \mathrm{mcf}, \xi / \mathrm{gal}$, and $\xi / \mathrm{KWH}$ (IEF). 10) Total BTUs per SFDU per year, TBTU (in $10^{6}$ BTU) are given by the formula, TBTU = DEGDAYS * 15./1000.

where DEGDAXS are degree days. Design output in $10^{3} \mathrm{BTU} / \mathrm{hr}$ (size of the system needed in SFDU)。 is computed as DMBTUH $=65-T 97$,

*See Appendix B for derivation or source of formulas and assumptions. 
where $\mathrm{T} 97$ is the 97 th percentile temperature. 11) The heat pump operates alone down to a temperature of $35^{\circ} \mathrm{F}$ (=THP) and is assisted by electric resistance heating elements below that temperature. The percentage of the degree days supplied by a heat pump is computed as:

$$
\mathrm{HPP}=1 .-\frac{\max (\mathrm{THP}-\mathrm{T} 97,0)^{2}}{65 .-\mathrm{T} 97} \text {. }
$$

The DMBTUH for the heat pump is always less than 30. 12) After the terminal year。 TTERM, prices, unit costs。 and efficiencies are assumed to remain fixed and constant at their values at that time.

III. Method of calculation. The optimal system to be used in a SFDU in each year is computed by the method of dynamic programming. This is a solution procedure whose major stage consists of computing backwards in time. However, in order to describe the set-up of the problem in more detail, it is convenient to do so from the point of view of the householder looking forward.

At the end of relative year $T$ ( initial calendar yedro IY, is relative year 1) each SFDU has one of seven heating system types installed which has a given age from 1 to $I$ years, where I is presently taken as 20 , or is being newly constructed. Thus at the end of a year a SFDU is in one of 141 configurations indexed from 0 to 140. The zero configuration is new construction; the configurations indexed from $(\mathrm{K}-\mathrm{I}) * \mathrm{~L}+\mathrm{l}$ to $\mathrm{K} * \mathrm{~L}$ refer to the $\mathrm{Kth}$ heating system type from one to I years old. An I year old system must be replaced.

The task of the householder is to choose either to continue with the old system or to replace it with a new system so as to minimize discounted future total heating costs. Because of technological improvements, the replacement is not necessarily to d different type of system.

Let $\mathrm{EV}(J)$ be the minimum discounted future cost after the end of the present year, if the system is in state $J$ at the end of the year, discounted to the end of the year. The householder can then compute the cost discounted to the beginning of the year for any choice this year by computing the cost for the current year and adding to it the discounted value of EV (evaluated at the system chosen this year one year older). If the minimizing choice is made, $\mathrm{BV}_{0}$ the minimum discounted future cost at the beginning of the year can be computed by expression (11) below. using the notation:

$K$ - system type at the end of previous year, $K=0, \ldots, 7$.

$\mathrm{KK}$ - system type at the end of present year, $\mathrm{KK}=1, \ldots, 7$.

$J$ - age of system at end of previous year, $\mathrm{J}=\mathrm{I}_{0} \ldots{ }_{0} \mathrm{~L}$.

$F$ - fuel index of system KK

$C(I+K, K K)$ - total cost of converting from system $K$ to system $K K$. (The first index must be increased by 1 since the index zero is not allowed on the computer.) If $K$ and $K K$ are the same, 
it means that the old system is replaced by a new one of the same type.

$\mathrm{OM}(\mathrm{KK}, \mathrm{M})$ - total operation and maintenance expenditures in relative year $\mathrm{T}$.

$M$ - index of relative year in which system KK was purchased.

$$
\begin{aligned}
& \text { If } K \neq 0 \\
& \text { If } \dot{K}=0 \\
& \left.\begin{array}{l}
\mathrm{BV}(\mathrm{K}-\mathrm{D} \cdot \mathrm{L}+\mathrm{J}) \\
\mathrm{BV}
\end{array}\right\}= \\
& \mathrm{OM}(\mathrm{KK}, \mathrm{M}) \cdot \mathrm{TXIN} \cdot \mathrm{C}(\mathrm{I}, \mathrm{KK}) \\
& +Q(F) \cdot[T B T U / E F F(K, M)] \circ P(F) / 100 \text { 。 } \\
& +\left\{(1+R)^{-1} \cdot \operatorname{EV}(K-1) \cdot(L+J+1) \text { if } K K=K \text { and } J<L\right. \text {. } \\
& \{+C(1+K, K K)+(1+R)-1 E V(K K-1) \cdot(L+1) \text {, if, } K K \neq K \text { or } J=L \text {. }
\end{aligned}
$$

Both EV and BV are measured in dollars.

The decision of the householder can then be recorded in the variables :

MSFO(T) - index of system type installed in new construction

at end of relative year $T$;

MSF (K,T) - index of system type installed in existing housing

at end of relative year $T$, when existing system is type $K$.

MAGE $(K, T)$ - age at which existing system $K$ at end of rel-

ative year $\mathrm{T}$ is replaced.

Of course, BV becomes EV for the previous year. The common value of BV and EV at a year beginning (end) will be referred to as the value of the $V$ function at that point in time.

The dynamic programming calculation starts at the end of the relative terminal year TTERM. Since the cost parameters do not change after TTERM, the optimal path after this point is easily computed, which gives EV at the end of TTERM. The $V$ function is then moved backwards by means of (1). When the optimal decisions are known for the end of relative year 1 ; the actual number of SFDU's with each fuel system type and age can be determined for each year.

The number of $\left(10^{3}\right)$ SFDU's in a given state with each system type is given at the beginning of year 1 and its age distribution is arbitrarily set as uniform over 1 to $L$.

The number of existing SFDU's at the end of relative year $T$ in configuration (system type and age) $\mathrm{J}$ is stored in $\mathrm{DU}(\mathrm{J}), \mathrm{J}=\mathrm{I}_{a}$ ... 140. The number of all SFDU's is given by $Z$. First the number of newly constructed $\mathrm{SFDU}^{\circ} \mathrm{s}$ is given by $(\mathrm{GAM}+\mathrm{RHO}) \cdot \mathrm{Z}=\mathrm{DUO}$ 。 Then all components of DU are reduced by the removal rate and DU becomes ( 1 - RHO) - DU. Nowo since the optimal decisions of SFDU's in each configuration are known, the SFDU's in each component of DU can be transferred and added to a component of a vector DDU. DUO is also added to the appropriate component of DDU. The values in DU are then replaced by those in DDU.

The DU thus computed is that effective throughout and at the end of year $\mathrm{T}+1$. At this point the number of $\mathrm{SFDU}^{\circ} \mathrm{s}$ with system type $K, \operatorname{DUK}(K)$, and the demand for fuel $J$ a $D E(J)$ 。 can be computed. 
IV. Flow of program. The program works through a sequence of sub-programs. A diagrammed flow of the program through main iterations and subprograms is given in Table IV.

(Note: There are two versions, SPOT and FLOOD. Version SPOT outputs a very abbreviated set of micro-data, while FLOOD outputs almost all calculated micro-data. The former should be used when extensive demand curves are calculated; the latter can be used to make detailed analyses at a few well chosen prices.)

The following is a fairly detailed explanation of each subprogram. For each sub-program, an outline of the tasks performed is given first. Then a more detailed explanation is given of the less obvious points in the form of numbered footnotes. The letters in the left margin of the outline match up with the letters in Tahle $\mathrm{TV}$.

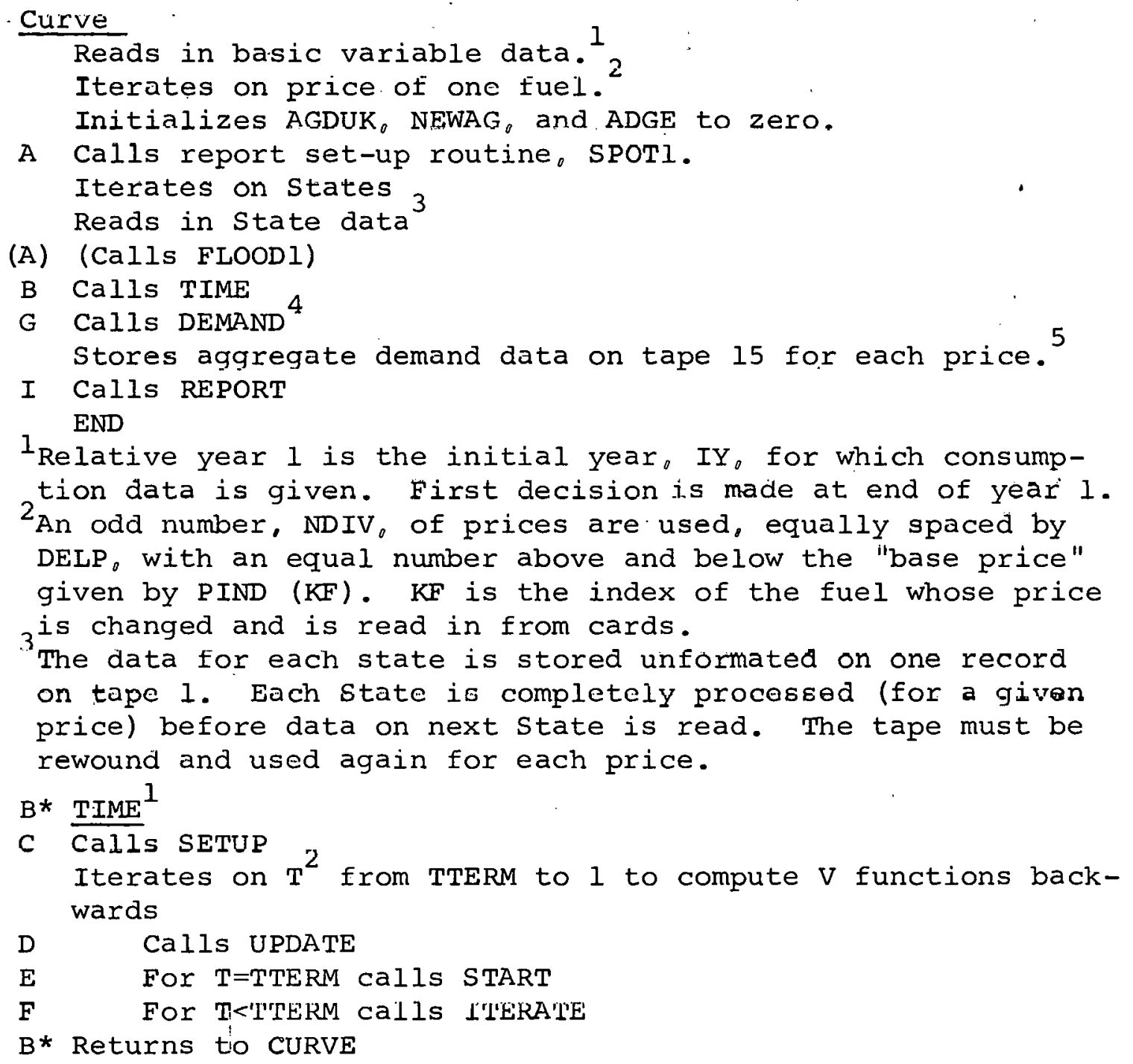


Global Flow of Program CURVE, SPOT Version

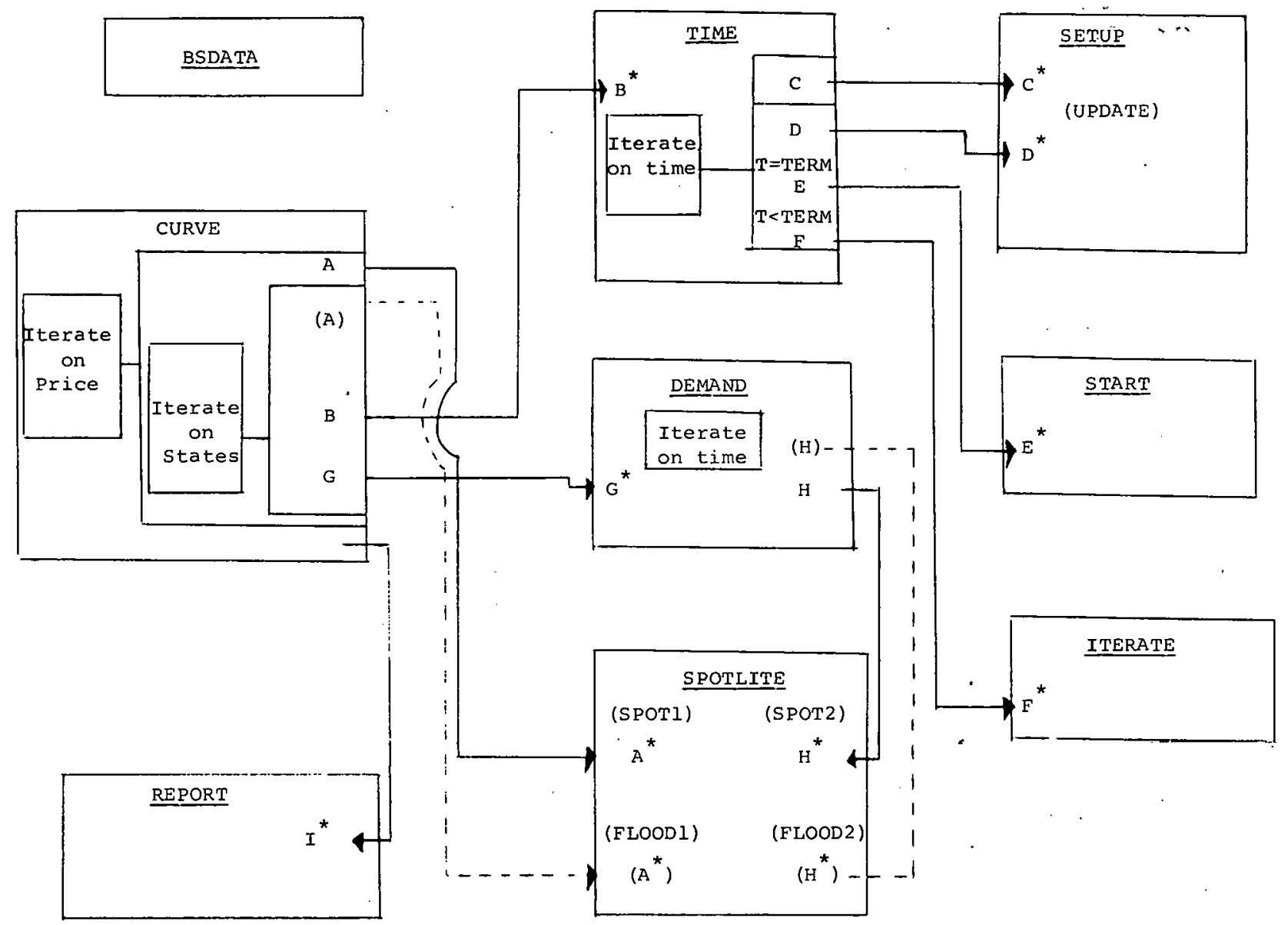

Letters, such as $A$, indicate CALLs; letters with asterisks indicate entry point in program called from point with plain letter. (Letters in parentheses indicate alternate route for FLOOD version.) Names in parentheses indicate entry points for sections of subprograms indicated by divisions by dashed lines. 


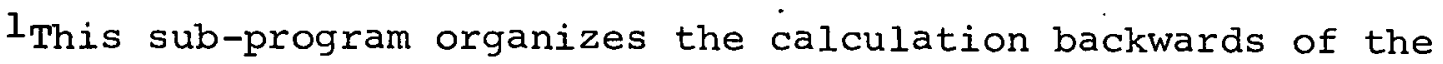
$\mathrm{V}$ function.

2 T here indicates decisions are being made at the end of relative year $\mathrm{T}$.

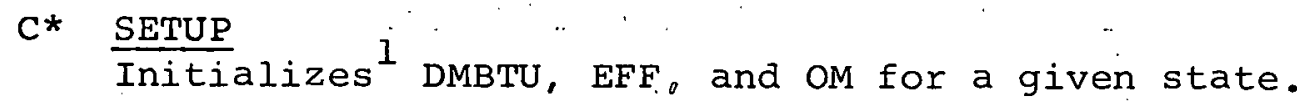

C* Returns to TIME

D* (UPDATE)

Calculates $\mathrm{C}^{2}$ and $\mathrm{P}$ for current $\mathrm{T}$

D* Returns: to TIME

${ }^{1}$ Calculations involving the heat pump. system type 7 , using THP and HPP, are explained in section on system cost and Size Estimates.

${ }^{2}$ For $C$ and $B C$ the first computer index ( 1 to 8 ) must be decreased by one to give correct conceptual index ( 0 to 7 ).

\section{$E * \quad$ START}

Determines $V$ function at end of TTERM (sets EV ą. TTERM) ${ }^{1}$

E* Returns to TIME

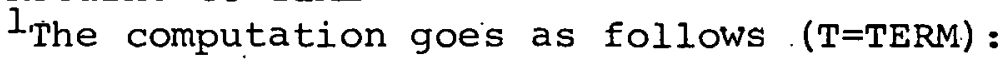

There is an outer loop over system types, $K=1$ to 7. New construction information is not needed since the exogenous data does not vary after TTERM, a switch is either made at TTERM or at the end of the life of the present system. Afterwards the same system is kept permanently。 needing only replacement (by the same system type) every L years.

First, For each system type, $K_{\theta}$ we evaluate the discounted costs of switching permanently to system type KK. The costs are discounted back to the switching time. This cost is computed as:

$$
\begin{gathered}
\mathrm{VV}=c\left(1+K_{0} \mathrm{KK}\right)+{ }_{\mathrm{a}=1}^{\infty} \cdot(1+\overline{\mathrm{K}})^{-\mathrm{a} L} \mathrm{c}(1+\mathrm{KK}, \mathrm{KK}) \\
+{ }_{\mathrm{a}}=\sum_{0}^{\infty}(1+\mathrm{R}) \cdot-\mathrm{a}[\mathrm{TXJN} * \mathrm{C}(\mathrm{J}, \mathrm{KK})+\mathrm{OM}(\mathrm{KK}, \mathrm{T}) \\
\quad+\mathrm{Q} *(\mathrm{P} / 100 .) * \mathrm{TBTU} / \mathrm{EFF}(\mathrm{KK}, \mathrm{T})]
\end{gathered}
$$

The system type index for which this cost is a minimum is stored in NN and the minimum cost is stored in VV. We immediately set. $\mathrm{EV}\left(\mathrm{K}^{*} \mathrm{~L}\right)=\mathrm{VV}$ and $\mathrm{MSF}\left(\mathrm{K}_{\theta} \mathrm{T}\right)=\mathrm{NN}_{0}$ since a system of $L$ years is at the end of its life and the system to which a switch is made does not depend on age.

Now, the program initializes $\operatorname{MAGE}(K, T)=1$ and looks at switching at the end of life, $L_{0}$ versus immediately, $i . d . "$ it compares, for each $J 。 V V$ with

$$
\begin{aligned}
\mathrm{VVV}= & \sum_{\mathrm{a}=0}^{\mathrm{L}-\mathrm{J}-1}(1+\mathrm{R}) \quad-\mathrm{a}[\operatorname{TXIN} * \mathrm{C}(1, \mathrm{~K})+\mathrm{OM}(\mathrm{K}, \mathrm{M})+ \\
& \mathrm{Q} *(\mathrm{P} / 100 .) * \mathrm{TBTU} / \mathrm{EFF}(\mathrm{K}, \mathrm{M})] \\
+ & (1+\mathrm{R})-(\mathrm{L}-\mathrm{J}) * \mathrm{VV} .
\end{aligned}
$$


If VVV is less than $V V$ a switch is not made at age $J$, $\mathrm{EV}((\mathrm{L}-\mathrm{l}) * \mathrm{~K}+\mathrm{J})=\mathrm{VVV}$, and $\operatorname{MAGE}(\mathrm{K}, \mathrm{T})$ is incremented by 1 . IF $\mathrm{VV}$ is less than VVV a switch is made to $\mathrm{KK}$ for systems of type $\mathrm{K}$ of age $\mathrm{J}_{0}$ and $\mathrm{EV}((\mathrm{I}-\mathrm{I}) * \mathrm{~K}+\mathrm{J})=\mathrm{V}$. [MAGE $(\mathrm{K}, \mathrm{T})$ has already been set to $\mathrm{J}$ or less.]

\section{F* ITERATE}

Determines $\mathrm{BV}$ from $\mathrm{EV}$ and determines at the same time $\operatorname{MSFO}(T)$ MSF $(K, T)$ and MAGE $(K, T)$

F* Returns to TIME

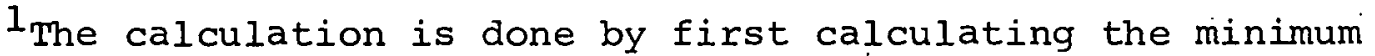
cost system to which to switch if a switch is optimal. This also determines the decision for age $=\mathrm{L}$ and new construction. Then starting with age $J=1$ and $M A G E=I_{\text {o }}$ staying with the same system is compared with switching for each $J$. If no switch is required, then BV is set for that age and MAGE is set up by 1 to $\mathrm{J}+1$. If a switch is required, $B V$ is set and MAGE is left at the age of first switching.

Finally, EV is replaced by $\mathrm{BV}$.

G* DEMAND

Iterates forward from $\mathrm{T}=0$ to $\mathrm{TTERM}-1$ to determine $\mathrm{DU}, \mathrm{DUK}$ DE and update AGDUK, AGDE, and NEWAG for the consumption years $\mathrm{T}+\mathrm{l} . \mathrm{I}$

(H) (Calls FLOOD2 for each $T$ in FLOOD version)

$\mathrm{H}$ Calls SPOT2 at end of iteration to give results for TTERM. G* Returns to CURVE

$l_{\text {DDU }}$ is initialized by spreading BDU equally over all ages, then demand for $T=0$ (consumption in year $1=1 \mathrm{Y}$ ) is determined separately before Do loop. Then $T$ loops from 1 to TTERM-1。 computing for each $T$ the new stock of SFDU's in each state during the consumption year (DDU) and branching to the end segment of the program to compute the fuel demands and update aggregate data. The end segment is used for all $T$ and starts by setting $D U=D D U$.

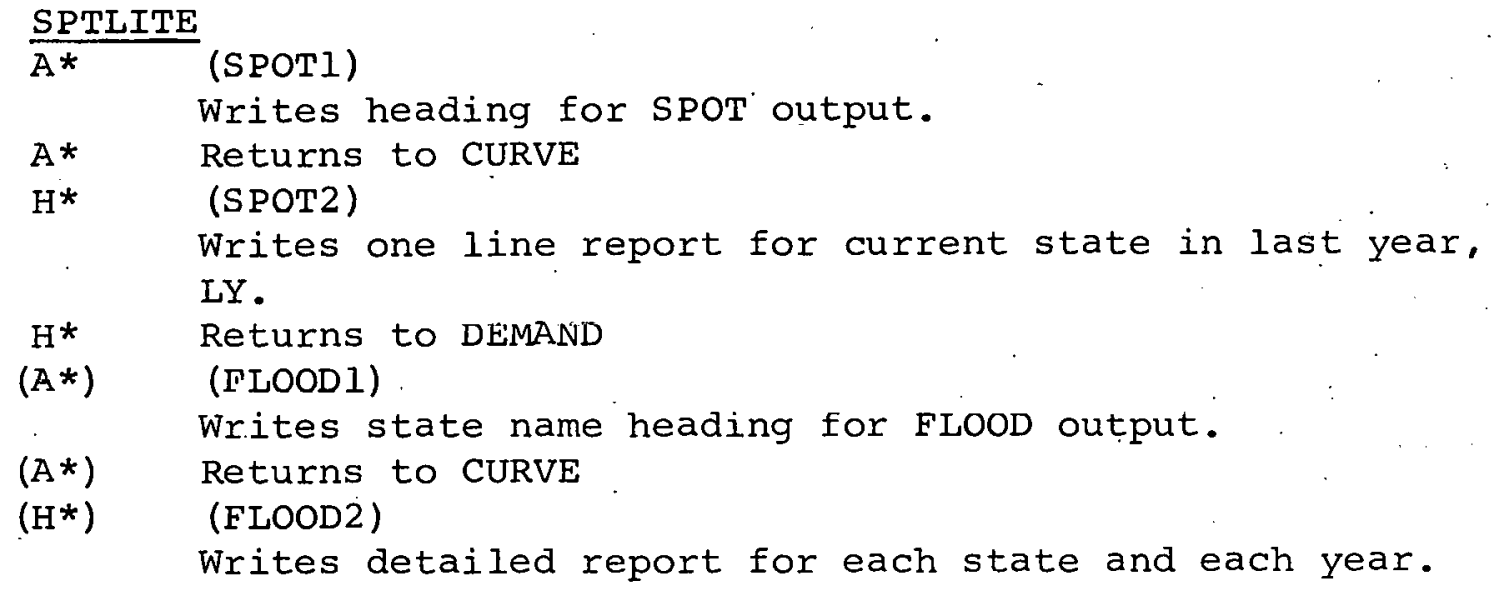


(H*) Returns to DEMAND

I* REPORT

Prints heading

Iterates on prices. 1

Reads in one record for each price from tape 15

Writes report on aggregate demand for all years.

I* Returns to CURVE

lThis routine uses NDIV to determine number of records to

read (unformated). Actual price data is on record.

BSDATA

No call to this routine necessary. Fills basic data block.

The complete program listing for CURVE (Spot Version) is presented in Table $\mathrm{V}$.

v. Input data. Input ala is in two fuins -- caras

and tape. The card input is on 5 cards free format.

card 1 - PIND (base prices for 3 fuels), KF (index of fuel price varied), NDIV (number of price points computed on demand curve, must be odd)

DELP (increment betweon price points)

card 2 - ALPHA (yearly rates of fuel price increases。3, decimal)

Card 3 - BETA (yearly rates of investment cost decrease。7。 decimal)

Card 4 - ETA (yearly rates of O\&M cost decreases, 7, decimal)

card 5 - R (interest rate, decimal), TXIN (taxes and insurance rate decimal)

The tape input on tape 1 is unformated (i.e., binary to be read directly into core memory) with one record per state. The variables stored on the record in turn are: STNAME (state name, in holerith), BDUं (number of SFDU ${ }^{\circ} \mathrm{s}$ in $10^{3}$ units of each system type at end of year 1, 7)。 GAM (rale of increase of total SH'DU's, decimal), RHO (rate of removal of SFDU's, decimal), DEG DAYS (de-

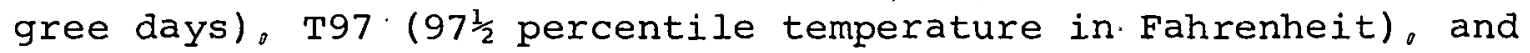
TDP (transportation costs, 3, $/ / \mathrm{mcf}_{0} \phi / g a l_{0} \phi / k w h$ ). This tape can be written by a program which writes the data onto the tape unformated one write statement per state.

VI. Output. The atandard output (GPOT version) is shown in Table VI. It comes in two sections. The first, produced by SPOTLITE。 shows the results state by state for a given year (now set at $L Y=1985$ ). Each linc givas: state name, ghosen year fuel demands (3). SFDU ${ }^{\circ} \mathrm{s}$ with each system (7). systems chosen for new construction. This report is repeated for each price point.

second, the aggregate report generated by REPORT is given and repeated for each price point. For each year, the report gives in order: aggregate fuel demand (3)。 aggregate SFDU's with each system (7), number of states where each system is chosen for new construction (7)。 
TABLE V

Listing of Program CURVE (SPOT Version)

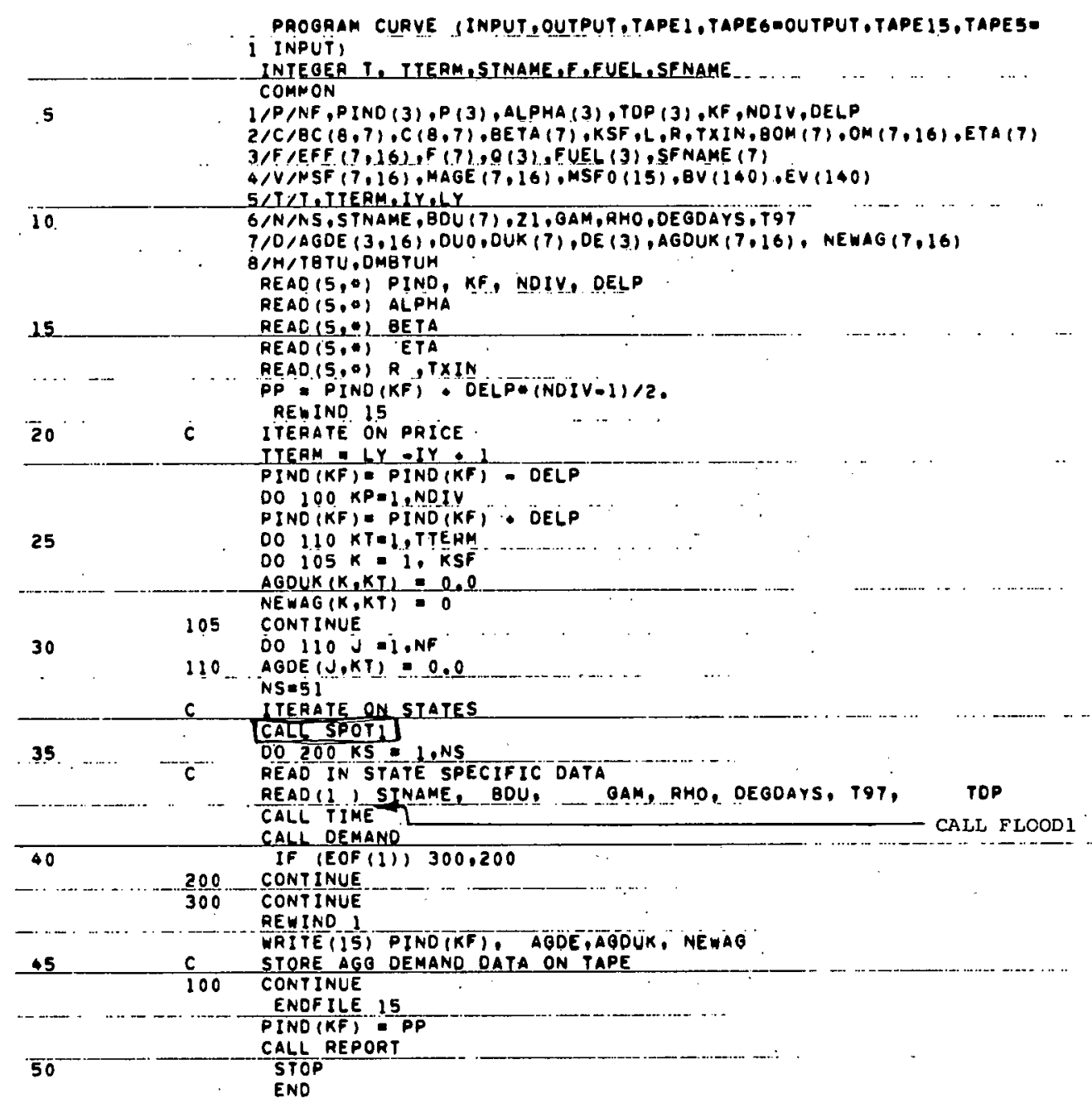

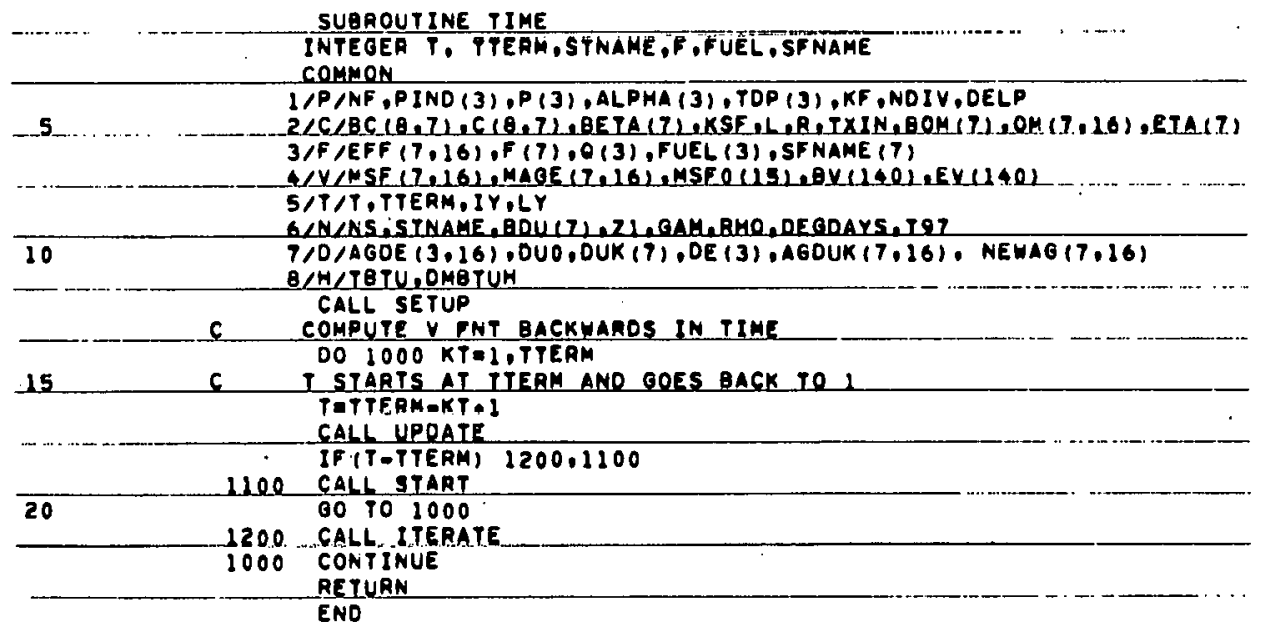




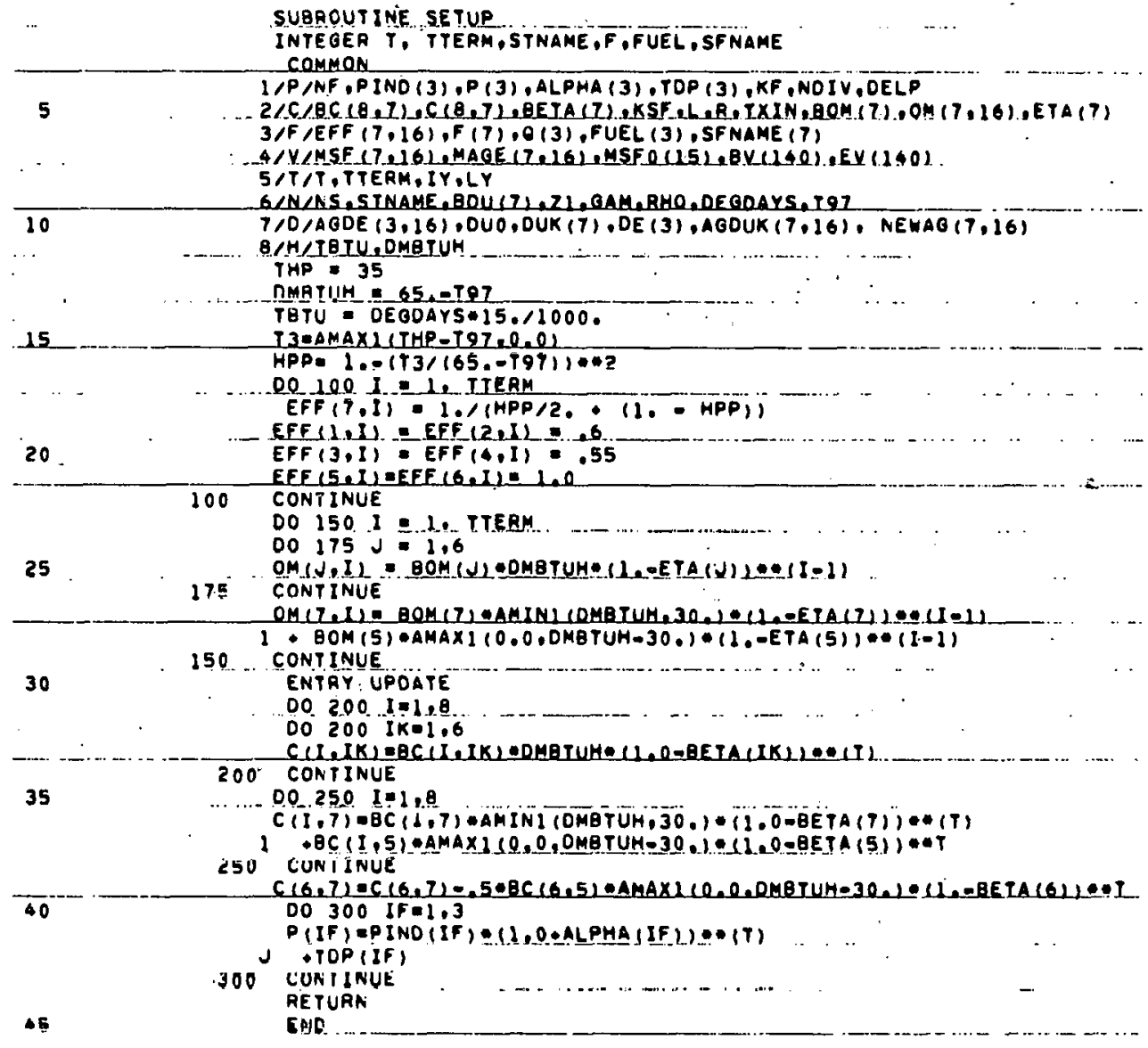




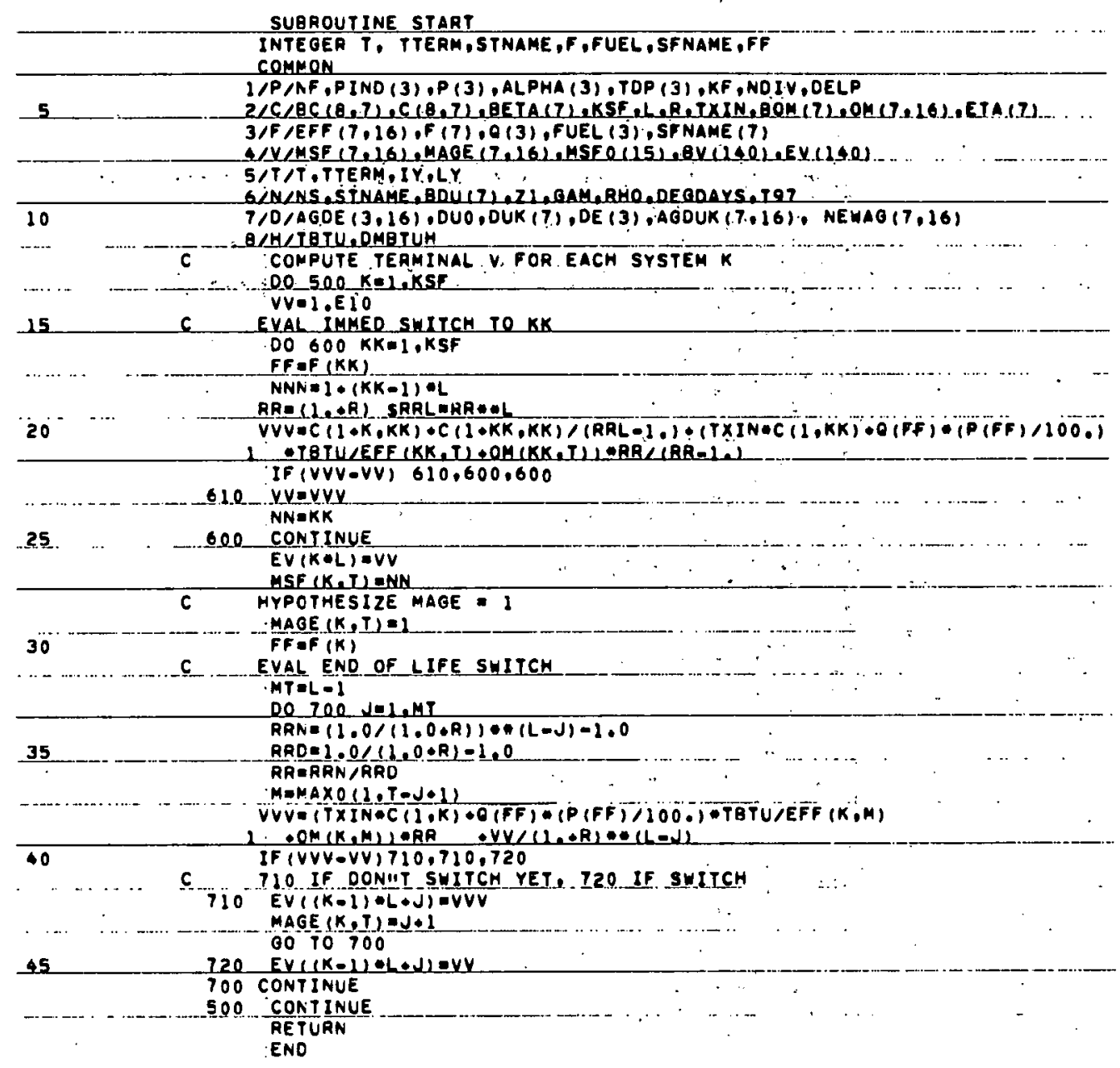




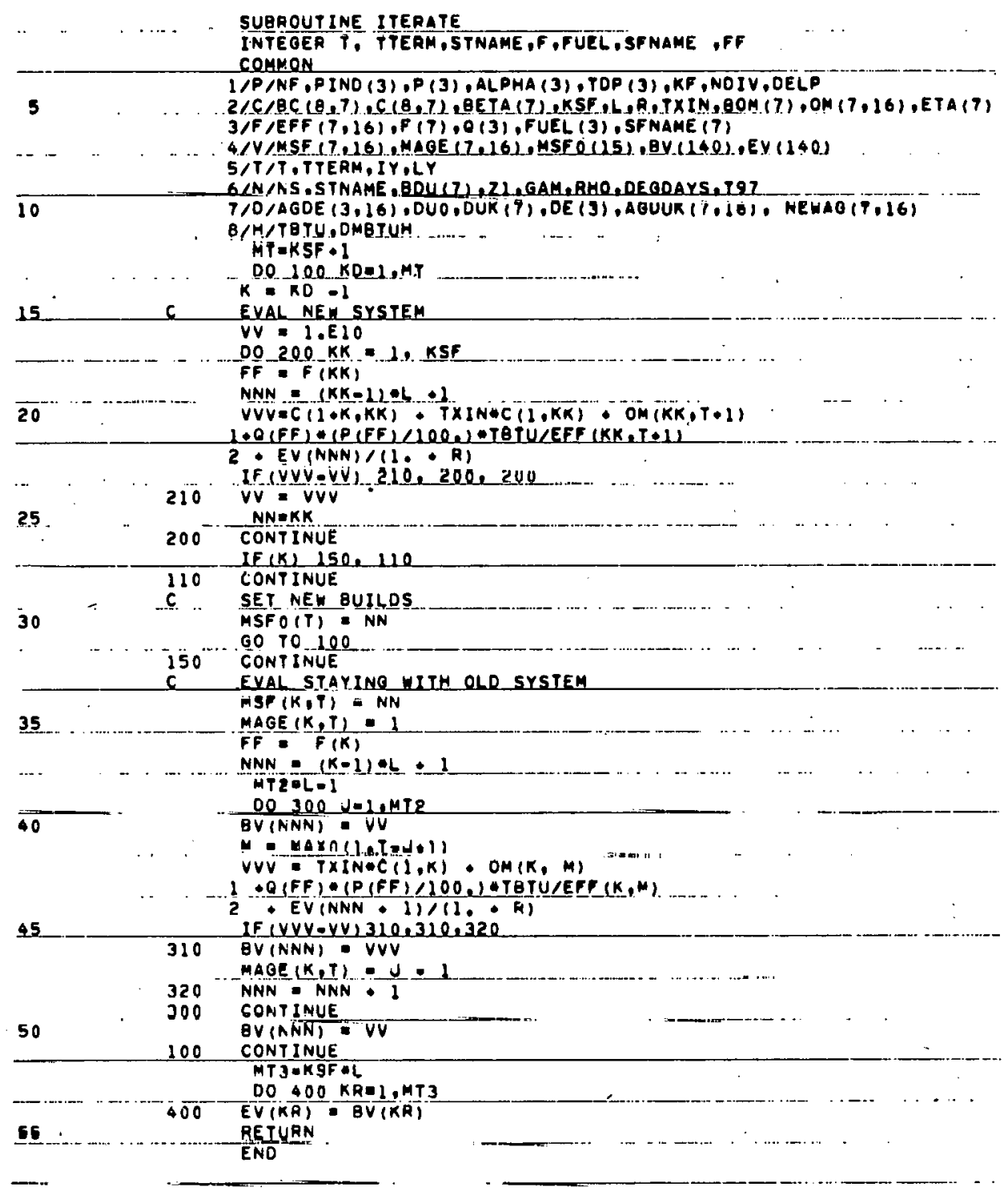




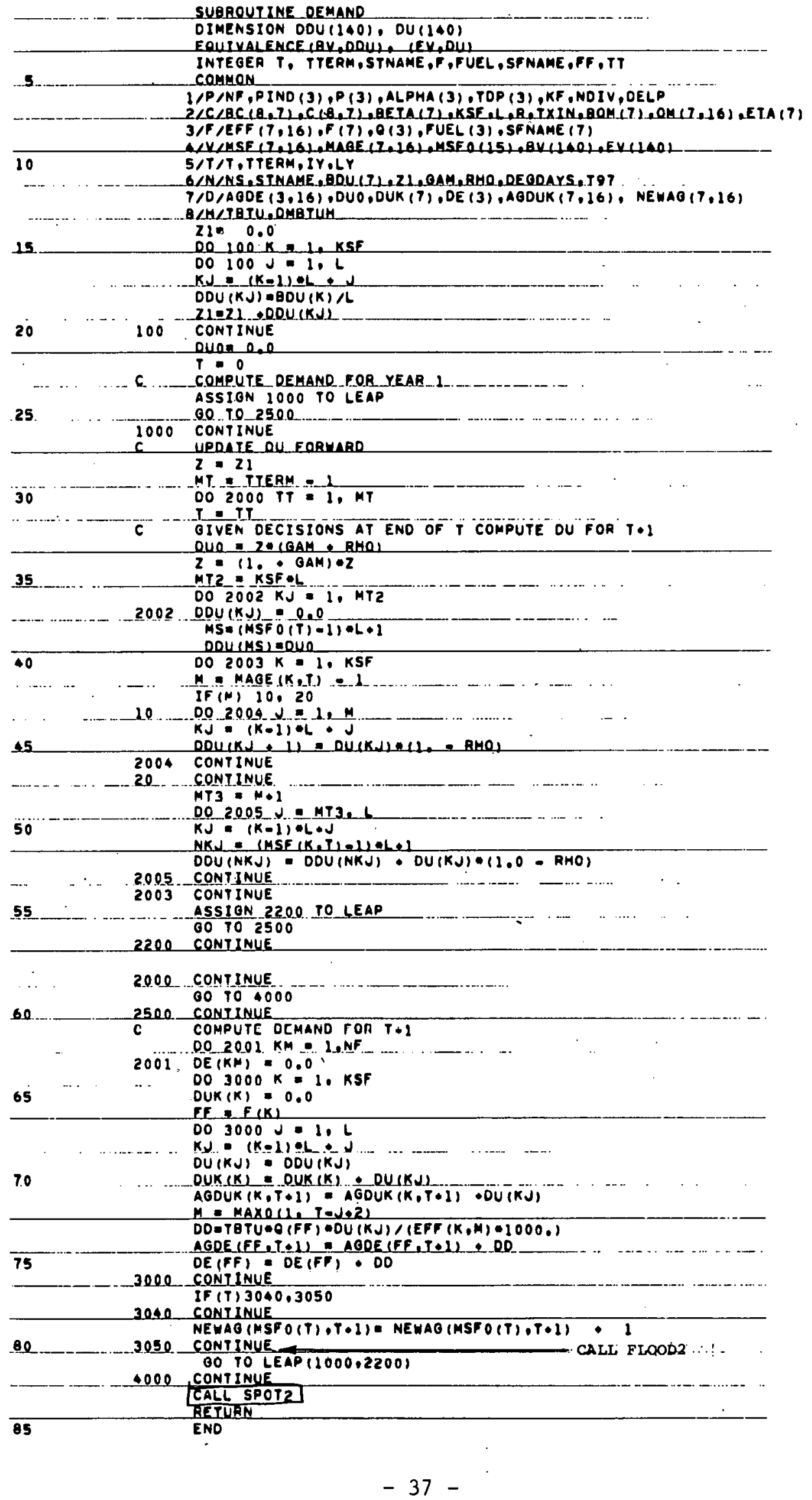




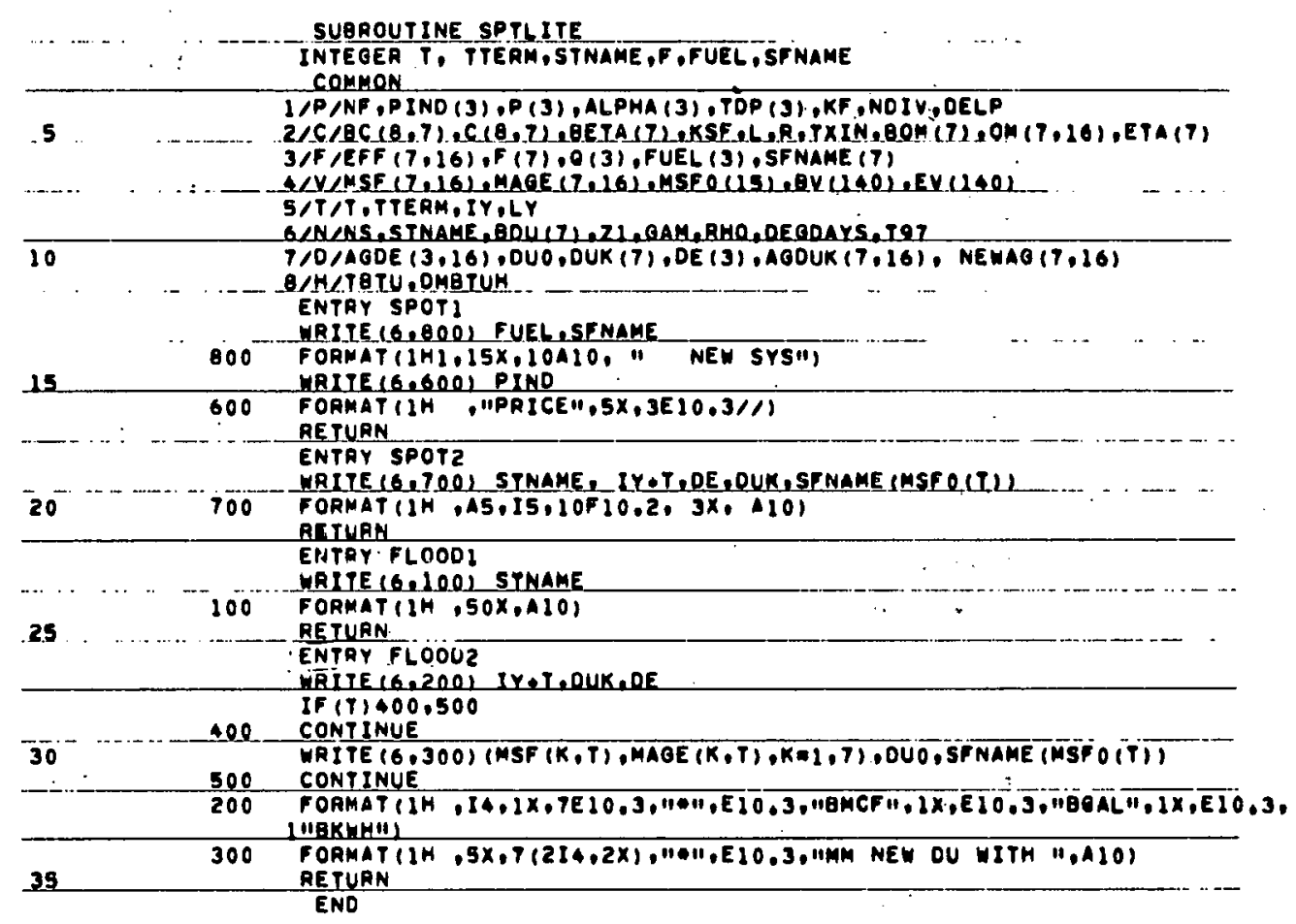

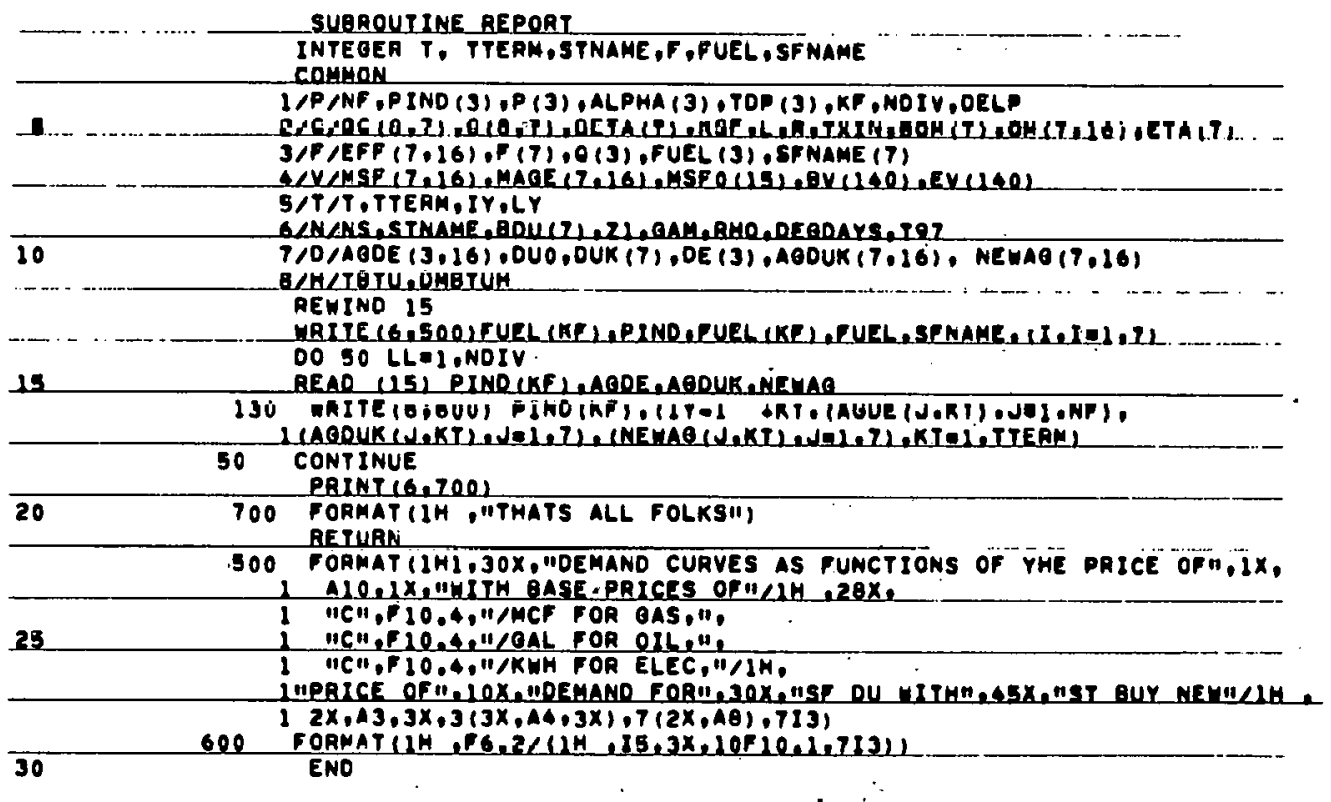




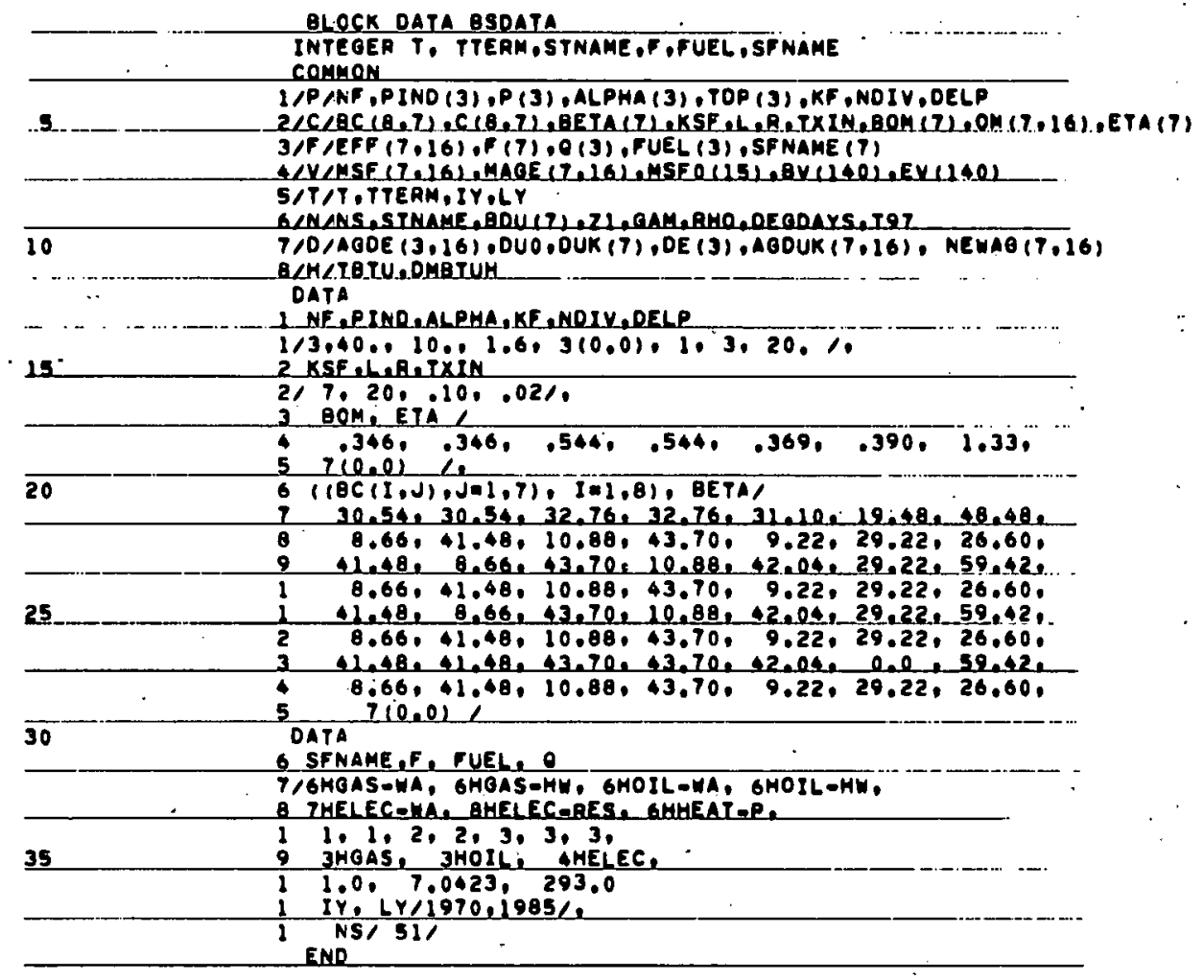


TÅBLE VI

Standard output (SPOT Version)

\begin{tabular}{|c|c|c|c|c|c|c|c|c|c|c|c|c|}
\hline \multicolumn{2}{|c|}{ PHICE } & $\begin{array}{c}\text { GAS } \\
.220 F+03\end{array}$ & $\begin{array}{c}\text { OIt } \\
\text { : } 2 n 0 E+\cap ? \text { ? }\end{array}$ & $\begin{array}{c}\text { ELEC } \\
.8 \cap \cap E \rightarrow \cap 0\end{array}$ & GAS-WI & GAS $=H W$ & OIL-WA & $O I L=H W$ & ELEC $-W A$ & ELEC-RES & HEAT - P & NEW \\
\hline MAIN & 1085 & 0.00 & $? 82.86$ & $0.0 n$ & $0.0 n$ & $0.0 n$ & 139.46 & $33,8\}$ & 0.00 & 0.00 & 0.00 & $O I L-W A$ \\
\hline VERM & 1985 & $0 . n n$ & $134.7 ?$ & $n .0 n$ & n.nn & 0.00 & 76.27 & 11.41 & n.no & 0.00 & 0.00 & OIL-WA \\
\hline NHAM & 1985 & 0.00 & 725.55 & $n . n n$ & 0.00 & $0.0 n$ & 127.16 & 29.42 & 0.00 & 0.00 & 0.00 & $O I L-W A$ \\
\hline MASS & 1985 & 0.00 & 1472.64 & $0.0 n$ & 0.00 & $0.0 n$ & $908.0 \mathrm{~g}$ & 271.56 & $n .00$ & 0.00 & 0.00 & OIL-WA \\
\hline CONN & 1985 & $0.0 n$ & 732.41 & $0 . n n$ & 0.00 & $n .0 n$ & $496 . A 3$ & 138.91 & 0.00 & 0.00 & 0.00 & $O I L$-WA \\
\hline RHIS & $19 R 5$ & 0.00 & $? ? 2.9 ?$ & $n .0 n$ & $0.0 n$ & $0.0 n$ & 145.51 & 47.93 & 0.00 & 0.00 & 0.00 & OIL-WA \\
\hline N.Y. & 1985 & 0.00 & 4111.32 & $0.0 n$ & $n, n n$ & $0.0 n$ & 2625.1 & 942.51 & 0.00 & 0 & 0.00 & OIL-WA \\
\hline PENN & 1985 & 15.94 & 2043.95 & 752.44 & 70.63 & $45.3 ?$ & 1621.83 & 313.10 & 0.00 & 31.13 & 0.00 & OIL-WA \\
\hline P.J. & 1995 & 0.00 & $1.390 .<8$ & $n .0 n$ & 0.00 & $0.0 n$ & 1176.92 & 331.58 & 0.00 & $n .00$ & 0.00 & OIL-WA \\
\hline MYLD & 1985 & 0.00 & 1020.94 & $n .0 n$ & 0.00 & 0.00 & $10 A 2 . A 3$ & 98.42 & 0.00 & $n .00$ & 0.00 & OIL-WA \\
\hline $0 . c$. & 1985 & 0.00 & 151.79 & $0.0 n$ & 0.70 & 0.00 & 154.05 & 34.08 & 0.00 & 0.00 & 0.00 & DIL-WA \\
\hline DELA & 1989 & 0.00 & 124.50 & $0.0 n$ & 0.00 & $0.0 n$ & 118.67 & 10.97 & 0.00 & $n .0 n$ & n. nn & $O I L=W A$ \\
\hline Wva. & 1985 & 2.87 & 307.75 & 125.31 & 24.86 & .61 & 349.58 & 5.92 & $0.0 n$ & 5.83 & 0.00 & OIL-WA \\
\hline VIRG & 1985 & 0.00 & $9 a 0.3 a$ & n.nn & 0.00 & $0.0 n$ & 1205.64 & 70.47 & 0.00 & 0.00 & 0.00 & OIL-WA \\
\hline N.C. & 1985 & $0.0 n$ & $945 . \times 5$ & 0.00 & $0.0 n$ & 0.00 & 1390.24 & 16.49 & n.00 & 0.00 & 0.00 & OIL-WA \\
\hline s.c. & 1985 & 1.35 & 318.57 & 130.25 & $>1.61$ & 0.00 & 654.10 & 0.37 & $0.0 n$ & 11.85 & 0.00 & OIL-WA \\
\hline GEOR & 1945 & 4.60 & 571.01 & 745.97 & 73.68 & $0.0 n$ & 1185.01 & 5.88 & 0.00 & 22.39 & 0.00 & OIL-WA \\
\hline FLA. & 1985 & 35.73 & 4.96 & 240.49 & 2362.11 & 19.8 ? & 36.42 & 6.61 & 0.00 & 91.20 & 0.00 & GAS-WA \\
\hline WISC & 1995 & 0.00 & 1639.77 & 0.00 & n.on & $0.0 n$ & 1041.07 & 67.72 & 0.00 & 0.00 & 0.00 & OIL-WA \\
\hline $\mathrm{MICH}$ & 1985 & $0.0 n$ & 2252.90 & 0.00 & 0.00 & 0.00 & 1491.17 & 72.83 & 0.00 & $n .00$ & 0.00 & OIL-WA \\
\hline ILL. & 1995 & 27.32 & 2750.80 & $n .0 n$ & 132.54 & 59.16 & 2282.81 & $2 ? 9.80$ & 0.00 & 0.00 & 0.00 & OIL-WA \\
\hline IND. & 1985 & 10.81 & 1412.44 & 0.00 & 74,55 & 1.20 & 1248.75 & 41.44 & $0.0 n$ & 0.00 & 0.00 & OIL-WA \\
\hline OMIO & 1985 & $\begin{array}{c}28 . ? 2 \\
0\end{array}$ & 2837.49 & 0.00 & 177.60 & $17.0 n$ & 2451.87 & 95.33 & 0.00 & $\begin{array}{l}0.00 \\
0.00\end{array}$ & 0.00 & OIL-WA \\
\hline KTY. & 1985 & $0.0 n$ & SBO.>2 & 334.31 & $0.0 n$ & 0.00 & 761.40 & A. 5 ? & 0.00 & 19.64 & 0.00 & OIL-WA \\
\hline TENN & 1985 & 0.00 & $0.0 n$ & 15 AGA.:1 & 0.00 & $0.0 n$ & $0.0 \mathrm{e}$ & 0.00 & 176.17 & 855.40 & 0.00 & ELEC-RES \\
\hline MISS & 1985 & $29.4 n$ & 1? & 90.94 & 534.30 & .28 & .20 & .09 & 0.00 & 9.41 & 0.00 & GAS-WA \\
\hline$\triangle L A B$ & 1985 & $4 A .9 R$ & .59 & 198.75 & 250.63 & $1.2 \mathrm{~A}$ & .91 & .42 & 0.00 & 19.62 & 0.00 & GAS-WA \\
\hline PDAK & 1985 & 0.00 & 225.70 & $0.0 n$ & 0.00 & 0.00 & 116.03 & 10.33 & 0.00 & 0.00 & 0.00 & OIL-WA \\
\hline SDAK & 1985 & 1.70 & 211.65 & $0.0 n$ & 8.71 & n.on & 135.23 & 6.05 & 0.00 & 0.00 & 0.00 & OIL-WA \\
\hline MINN & 1985 & $0.0 n$ & 1691.40 & 0.00 & 0.00 & $0.0 n$ & 904.77 & $84.7 ?$ & 0.00 & 0.00 & 0.00 & OIL-WA \\
\hline PES. & 1985 & 4.95 & $419 \times 2$ & 0.00 & 28.29 & $\begin{array}{l}0.0 n \\
1.24\end{array}$ & $310^{\circ} .25$ & 7.99 & 0 & 0.00 & $\begin{array}{l}0.00 \\
0.00\end{array}$ & OIL-WA \\
\hline :OWA & 1985 & 0.39 & 024.05 & $n .0 n$ & 47.50 & 1.80 & 609.01 & $21: 96$ & 0.00 & $\begin{array}{l}10.00 \\
n .00\end{array}$ & $n .00$ & OIL-WA \\
\hline KAN. & 1985 & 68.40 & .91 & $0.0 n$ & 1519.02 & $7.1 ?$ & .55 & .26 & 0.00 & 0.00 & 0.00 & GAS-WA \\
\hline MSHI & 1985 & 11.24 & 1031.18 & $n=n n$ & 04.17 & $7.6 ?$ & 1060.82 & 34.89 & $0.0 n$ & 0.00 & 0.00 & OIL-WA \\
\hline OKLA & jo.95 & 0.34 & . & 0.00 & 703.80 & 1.34 & .OP & .04 & 0.00 & 0.00 & 0.00 & GAS-WA \\
\hline ARK. & 1985 & 2.58 & 267.17 & 0.00 & 34.35 & $0.0 \mathrm{n}$ & 463.35 & .33 & 0.00 & 0.00 & 0.00 & OIL-WA \\
\hline$=E X_{0}$ & 1985 & 199.09 & .43 & $0.0 n$ & 3179.64 & 6.83 & .61 & .28 & 0.00 & 0.00 & 0.00 & $G A S-W A$ \\
\hline LSNA & 1985 & 37.49 & .12 & 44.98 & 935.00 & 2.17 & .27 & .13 & 0.00 & 6.40 & 0.00 & GAS-WA \\
\hline IUA. & 1985 & $0.0 n$ & 174.15 & $0 . n n$ & 0.00 & $0.0 n$ & 137.17 & 2.33 & $0.0 n$ & 0.00 & 0.00 & OIL-WA \\
\hline MCNT & 1985 & n.on & 209.39 & non & $n .0 n$ & $0.0 n$ & 132.07 & 4.20 & 0.00 & 0.00 & 0.00 & OIL-WA \\
\hline wYo. & 1985 & $12.8 \mathrm{R}$ & .23 & $n . n n$ & 65.92 & 1.84 & .11 & .05 & 0.00 & 0.00 & 0.00 & GAS-WA \\
\hline NEV. & 1985 & 22.67 & 1.29 & $0.0 n$ & 143.0 .3 & $.9 n$ & .76 & .30 & 0.00 & 0.00 & 0.00 & GAS-WA \\
\hline UTAH & 1985 & $37.3 ?$ & .95 & $0.0 n$ & 241.24 & $3.5 n$ & .50 & .23 & 0.00 & $n .00$ & 0.00 & GAS-WA \\
\hline COL. & 1985 & 90.90 & .2 & $n .0 n$ & 544.85 & 19.62 & .35 & .16 & 0.00 & 0.00 & 0.00 & GAS-WA \\
\hline AAIZ & 1985 & 7.69 & 309.16 & non & 20.42 & .12 & 487.17 & .61 & 0.00 & 0.00 & 0.00 & OIL-WA \\
\hline NMEX & 1985 & 2.75 & 395.90 & $0.0 n$ & 23.56 & .34 & 446.51 & 1.49 & 0.00 & 0.00 & 0.00 & OIL-WA \\
\hline WASH & 1985 & $0.0 n$ & $784.4 ?$ & $0.0 n$ & 0.00 & $0.0 n$ & 741.98 & 14.35 & 0.00 & $n .00$ & $0.0 n$ & OIL-WA \\
\hline ORE. & 1985 & 0.00 & 536.57 & $0 . n n$ & 0.00 & $0.0 n$ & 483.68 & 6.81 & 0.00 & 0.00 & 0.00 & OIL-WA \\
\hline CAL. & 1985 & 18.28 & 2734.29 & $n \cdot n n$ & 236.17 & 7.51 & 4720.61 & $24, A A$ & 0.00 & 0.00 & 0.00 & OIL-WA \\
\hline ALSK & 1985 & 0.00 & 158.57 & $0.0 n$ & 0.00 & $0.0 n$ & 61.48 & $7.3 ?$ & n. no & 0.00 & 0.00 & $O I L-W A$ \\
\hline HAW. & 1085 & .00 & $.0 n$ & 5.92 & 14.66 & 1.39 & .40 & $.2 ?$ & 3.11 & 131.56 & 0.00 & ELEC-RES \\
\hline
\end{tabular}


The non-standard output (FLOOD version) substitutes an extensive report in place of the first, SPOT, report above. A full report is generated for each price, state, and year. A sample output for a given price and state, is given in Table VII.

The output is given in two lines. Line 1: year。 DUK (7), DE (3). Iine 2: MSF (7)。MAGE (7), DUO, name of system chosen for new buildings.

VII. Curve variables - definitions and units by common block. (*denotes input data)

$\begin{array}{ll}/ \mathrm{P} / & \text { *NF } \\ & \text { *PIND (3) } \\ & \mathrm{P}(3) \\ & \text { *ALPHA } \\ & \text { *TDP (3) } \\ & \text { * } \mathrm{KF} \\ & \text { *NDIV } \\ & \text { *DELP } \\ & \text { *BC }(8,7) \\ & \mathrm{BC}(\mathrm{I}, \mathrm{J})\end{array}$
number of fuels $(=3)$ nat ${ }^{0} \mathrm{i}$. price indices: $\xi / \mathrm{mcf}_{\natural} \xi / \mathrm{gal} ., \xi / \mathrm{kwh}$ at start of relative year 1 . prices in given state and time. rate of fuel price increase (initial value. is PIND)

nat ${ }^{1} 1$. price minus state price: index $(1,2,3)$ of price to be changed number of prices above base to be tested change (delta) in price for each iteration cost of transforming basic system I to basic system $\mathrm{J}$ at start of relative year $l_{0}$ expressed in $\$ / 10^{3} \mathrm{BTU} / \mathrm{h}$ output $I=1,2, \ldots .8(=0,1, \ldots .7), J=1, \ldots 7$.

Systems : (system-fuel types)

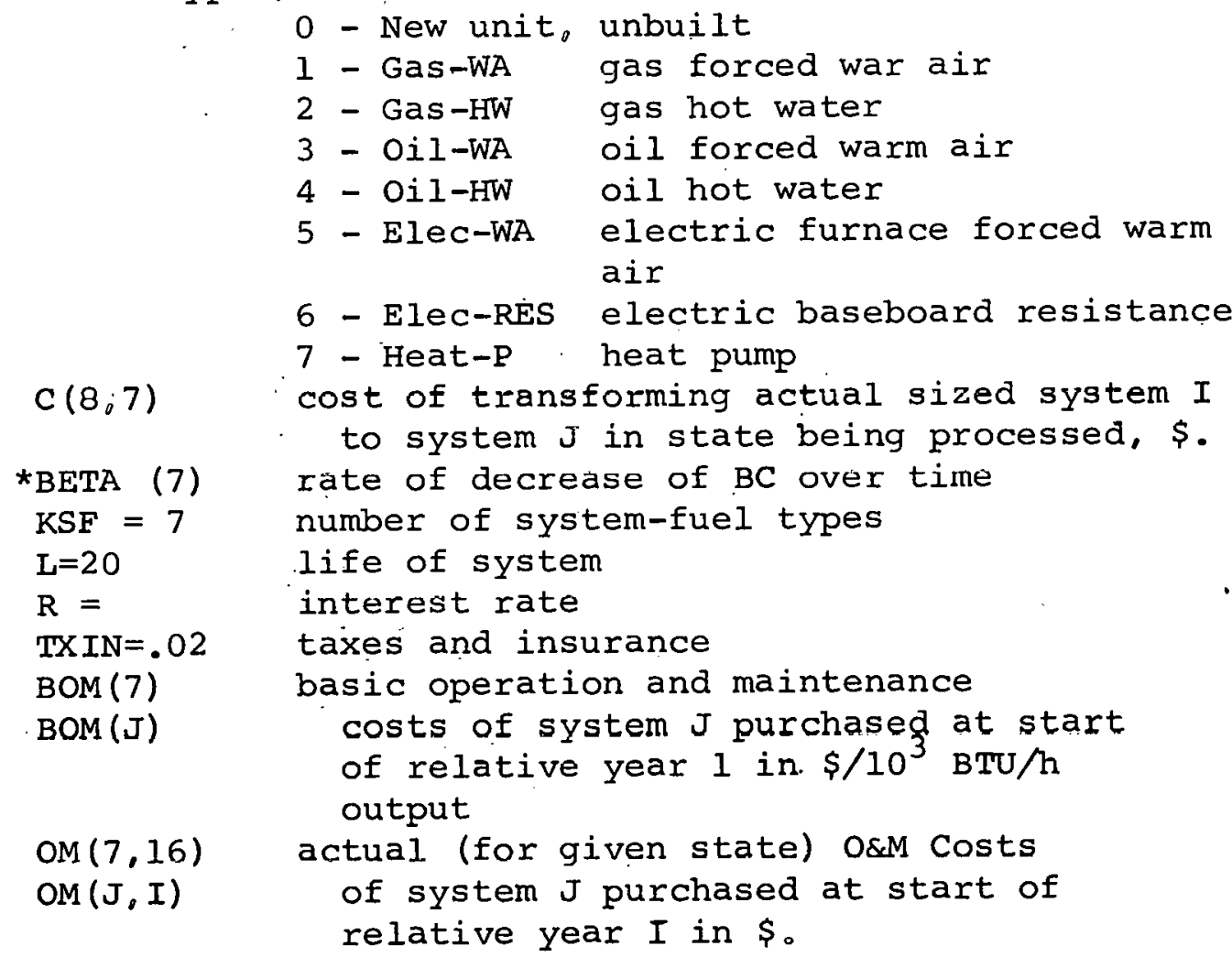


TABLE VII

Standard Output (FLOOD Versien.

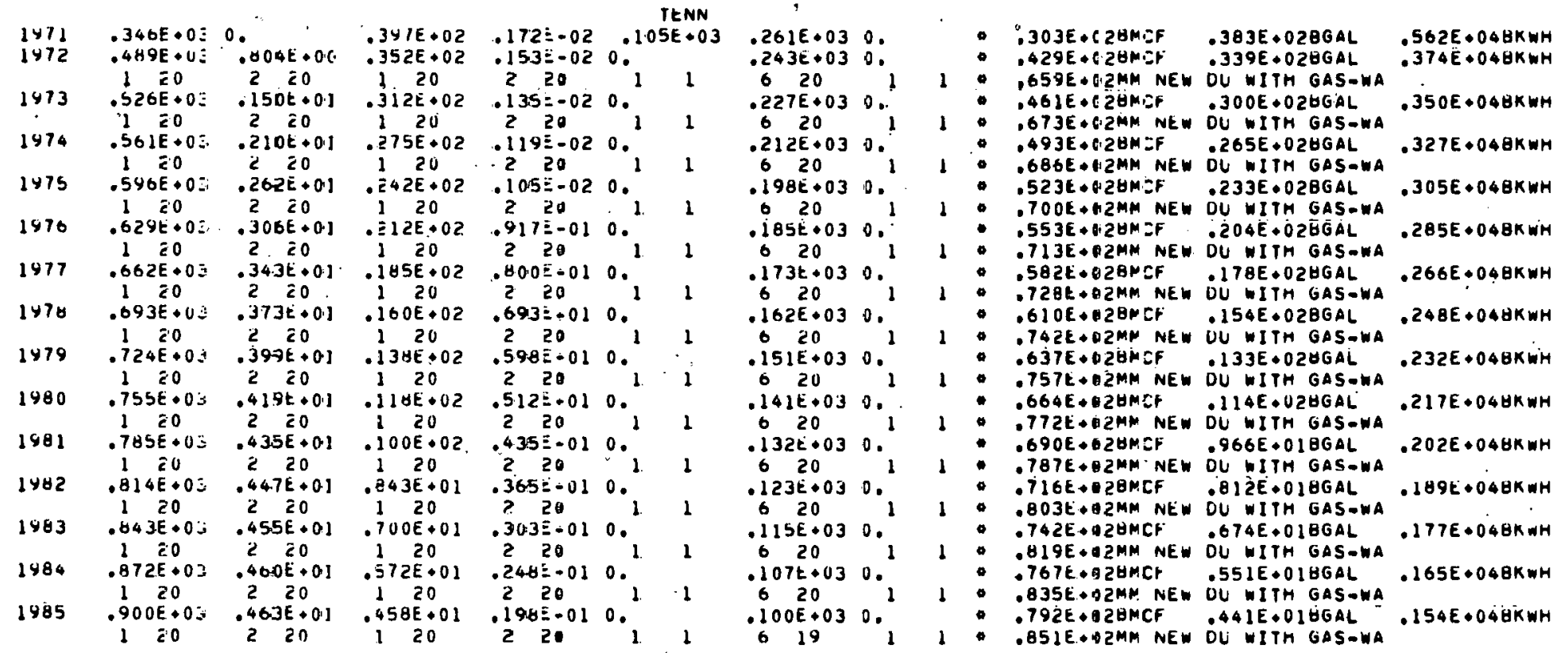




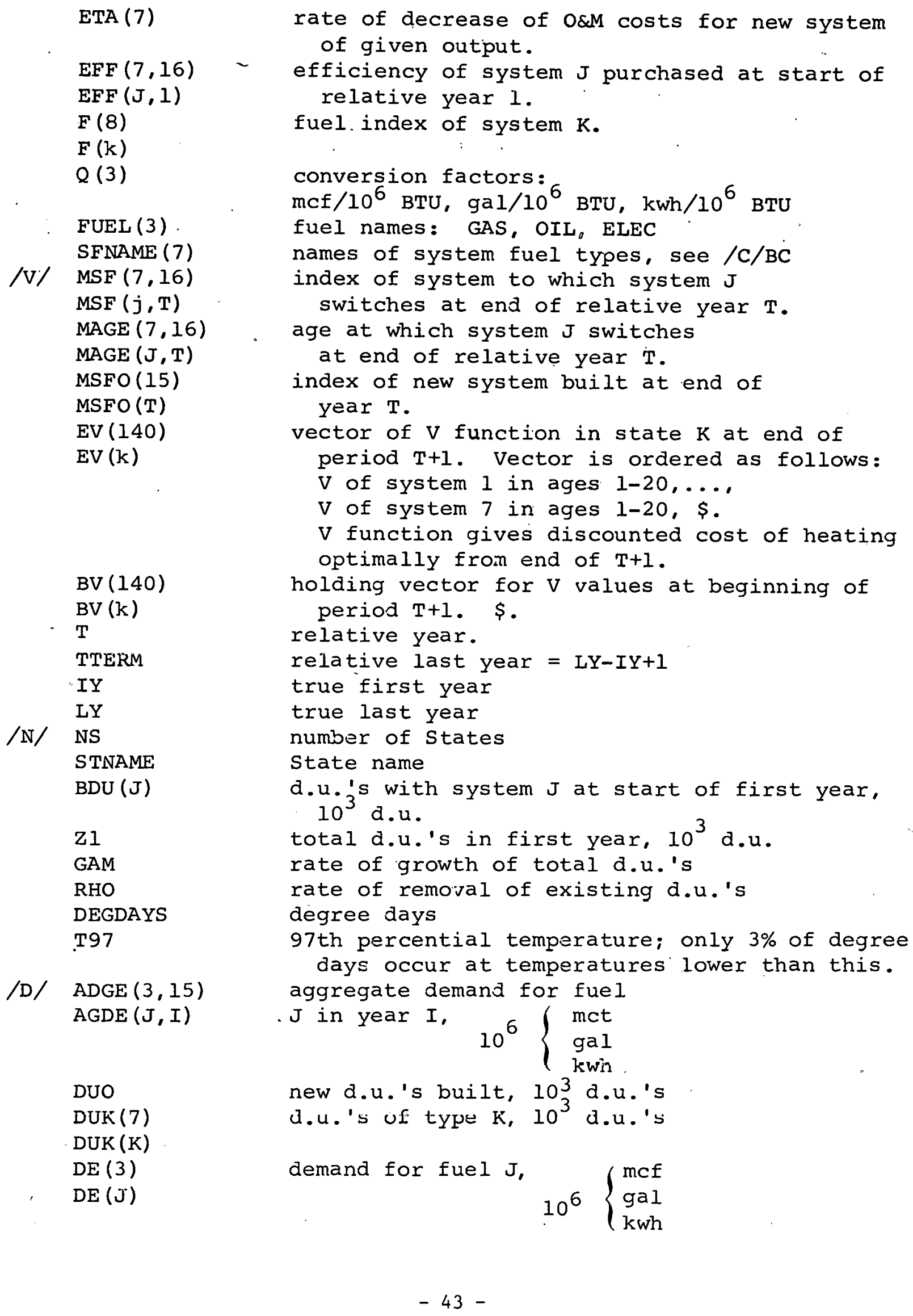


THTU
DMBTU total BTU's per d.u. per year, $10^{6} \mathrm{BTU}$
design BTU/hr, $10^{3} \mathrm{BTU} / \mathrm{hr}$

Variables unique to subroutines

SETUP: THP Minimum operating temperature of heat pump

HPP Percentage of degree days supplied by heat pump

START: VV, VVV Preliminary values for computing $V$ function, \$. ITERATE: $V V$, VVV Preliminary values for computing $V$ function, DEMAND: DU (140), DU (K) d.u.'s in configuration $K$ at start of period $T+1$

DUU(140) Holding values for computing DU.

6 
I. System Size, Efficiency, And Cost Estimates

All estimates are supposed to be for a 1970 time frame. Lack of timely and dated data has made the actual result, at best, only approximate.

I. 1. System size. The systen size is determined by the design BTU's per hour of effective heat output to the home (in thousands), denoted DMBTUH.

Reference. [1, p. 667] indicates that the main governing variable in determining DMBTUH for an actual home is the $971 / 2$ th percentile temperature, denoted here T97, for an area. This means that for only $2.5 \%$ of the degree days, the temperature falls below the T97.

Reference [12, p.6, Table 3] contains actual engineer's estimates of furnace size for an "average" home in 13 cities. Using this data, a rough linear fit is determined between DMBTUH and T97:

$$
\text { DMBTUH }=55 .- \text { T97. }
$$

The fit is rough since the engineering estimates are not made on a necessarily consistent basis and many other design and locational factors have a bearing. For instance, the "average home" could change among cities.

Note: The heat pump must be handled separately. References $[12, p .5-7]$ and $[13, p .5-18]$ indicate that the heat pump has a significantly greater efficiency than other electric heat sources only for DMBTUH less than 30. Thus the excess of DMBTUH over 30 is provided by electric furnace which uses the sane duct system. [See section on Climate Data for source of T97's.]

I. 2. System efficiencies. System efficiencies (effective heating output in BTU's/input fuel BTU) are taken from Roference [12, p.5-7] to be .60 for gas,..55 for oil, 1.0 for electric resistence and electric furnace, and 2 for pure heat pump.

Note: Since heat pump systems generally require both heat pump and electric furnace, a combined efficiency must be determined. Tnis was done by first determining for each state the proportion of the degree days of heating, denoted HPP, that were contributed by the heat pump. Then the efficiency was taken as the weighted efficiency:

$$
\mathrm{EFF}=1 /[\mathrm{HPP} / 2+(1-\mathrm{HPP})]
$$

The HPP was determined by assuming that an equal number of days were spent. at each temperature between the T97 temperature and $65^{\circ}$. Let $\mathrm{THP}=35$, the temperature to which the heat pump is effective. 


$$
\begin{aligned}
\text { HPP }= & \left(\frac{T H P-T 97}{65-T 97}\right)(65-T H P)+\left(\frac{1}{65-T 97}\right) \int_{\text {THP }}^{65}(65-t) d t \\
& \left(\frac{1}{65-T 97}\right) \int_{T 97}^{65}(65-t) d t \\
= & 1-\left(\frac{T H P-T 97}{65-T 97}\right)^{2} \text { if T97 } 535 \\
\text { HPP }= & 1 \text { if T97>35. }
\end{aligned}
$$

I. 3 . System costs. The basic data for capital costs for new construction was taken from Reference [12, p. 15-17, Tables 9-11]. The basic assumptions made to use these tables were:

a) Costs are proportional to DBMTUH.

b) 'l'he proportionality factor was determined by using a $50 \times 10^{3} \mathrm{BTU} / \mathrm{hr}$ output system $\left(30 \times 10^{3} \mathrm{BTU} / \mathrm{hr}\right.$ for the heat pump).

c) A 3 ton rating for heat pump and duct work is interpreted as $36 \times 10^{3} \mathrm{BTU} / \mathrm{hr}$ output:

d) An installation labor index of 1.3 is used.

The capital costs in $\$ / D M B T U H$ can then be determined from the formulae below separately for (1) duct work, (2) gas furnace, (3) oil furnace, (4) electric furnace, and (5) electric resistance (baseboard).

Investment costs of 50 DMBTUH output system =

$=$ cost of system in Table 9 with labor index $1.3 /$ cost given in Table (labor index 1.0)

$x[$ (cost given in table)

+ ((required size minus table size)/increment size)

$x$ (cost of increment) ]

This yialds $I_{1}=(400+1.3 \times 400) / 800\left[800+\frac{(50-30)}{6} \times 50\right]=1054$

$$
\mathrm{K}_{1}=I_{1} / 50=21.08
$$

Gas: $\quad I_{2}=(300+1.3 \times 150) / 450\left[450+\frac{83-130}{1.0} \times 12\right]=433$

$$
K_{2}=I_{2} / 50=8.66
$$

U11: $\perp_{3} \equiv(400+1.3 \times 150) / 5 b 0\left[550+\frac{91-130}{1.0} \times 12\right]=544$

$$
\mathrm{K}_{3}=\mathrm{I}_{3} / 50=10.88
$$

Elec. Furn: ${ }^{I_{4}}=(350+1.3 \times 150) / 500\left[500+\frac{14.6-19.2}{4.8} \times 80\right]$

$$
K_{4}=I_{4} / 50=9.22
$$

Elec. Res.: $I_{5}=(300+1.3 \times 600) / 900\left[900+\frac{14.6-19}{1.0} \times 30\right]=975$

$$
K_{5}=I_{5} / 50=19.48
$$

The heat pump capital cost is determined by backing out the cost of electric furnace with size indicated in Table. 
Step A Combined (3 ton) heat pump and (14.4 kw) electric at table size:

in table $=1550$

with 1.3 labor index $=1625$

Step.B Electric furnace at $14.4 \mathrm{kw}$

with labor index $1.0=\left[500+\frac{14.4-19.2}{4.8} \times 80\right]=420$

with index 1.3

Step C Heat pump at 3 tons capacity $=(350+1.3 \times 150)[458]=458$

with labor index $1.0=1550-420=1130$

with labor index $1.3=1625-158=1167$

Step D Heat pump at 2.5 tons $=30$ DMBTUH

$$
\begin{aligned}
I_{6} & =1167 / 1130\left[1130+\frac{30-36}{6} \times 100\right]=1064 \\
K_{6} & =I_{6} / 30=35.47
\end{aligned}
$$

For hot water systems the piping cost is taken to be the

same as the ducting cost.

The K's are summarized in Table VIII.

Annual operation and maintenance cost are assumed proportional to capital cost. They are given in Table IX.

I. 4. BESOM input. For BESOM input, the annual capital charge equal to $10 \%$ plus the OSM percentage of the $K^{\prime} s$ is computed. These total capital plus OSM costs are given as A's in Table X. The objective function coefficients in $\$ / 10^{6}$ BTU of input IEF usage for BESOM for each state are then computed as follows:

$c($ gas $)=$ DMBTUA $\times\left(A_{1}+A_{2}\right) \times .6 / T B T U+$ IDP (1)

$c($ oil $)=$ DMBTUH $\times\left(A_{1}^{1}+A_{3}^{2}\right) \times .55 / T B T U+\operatorname{TDP}$ (2)

$c($ elect.f. $)=$ DMBTUH$^{1} \times\left(\mathrm{A}_{1}+\mathrm{A}_{4}\right) \times 1.0 / \mathrm{TBTU}+\mathrm{TDP}$ (3)

$c\left(e l . r e s_{.}\right)=$DMBTUH $\times\left(A_{5}\right)^{\prime} \times 1.0 / T B T U+T D P$ (3)

$c\left(h \cdot p_{.}\right)=$DMBTU $\times A_{1}+\min (D M B T U H, 30) \times A *$

$+\max ($ DMBTUH $-30,0) \times \mathrm{A}_{4}$ EFF/TBTU

$$
+\operatorname{TDP}(3)
$$

See Appendix. Sec. 6, for table of data by state. Note that $A{ }_{6}{ }_{6}$ is $.75 \times A_{6}$ i.e., .25 of the cost is attributed to air conditioning. See the section on fuel costs for explanation of TDP.

I. 5. Curve input. The BC and BOM matrices are computed for CURVE with following assumptions.

a) To replace piping with duct work or the reverse, the cost is 1.5 times that for new construction.

b) Air conditioning bears .25 of heat pump costs.

c) Furnaces must be replaced at $L$ years at the cost of a new furnace. Duct and piping has infinite life.

d) Electric resistance has zero replacement cost.

e) Furnaces can be converted at cost of naw furnace.

The $\mathrm{BC}$ and $\mathrm{BOM}$ matrices are given in Table XI.

I. 6. Comments on data. 1) Many relationships were assumed to be linear with no constant term and eyeballed at that. However, to build up nore exact and consistent representations from micro 
TF.BLE $X$

Annual Amort:zed System Cost for BESOIA

Duct:

$A_{1}=2.1080$

Gas Furnace

$A_{2}=1.2124$

O.il Furnace:

$A_{3}=1.6320$

Electric Furnace:

$A_{4}=1.2908$

Electric Basebcard:

$A_{5}=2.3376$

Heat Pump:

$A_{5}=5.32$
TABLE IX

Operating ard Maintenance

as a percentage of Capital costs

Duct :

$\frac{\mathrm{OM}_{1}}{\mathrm{~K}_{1}}=0.0$

Gas Furnace:

$\frac{\mathrm{OM}_{2}}{\mathrm{~K}_{2}}=4.0$

Oil Furnace:

$\frac{\mathrm{OH}_{3}}{\mathrm{r}_{5}}=5.0$

Electric Furnace:

$\frac{\mathrm{O} \mathrm{H}_{4}}{\mathrm{~K}_{4}}=\leq .0$

Electric Baseboard:

$\frac{\mathrm{CN}^{\mathrm{N}}}{\mathrm{K}_{5}}=2.0$

Heat Plimp:

$\frac{O M_{6}}{K_{6}}=5.0$
TABLE VIII

Investment cost in $\$ / D a s i g n$ $10^{3} \mathrm{BTU} / \mathrm{hr}$ of Output

Duct:

$\mathrm{K}_{1}=21.08 \$ / 10^{3} \mathrm{BTU} / \mathrm{h}$

Gas Furnace:
$\mathrm{K}_{2}=8.66 \$ / 10^{3} \mathrm{BTU} / \mathrm{h}$

Oil Furnace:

$\mathrm{K}_{3}=10.88 \$ / 10^{3} \mathrm{BTU} / \mathrm{h}$

Electric Furnaçe:

$\mathrm{K}_{4}=9.22 \$ / 10^{3} \mathrm{BTU} / \mathrm{h}$

Electric Baseboard:

$\mathrm{K}_{5}=19.48 \$ / 10^{3} \mathrm{BTU} / \mathrm{h}$

Heat Pump:

$\mathrm{K}_{5}=35.47 \$ / 10^{3} \mathrm{BTU} / \mathrm{h}$

$.75 \mathrm{~K}_{5}=26.60$ AC disc. 
TABLE XI

Matrices (BC and $B O M$ ) of Unit Capital costs for CURVE.

\begin{tabular}{|c|c|c|c|c|c|c|c|}
\hline $\begin{array}{c}B C \\
(x=\text { relevant } \\
\text { switches) }\end{array}$ & GAS-WA & GAS-HW & OIL-WA & $\begin{array}{c}\text { OIL-HW } \\
4\end{array}$ & ELEC-WA & $\begin{array}{c}\text { ELEC-RES } \\
6\end{array}$ & $\begin{array}{l}\text { HEAT-P } \\
7\end{array}$ \\
\hline 0 & $\begin{array}{c}K_{1}+K_{2}{ }^{\mathrm{x}} \\
30.54\end{array}$ & $\begin{array}{l}\mathrm{K}_{1}+\mathrm{K}_{2} \\
30.54\end{array}$ & $\begin{array}{c}\mathrm{K}_{1}+\mathrm{K}_{3}^{\mathrm{x}} \\
32.76\end{array}$ & $\begin{array}{l}\mathrm{K}_{1}+\mathrm{K}_{3}^{\mathrm{x}} \\
32.76\end{array}$ & \begin{tabular}{|}
$\mathrm{K}_{1}+\mathrm{K}_{4}^{\mathrm{x}}$ \\
31.10
\end{tabular} & $\begin{array}{c}K_{5}{ }^{x} \\
19.48\end{array}$ & $\begin{array}{l}K_{1}+K_{6}{ }^{x} \\
48.48\end{array}$ \\
\hline GAS-WA & $\begin{array}{l}K_{2}{ }^{x} \\
8.66\end{array}$ & $\begin{array}{c}1.5 \mathrm{~K}_{1}+\mathrm{K}_{2} \\
41.48\end{array}$ & $\begin{array}{l}K_{3} \mathrm{x} \\
10.88\end{array}$ & $\left|\begin{array}{c}1.5 \mathrm{~K}_{1}+\mathrm{K}_{3} \\
43.70\end{array}\right|$ & $\begin{array}{l}K_{4}{ }^{x} \\
9.22\end{array}$ & $\begin{array}{l}1.5 \mathrm{~K}_{5}^{\mathrm{x}} \\
.29 .22\end{array}$ & $\begin{array}{ll}K_{6} & x \\
26.60\end{array}$ \\
\hline GAS-HW & $\begin{array}{l}1.5 \mathrm{~K}_{1}+\mathrm{K}_{2} \\
41.48\end{array}$ & $\begin{array}{l}K_{2} \\
8.66\end{array}$ & $\left|\begin{array}{r}1.5 \mathrm{~K}_{1}+\mathrm{K}_{3} \\
43.70\end{array}\right|$ & $\begin{array}{c}\mathrm{K}_{3} \mathrm{x} \\
10.88\end{array}$ & $\begin{array}{c}.5 K_{1}+K_{4}^{X} \\
42.04\end{array}$ & $\begin{array}{l}1.5 \mathrm{~K}_{5}^{\mathrm{x}} \\
29.22\end{array}$ & $\begin{array}{r}1.5 K_{1}+K_{6}^{x} \\
59.42\end{array}$ \\
\hline OIL-WA & $\begin{array}{c}K_{2} \\
8.66\end{array}$ & $\begin{array}{c}1.5 \mathrm{~K}_{1}+\mathrm{K}_{2} \\
41.48\end{array}$ & $\begin{array}{c}K_{3} \\
10.88\end{array}$ & $\begin{array}{r}1.5 \mathrm{~K}_{1}+\mathrm{K}_{3} \\
43.70\end{array}$ & $\begin{array}{l}K_{4} \\
9.22 \\
9\end{array}$ & $\begin{array}{l}1.5 \mathrm{~K}_{5}^{\mathrm{x}} \\
29.22\end{array}$ & $\begin{array}{l}K_{6} \\
26.60\end{array}$ \\
\hline OIL-HW & $\begin{array}{c}1.5 \mathrm{~K}_{1}+\mathrm{K}_{2} \\
41.48\end{array}$ & $\begin{array}{|rr|} & x \\
K_{2} & . \\
8 & .66\end{array}$ & $\begin{array}{r}1.5 \mathrm{~K}_{1}+\mathrm{K}_{3} \\
43.70\end{array}$ & $\begin{array}{l}\mathrm{K}_{3} \\
10.88\end{array}$ & \begin{tabular}{|c|}
$1.5 K_{1}+K_{4}$ \\
42.04
\end{tabular} & $\begin{array}{c}1.5 K_{5}{ }^{x} \\
29.22\end{array}$ & $\begin{array}{r}x \\
1.5 K_{1}+K_{6} \\
59.42\end{array}$ \\
\hline ELEC-WA & $\begin{array}{l}\mathrm{K}_{2} \cdot \mathrm{x} \\
8.66\end{array}$ & $\begin{array}{r}1.5 \mathrm{~K}_{1}+\mathrm{K}_{2} \\
41.48\end{array}$ & $\mid \begin{array}{lll}x & & \\
& K_{3} & \\
10 & .88\end{array}$ & $\begin{array}{c}.5 \mathrm{~K}_{1}+\mathrm{K}_{3} \\
43.70\end{array}$ & $\begin{array}{l}K_{4} \\
9.22\end{array}$ & $\begin{array}{c}1.5 K_{5} \\
29.22\end{array}$ & $\begin{array}{l}K_{6} \quad x \\
26.60\end{array}$ \\
\hline $\begin{array}{r}\epsilon \\
\text { ELEC-RES }\end{array}$ & \begin{tabular}{|l}
$1.5 \mathrm{~K}_{1}+\mathrm{K}_{2}^{\mathrm{x}}$ \\
41.48
\end{tabular} & $\begin{array}{c}1.5 \mathrm{~K}_{1}+\mathrm{K}_{2} \\
41.48\end{array}$ & \begin{tabular}{|c|} 
\\
$1.5 K_{1}+K_{3}$ \\
43.70
\end{tabular} & $\begin{array}{c}1.5 K_{1}+K_{3} \\
43.70\end{array}$ & 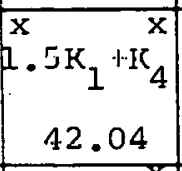 & $\begin{array}{ll} & \\
\end{array}$ & $\begin{array}{r}1.5 K_{1}+k_{6}^{x} \\
59.42 \\
\end{array}$ \\
\hline HEAT-P & $\begin{array}{c}K_{2} \\
8.66 \\
\end{array}$ & $\begin{array}{c}1.5 \mathrm{~K}_{1}+\mathrm{K}_{2} \\
41.48 \\
\end{array}$ & $\begin{array}{c}K_{3}{ }^{x} \\
10.88 \\
\end{array}$ & $\begin{array}{c}1.5 \mathrm{~K}_{1}+\mathrm{K}_{3} \\
43.70\end{array}$ & $\begin{array}{l}K_{4}{ }^{X} \\
9.22 \\
\end{array}$ & $\begin{array}{l}1.5 \mathrm{~K}_{5}{ }^{\mathrm{x}} \\
29.22 \\
\end{array}$ & $\begin{array}{l}K_{6}{ }^{x} \\
26.60 \\
\end{array}$ \\
\hline BOM & $\begin{array}{c}.04 * \mathrm{~K}_{2} \\
.346\end{array}$ & $\begin{array}{r}.04 * \mathrm{~K}_{2} \\
.346\end{array}$ & $\begin{array}{r}.05 * \mathrm{~K}_{3} \\
.544\end{array}$ & $\begin{array}{r}.05 * K_{3} \\
.544\end{array}$ & $\begin{array}{c}.04 * \mathrm{~K}_{4} \\
.369\end{array}$ & $\begin{array}{r}.02 * \mathrm{~K}_{5} \\
.390\end{array}$ & $\begin{array}{c}.05 * \mathrm{~K}_{6} \\
1.33\end{array}$ \\
\hline
\end{tabular}


data would be costly and cumbersome. 2) Better techniques and -more balanced data collection (experimental design) should be used to improve the approximation by simple relationships. 3) The best short term method would be to calibrate using the nacro results of the model over a few years and regions. That is, estimate the parameters using the predictions of the models developed in the study.

\section{Fuel Price Data}

Since fuel prices generally vary across the country, a simple scheme was sought so that demand curves could be calculated as functions of a single exogenous price for each fuel. This was done by assuming that whatever caused the p:ice difference was in long run equilibrium and that its influence would stay constant under fuel demand and supply changes. Thus the exogenous prica was taken to be the national. average price. Regional home fuel prices were computed by taking fixed differences from the national average. These differences are labelled TDP(3) (meaning "transportation differences in price"). All references for price are to [7].

The national average price used to compute the TDP's were the Chicago comnercial prices of : 68\%/mcf (Table 5-a, p. 190), 10\%/gal (Table 5-b, p. 192), and 1.6\%/kwh (Table 5-d, p. 196).

All price series were quite stable up to 1967, so that year was used to compute the state specific prices for the TDP's. Since prices are given for only a few cities, guesses had to be made about the reasons for the differences so that they could be extended to a list covering all states. This is discussed by fuel.

II. 1. Gas. When the residential, price data points given in table $4 b, p . \overline{182}$ are put on a map and compared to gas sources in Reference [8], they appear in the major part to he determined by transport costs. The actual list of TDP's was then determined by roughly interpolating and extrapolating the given data, assuming they are caused by transportation differences.

II. 2. Oil. Residential oil prices given in Table 4-c, p. 184 appear very flat as if subject to very low long distance transportation costs. Therefore a price of $16 \% / g a l$ was set for each state with a slight increase to $17 \% / g a l$ in New England.

II. 3. Elcctricity. Geographical price variations in Tablc 4-e, p. 188 for residential consumers appear very erratic. Since it is very costly to transport electric power, prices seem to depend on very local generation and distribution conditions such as: closeness to hydropower, age and efficiency of existing system, and physical structure of the area to be supplied. Reference [9] also strongly indicates that differences in fixed charges (not fuel prices) account for most of the regional price differences in electricity. Under this supposition, guesses were made to extend the given data to a list for all states. 
II. 4. Comments on data: 1) The biggest question is "How to represent regional price differences?" 2) To do better, more explicit models generating regional differences would have to be developed and more extensive data found or collected to estimate the models.

\section{Climatic Data}

III. 1. Degree days. A crude approximation to the degree days of each state was obtained by employing a map with the average annual degree days [9] and a list of average annual degree days for various aities located in each state [2, p.43.3-8, Table 2]. If a state was populous and geographically flat, we averaged the degree day zones that may cross through a particular state. If a. state was mountainous and hence had regions of high average degree days, we tended to use the average of degree days of the major cities since that is where the population tends to concentrate.

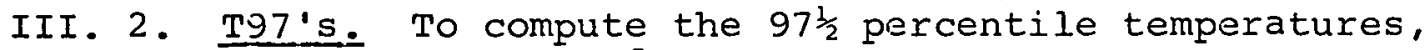
we used $[1, p .669-581$, Table 2] and "averaged" the values for major cities in a state, as with degree days.

IV. Housing stock And Projections

IV. 1. SFDU at the lueginning of 1970. The report of A.D. Little [11, p. 56, Table 2.6] provides estimates of SFDU in four geographical regions: north, south, central and west: Using the 1970 census of population, [14, p. 32, Table 2], we determined the Eraction of regional population in each state in that region by sumining the population in all states in a region and dividing each states population by this total. The product of this number with the A.D. Little figure yields an estimate of SFDU in each state.

IV. 2. Growth rates of SFDU. The same A.D. Little report provides projections of SFDU for the four regions mentioned above for 1980, 1985, and 1990 [11, p. 56, Table 2.6].

A simple loy linear regreasion of total reginnal. SFDU on time gives a crude approximation to the growth rate. Each state in a particular region is then assigned the regional growth rate.

IV. 3. Removal rate of SFDU. The same A.D. Little study has provided estimates of the removal rate by region for 1980,1985 , and 1990 [11, p. 53, Table 2.4]. Since the effects of this parameter are relatively small, the average of the numbers for the three years for each region was taken to be the removal rate between 1970 and 1985. Again. each state in a.given region is assumed to have the removal rate of the region in which it is located. 


\section{Existing Fuel Systems}

Only national data for a full table of fuel and heat distribution system was available, so we estimated these parameters, using a constrained least squares formulation, from known marginal data, by state, for fuels and heat systems, and known national conditionals for systems given fuels.

Let: $s_{i}=\%$ of all occupied DU in a given state using system i,

$\mathrm{f}_{i}=\%$ of all occupied DU in a given state using fuel j.

$B_{i j}=\%$ of single family DU nationally using fuel $j$ that have system $i$, $\begin{aligned} \mathrm{b}_{i j}= & \% \text { of single family } \mathrm{DU} \text { in a given state using tuel } \\ & j \text { that have system } i \text { (these are the numbare to }\end{aligned}$ be estimated).

The problem is to minimize $\sum_{i} \sum_{j}\left(B_{i j}-b_{i j}\right)^{2}$

$$
\begin{aligned}
\text { subject to } & \sum b_{i j} f_{j}=s_{11} m \\
& j \\
& i b_{i j}=1, b_{i j} \geq 0 .
\end{aligned}
$$

In our model, the fuels $j=1-4$, are oil, gas, electricity, and an "other" category. Similarly, the distribution systems, $i=1,5$, are warm air furnaces (WAF), steam or hot water (SHW) systems, floor, wall or pipeless furnaces (FWP), built in electric units (BIE) and an "other" classification. The $s$, and $f$ fiqures were obtained for each state from the 1970 Census of Housing [5, p. 1-248-1.259, Table 23-4]. The components of our numbers in terms of the census data are provided below:

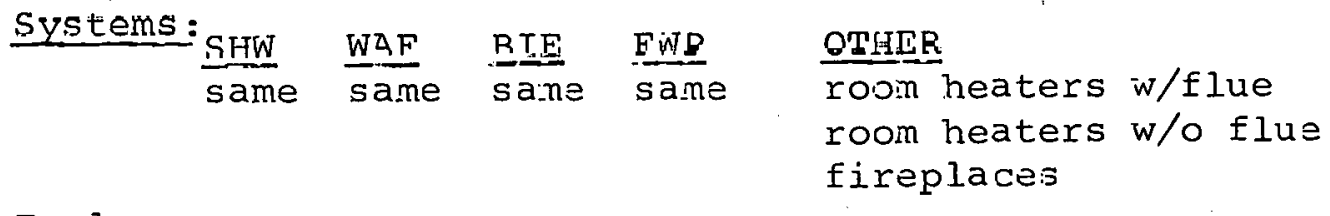

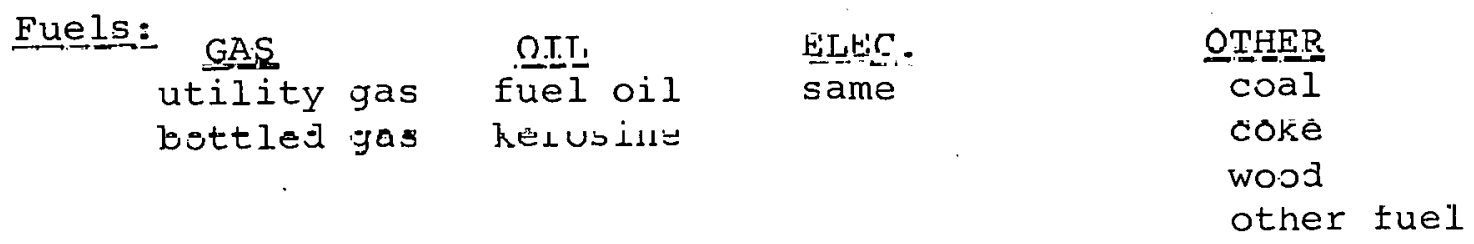

The known national figures for the $B_{\text {i }}$ were ultained from 4, p. 6-7, Table $A-4$ and are included ${ }^{j}$ here.

$\begin{array}{lcccc} & \text { OIL } & \text { GAS } & \text { OTHER } & \text { ELES. } \\ \text { WAF } & .4380 & .5493 & .2500 & .2560 \\ \text { OTHER } & .2018 & .2318 & .6200 & .0892 \\ \text { SHW } & .3178 & .0832 & .1036 & 0 \\ \text { FWP } & .0425 & .1357 & .0264 & 0 \\ \text { BIE } & 0 & 0 & 0 & .6548\end{array}$


The estimated $b_{j j}$, although estimated using all occupied housing data, were then used for the conditional percentages for SFDJs in the given state.

In CURVE we used 7 fuel heating distribidion system pairs with

the following definition

GAS-WA $=($ GAS $\times$ WAF $)+($ GAS $\times$ OTHER $)+($ GAS $\times$ FWP $)$

GAS-HW $=($ GAS $\times$ SHW $)$

OIL-WA $=($ OIL $\times$ WAF $)+($ OIL $\times$ OTHER $)+($ OIL $\times$ FWP $)$

OIL-HW $=$ (OIL $\times$ SHW)

ELEC-WA $=$ (WAF $\times$ ELEC $)+$ (OTHER FUEL $\times$ ELEC)

ELEC-RES $=$ (BIE $\times$ ELEC)

HEAT-P = Assumed zero in 1970

VI. CURVE And BESOM Data BY State

State specific data is presented in Table XII for BESOM and in Table XIII for CURVE. 
TABLE XII

State Specific Data for BESOM

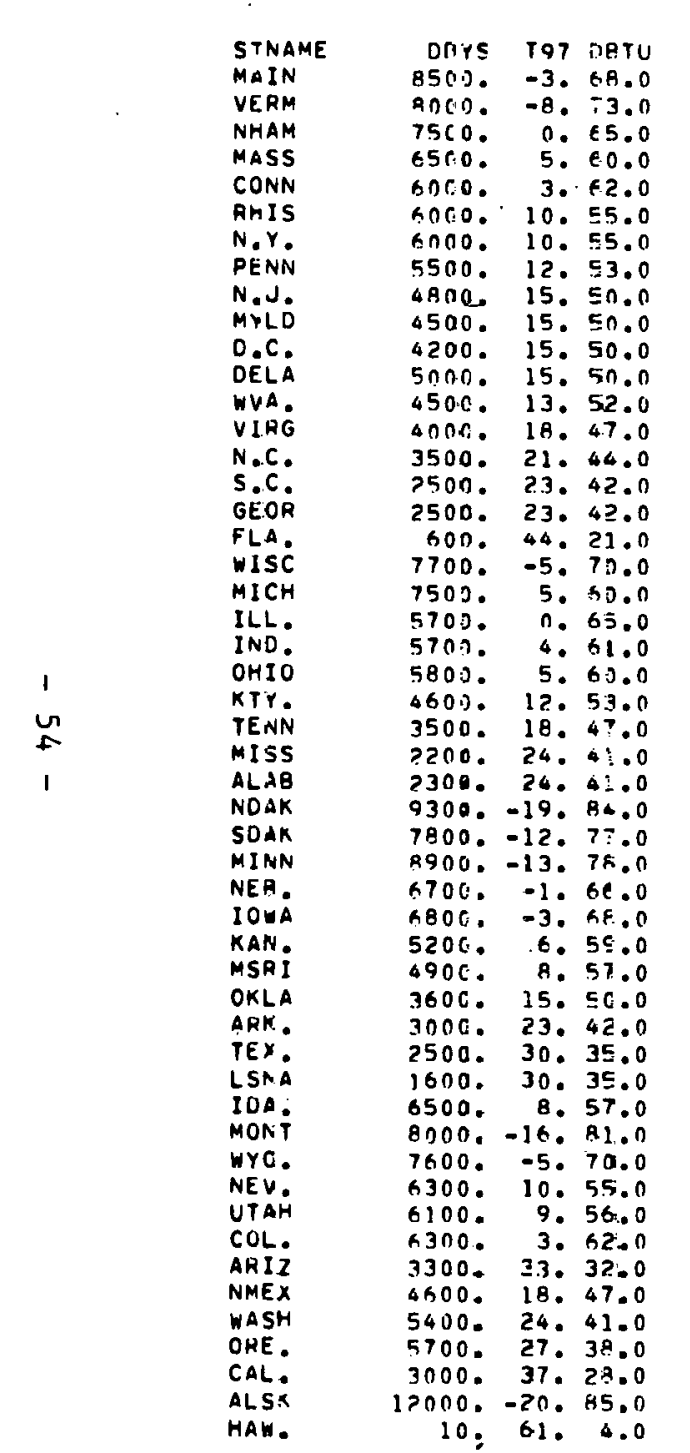

\begin{tabular}{|c|c|c|c|}
\hline TBTU & P0P70 & $\begin{array}{l}\text { HESOM } \\
\text { POP } 85\end{array}$ & DATA \\
\hline 127.5 & 150.3 & 17.8 .7 & 22.7791 \\
\hline 120.0 & $6 i .5$ & 90.7 & 10.8861 \\
\hline 112.5 & $1: \mathbf{z} .1$ & $159 . ?$ & 17.9107 \\
\hline 57.5 & 861.0 & 1190.6 & 116.0809 \\
\hline 90.0 & 459.1 & 640.3 & 57.6225 \\
\hline 90.0 & 343.7 & 194.5 & 17.5071 \\
\hline 90.0 & 2758.6 & 3657.4 & $3 ? 9.1649$ \\
\hline 82.5 & 1794.6 & 2362.4 & 194.8956 \\
\hline 72.0 & $I O E T .0$ & 1538.5 & 110.7689 \\
\hline 67.5 & $\operatorname{sc} 3.7$ & 1214.8 & A1.9994 \\
\hline 63.0 & 173.5 & 187.2 & 11.7929 \\
\hline 75.0 & 108.7 & 132.0 & 9.9033 \\
\hline 67.5 & 400.8 & 457.3 & 30.8685 \\
\hline 60.0 & 1068.1 & 142.3 .5 & 85.4103 \\
\hline 52.5 & 1168.6 & 1519.1 & 79.7514 \\
\hline $\begin{array}{l}37.5 \\
37.5\end{array}$ & 595.9 & 741.0 & 27.7885 \\
\hline 37.5 & 1056.4 & 1377.9 & 51.6707 \\
\hline 9.0 & $1571 . ?$ & 2459.3 & 22.1340 \\
\hline 115.5 & 973.0 & 1144.9 & 132.2304 \\
\hline 112.5 & $116 k .3$ & 1609.4 & 181.0537 \\
\hline 85.5 & 2444.4 & 2952.7 & 252.4525 \\
\hline 95.5 & 1143.1 & 1425.4 & 121.8723 \\
\hline 87.0 & 2345.8 & 2848.0 & 247.7782 \\
\hline 69.0 & 743.0 & 944.7 & 65.1838 \\
\hline 52.5 & 902.6 & 1211.8 & 63.6191 \\
\hline 33.0 & 508.7 & $595 . A$ & 19.6617 \\
\hline 34.5 & $792+1$ & 976.9 & 33.7024 \\
\hline 139.5 & 135.6 & 134.6 & 18.7724 \\
\hline 117.0 & 146.2 & 153.2 & 17.9271 \\
\hline 133.5 & 838.9 & 1019.9 & 136.1520 \\
\hline 100.5 & 327.0 & 359.9 & 36.1749 \\
\hline 102.0 & $52: .1$ & 694.1 & 70.7960 \\
\hline $7 e .0$ & 493.4 & 531.2 & 41.4310 \\
\hline 73.5 & 1030.0 & 1234.0 & 90.7008 \\
\hline 54.0 & 590.4 & 717.7 & 38.7534 \\
\hline 45.0 & $44 z \cdot 1$ & 543.2 & 24.4449 \\
\hline 37.5 & $258 \cong .3$ & 3213.5 & $120.5 n 55$ \\
\hline 24.0 & 836.5 & 959.2 & 23.0216 \\
\hline 97.5 & 155.1 & 154.5 & 15.0600 \\
\hline 120.0 & iso.A & 142.6 & 17.0900 \\
\hline 114.0 & 72.2 & 70.9 & 8.0795 \\
\hline 94.5 & 106.6 & 145.6 & 13.7635 \\
\hline 91.5 & 231.2 & 263.2 & 24.0788 \\
\hline 74.5 . & 481.3 & 580.4 & 54.8497 \\
\hline 49.5 & 387.5 & 521.2 & 25.7977 \\
\hline 69.0 & 421.5 & 500.3 & 34.5189 \\
\hline 81.0 & 738.5 & 784.2 & 63.5188 \\
\hline 85.5 & 954.7 & 517.4 & 44.2344 \\
\hline$\$ 5.0$ & 4324.9 & 5034.7 & 226.5629 \\
\hline 180.0 & $6 \pi .0$ & 77.2 & 13.8968 \\
\hline .2 & 164.8 & 194.5 & .0292 \\
\hline
\end{tabular}

CGAS
2.5825
2.7319
2.6711
2.6460
2.3964
2.2375
2.0375
1.4999
2.4135
2.1457
2.2511
2.3482
1.6048
2.2306
2.2397
2.5513
2.4713
4.7886
1.4574
1.2525
1.7646
1.6414
1.4440
2.1003
2.3535
2.3952
2.3876
1.4196
1.4311
1.3840
1.3183
1.4482
1.3770
1.6850
1.8547
1.9294
1.8694
2.7854
1.6847
1.6648
1.1433
1.0795
1.0293
1.1171
1.3379
1.4070
2.1084
1.4054
1.2596
2.7608
54.9464

CC1L
1.5503
1.7445
1.6817
1.7590
1.9102
1.7502
1.7150
1.7794
1.8765
1.9465
2.0553
1.7941
2.0074
2.0341
2.1467
2.7296
2.7356
5.7224
1.6694
1.5198
1.9866
1.8903
1.8414
2.0728
2.2543
2.9784
2.8673
1.6614
1.7765
1.6246
1.7736
1.7941
1.9787
2.0180
2.3274
2.3426
2.3426
3.4226
1.6253
1.8112
1.6858
1.6200
1.6817
1.7723
1.7525
1.7239
1.4640
1.3370
1.7027
1.3941
55.2761

CEFN
6.7917
7.0465
6.9428
9.1216
7.3204
$7.935 n$
6.1770
4.8185
5.5813
5.7384
5.9185
5.4869
5.2533
5.8834
6.6555
7.6137
7.6137
13.2025
7.0389
6.7917
8.4419
7.4039
6.4440
5.2457
2.4547
8.3228
8.1392
5.8536
6.0438
5.7928
6.3320
7.2449
6.6709
7.6148
7.5400
7.2727
7.2722
9.0566
5.7940
6.1112
5.8940
5.4921
5.5941
6.3299
5.7112
6.4151
5.5274
5.3176
5.5288
5.7050
94.7347

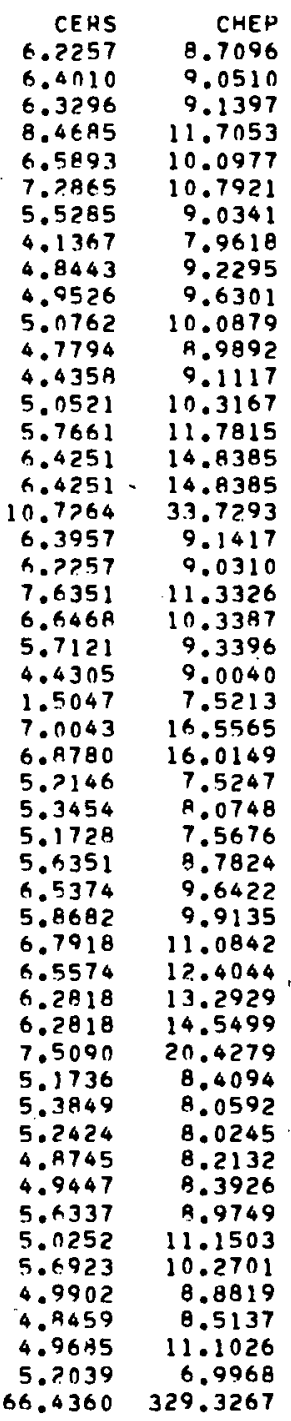

$E F F$
1.5241

1.4849

1.5505

1.6000
1.5793

1.6575

1.6575

1.6830

1.7241

1.7241

1.7241

1.6964

1.8161

1.8491

1.8691

1.5077

1.6000

1.5505

1.5895

1.6000
1.6930

1.6930

1.7686

1.8657

1.415 ?

1.4571

1.4571
1.4504

1.5414

1.5241

1.6108
1.6335

1.7241

1.8491
1.9600

$1.960 n$
$1.960 n$

1.6335

1.4327

1.5077
1.6575

1.6453

1.5797

1.9927

1.7 .686

1.8657

1.9151

$1.409 A$

2.0000 
TABLE XIII

State Specific Data for CURve

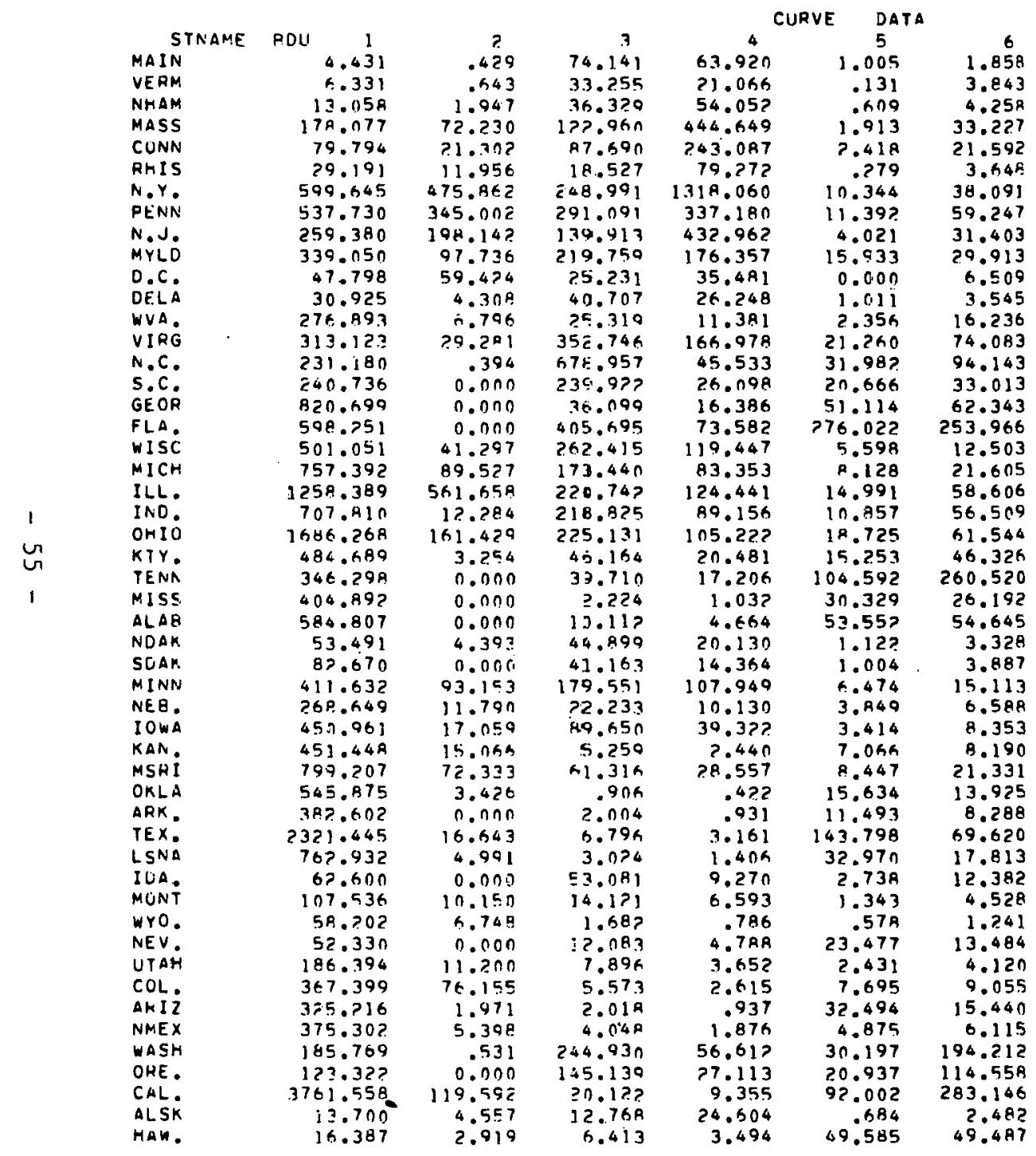

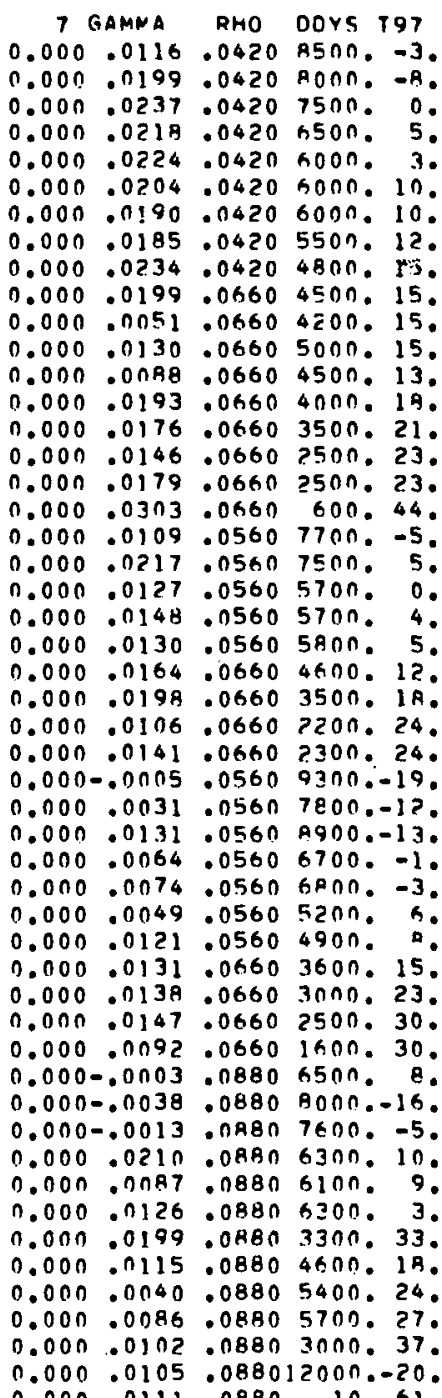

TOP 1

$152.0 n$ 152.00 143.00 102.00 102.00 22.10 0.02 .00
67.00 67.10 6r.nn 67.00 57.00 $32.0 n$ 24.00

14.00

25.00

19.00

25.00

22.01

7.00

57.00

$8.0 n$

2.000
$25.0 n$

25.

12.00

$2,0 n$

12.00

$-13.00$

14.00

7.00

1.00

-12.00
-52.00

$52.0 n$
32.00

$-8.00$

$-19.00$

$-19.00$

5.00

110.00

110.000
52.00

52.00

185.00
182.00

\begin{tabular}{ll} 
& \\
7.00 & 13 \\
7.00 & 1.70 \\
7.00 & 1.70 \\
7.00 & 1.70 \\
7.00 & 2.40 \\
7.00 & 1.70 \\
6.50 & 2.00 \\
6.50 & 1.40 \\
6.50 & 1.90 \\
6.00 & 1.10 \\
6.00 & 1.10 \\
6.00 & 1.10 \\
6.00 & 190 \\
6.00 & 1.10 \\
6.00 & 1.30 \\
6.00 & 1.30 \\
6.00 & 1.30 \\
6.00 & 1.80 \\
6.00 & 1.70 \\
6.00 & 1.70 \\
6.00 & 2.00 \\
6.01 & 1.70 \\
6.00 & 1.40 \\
6.00 & .90 \\
6.00 & -.20 \\
6.00 & 1.40 \\
6.00 & 1.40 \\
6.00 & 1.30 \\
6.00 & 1.30 \\
6.00 & 1.30 \\
6.10 & 1.40 \\
6.00 & 1.70 \\
6.00 & 1.40 \\
6.00 & 1.70 \\
6.00 & 1.50 \\
6.00 & 1.40 \\
6.00 & 1.40 \\
6.00 & 1.40 \\
6.00 & 1.30 \\
6.00 & 1.30 \\
6.00 & 1.30 \\
6.00 & 1.20 \\
6.00 & 1.20 \\
6.00 & 1.40 \\
6.00 & 1.20 \\
6.00 & 1.40 \\
6.00 & 1.30 \\
6.00 & 1.30 \\
6.00 & 1.20 \\
6.00 & 1.40 \\
6.00 & 1.40 \\
& \\
\hline
\end{tabular}




\section{REFERENCES}

1. ASHRAE Handbook of Fundamentals, Chapter 33.

2. ASHRAE System Handbook Chapter 43.

3. Brookhaven Energy System Optimization Model (BESOM) (Topical Report), E。A。Cherniavsky。 Energy Systems Analysis and Technology Assessment Program; Department of Applied Science, Brookhaven National Laboratory, BNL 19569.

4. 1970 Census of Housing, Structural Characteristics of the Housing Inventory.

5. 1970 Census of Housing, U.S. Summary, Vol. 1 .

6. Energy Consumption and Fuel Choice by Residential and Commercial Consumers in the United States, M.Baughman and P. Joskow, MTT, July 1974 (Mimeo).

7. Fneriy Priaoc 1960-73, Fusler Associatès, Inr. (a Report to the Energy Policy Project of the Ford Foundation)。 Ballinger Publishing Company, Cambridge, Mass.

8. Tlie National Atlas of the United States of America, U.S. Department of the Interior, Geological Survey, Washington, D.C. 1970.

9. The 1970 National Power Surveye Federal Power Commission (Part 1)。

10. Patterns of Energy Consumption in the United States office of Science and Technology, Executive Office of the President。 Washington, D.C.20506, Stanford Research Institute.

11. Project Independence Report, A.D. Little and Co.

12. A Regional Comparison of Energy Resource Use and cost to Consumer of Alternate Residential Heating Systems, J.G。 Delene, ORNL-TM-4689.

13. Seasonal Fuel Utilization Efficiency of Residential Heating Systems, E.C. Hise。 ORNL-NSF-EP82.

14. Survey of Current Business, April 1974, U.S. Department of Commerce, Bureau of Economic Analysis.

15. Cost Data, M. Beller, Brookhaven National Laboratory Memorandum, September 22, 1975. 